\title{
Integrated Chronic Care for Patients with Atrial Fibrillation
}

Citation for published version (APA):

Hendriks, J. M. L. (2013). Integrated Chronic Care for Patients with Atrial Fibrillation. [Doctoral Thesis, Maastricht University]. Universitaire Pers Maastricht. https://doi.org/10.26481/dis.20130314jh

Document status and date:

Published: 01/01/2013

DOI:

10.26481/dis.20130314jh

Document Version:

Publisher's PDF, also known as Version of record

\section{Please check the document version of this publication:}

- A submitted manuscript is the version of the article upon submission and before peer-review. There can be important differences between the submitted version and the official published version of record.

People interested in the research are advised to contact the author for the final version of the publication, or visit the DOI to the publisher's website.

- The final author version and the galley proof are versions of the publication after peer review.

- The final published version features the final layout of the paper including the volume, issue and page numbers.

Link to publication

\footnotetext{
General rights rights.

- You may freely distribute the URL identifying the publication in the public portal. please follow below link for the End User Agreement:

www.umlib.nl/taverne-license

Take down policy

If you believe that this document breaches copyright please contact us at:

repository@maastrichtuniversity.nl

providing details and we will investigate your claim.
}

Copyright and moral rights for the publications made accessible in the public portal are retained by the authors and/or other copyright owners and it is a condition of accessing publications that users recognise and abide by the legal requirements associated with these

- Users may download and print one copy of any publication from the public portal for the purpose of private study or research.

- You may not further distribute the material or use it for any profit-making activity or commercial gain

If the publication is distributed under the terms of Article $25 \mathrm{fa}$ of the Dutch Copyright Act, indicated by the "Taverne" license above, 


\section{Integrated Chronic Care for Patients with Atrial Fibrillation}


(C) Copyright J.M.L. Hendriks, Maastricht 2013

ISBN 9789461592088

\section{Cover design: Bert Hoogeveen}

Layout: Tiny Wouters

Printing: Datawyse Universitaire Pers Maastricht

Cover illustration: The Royal Heart by Salvador Dali (1953)

The jewel was created in honor of the coronation of Queen Elizabeth II. The pulsating rubies in the centre represent the Queen, whose heart beats constantly for her people, while the heart of virgin gold symbolizes the people, sheltering and protecting their ruler. 


\title{
Integrated Chronic Care for Patients with Atrial Fibrillation
}

\author{
PROEFSCHRIFT \\ ter verkrijging van de graad van doctor aan de Universiteit Maastricht \\ op gezag van de Rector Magnificus, Prof. dr. L.L.G. Soete, \\ volgens het besluit van het College van Decanen, \\ in het openbaar te verdedigen \\ op donderdag 14 maart 2013 om 14.00 uur \\ door \\ Jeroen Marie Louis Hendriks \\ geboren op 2 mei 1975 te Swalmen
}

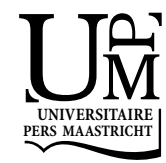




\section{Promotores}

Prof. dr. H.J.G.M. Crijns

Prof. dr. H.J.M. Vrijhoef

\section{Copromoter}

Dr. R.G. Tieleman

\section{Beoordelingscommissie}

Prof. dr. D. Ruwaard (voorzitter)

Prof. dr. T. van Achterberg, UMC St. Radboud Nijmegen

Prof. dr. A.P.M. Gorgels

Prof. dr. T. Jaarsma, Linköping University, Norrköping, Zweden

Prof. dr. C.P. van Schayck

Financial support by the Maastricht University Medical Centre and Stichting Hartsvrienden RESCAR is gratefully acknowledged.

Additional financial support by Bayer Health Care B.V., Boehringer-Ingelheim B.V., EuropeExPro, and Stichting Zorgvernieuwing Nederland is similarly appreciated. 
'The viewer is thus the final artist. His look, heart and mind imbue the jewel with life.'

Salvador Dali (1904-1989)

Voor mijn ouders 



\section{CONTENTS}

Chapter $1 \quad$ General introduction 9

$\begin{array}{lll}\text { Section I } & \text { Methodology and first results } & 29\end{array}$

Chapter $2 \quad$ An integrated chronic care program for patients with atrial 31

fibrillation - study protocol and methodology for a

prospective randomized controlled trial

Chapter 3 The Atrial Fibrillation Knowledge Scale: development, validation and results

Chapter 4 Improving guideline adherence in the treatment of atrial fibrillation by implementing an integrated chronic care program

Section II A randomized comparison

Chapter $5 \quad$ Nurse-led care versus usual care for patients with atrial fibrillation: results of a randomized trial of integrated chronic care versus routine clinical care in ambulatory patients with atrial fibrillation

Section III Quality of life and cost-effectiveness

Chapter 6 The impact of a nurse-led integrated chronic care approach on quality of life in patients with atrial fibrillation

Chapter 7 Cost-effectiveness of a specialized atrial fibrillation clinic versus usual care in patients with atrial fibrillation

Section IV Epilogue

Chapter 8 General discussion

Summary

Samenvatting

Dankwoord

Curriculum vitae 



\section{CHAPTER 1}

General introduction 


\section{PREFACE}

This thesis focuses on the redesigning of atrial fibrillation (AF) management. It considers the (cost)effectiveness of a newly developed Integrated Chronic Care approach, which consists of a nurse-led, guideline-based, software supported outpatient clinic for patients with AF.

This chapter gives an overview of the cardiac arrhythmia AF and its associated diseases and possible complications, its contribution to the total number of chronic diseases, and the impact on related costs for the society (first section). In the second section the Euro Heart Survey (EHS) on AF is highlighted as an important source and motivation for the current study. Also, the international guidelines on the management of $\mathrm{AF}$ have a prominent role in this section. The third section discusses the concept 'integrated chronic care' and focuses on two redesign models being, the Chronic Care Model and the Taxonomy on Disease Management. These models form the basis of the novel integrated care approach. The translation and interpretation of these models into the AF-Clinic is described in the fourth section. In the fith section I describe the development of the AF-Clinic as a logical next step after the most important AF studies of the past decade. In the final section the aims and outline of the thesis are presented. 


\section{ATRIAL FIBRILLATION}

Atrial fibrillation (AF) is the most common sustained cardiac arrhythmia in the Western world. The arrhythmia is characterized by fast and uncoordinated atrial activation. This causes an irregular and fast ventricular response rate. Patients may experience symptoms like palpitations, chest pain, dyspnoea, syncope and fatigue, but can also be totally asymptomatic.

Although AF can appear in many forms, three types of AF are distinguished, based on the presentation and duration of the arrhythmia. Paroxysmal AF is self-terminating, which means that a spontaneous conversion to sinus rhythm will occur, mostly within 48 hours. Persistent AF is not self-terminating and cardioversion (e.g. pharmaceutical or electrical) is required to terminate the arrhythmia. If repeated cardioversions have not been successful or the patient is asymptomatic, the stage of permanent AF is reached. In this stage the presence of the arrhythmia is accepted by both the patient and the care provider ${ }^{1}$ and the treatment strategy will be tuned accordingly.

In the majority of cases, AF is associated with underlying diseases like hypertension, heart failure, and valvular heart disease ${ }^{1,2}$. The cornerstone in the treatment of $A F$ is to adequately treat the underlying disease, as this can be the cause of $A F$, prior to the start of a rhythm control strategy. In the acute setting, the decision for restoration of the sinus rhythm (rhythm control) or management of the ventricular rate response (rate control) will be driven by the severity of symptoms, the duration of AF, and the need for anticoagulation. Regarding the latter, it is essential to determine the individual stroke risk in all AF patients, and to anticoagulate accordingly ${ }^{1}$.

\section{The impact of atrial fibrillation}

The prevalence of $A F$ is $1-2 \%$ in general population and increases with age from $<0.5 \%$ in individuals at $40-50$ years, to $5-15 \%$ in those older than 80 years of age $e^{2,3}$. In the Netherlands AF is currently accounting for 300,000 patients, but due to ageing of the population this number is expected to rise 2.5 -fold in the next 50 years ${ }^{2}$. In the United States of America alone, the number of AF-patients will exceed 10 million by then ${ }^{4}$. The growing patient population, as well as the complexity of the disease and possible severe complications fuel a strong awareness of the economic burden of AF. It is considered to be an expensive disease with significant influences on health $\operatorname{costs}^{5}$. In the Netherlands, the mean annual cost per patient is computed at $€ 2328$ and based on this the total economic burden is estimated at $€ 583.093 .264^{6,7}$. On the other hand, it must be noted that advanced management of $A F$ is economically profitable due to industrial activities producing workspaces, and thus it adds to increasing our standard of living.

As an additional consequence we are heading towards capacity problems in providing care for chronically ill patients ${ }^{8}$ and this particularly holds for the AF population. Currently, there are 17.250 medical specialists in the Netherlands. In 2028 at least 25.337 are needed to meet the growing demand, which represents a total grow of 
$47 \%(2.5 \% \text { per year })^{9}$. To balance the estimated care demand with the available care in cardiology, a yearly minimal growth of 50 cardiology specialists is needed ${ }^{9,10}$. Moreover, in the majority of patients, AF is progressive. The rate of recurrent AF is $10 \%$ in the first year after the initial diagnosis, followed by an approximately yearly $5 \%{ }^{11}$. Therefore it is likely that there will be a lack of cardiologists and electrophysiologist in the near future. To meet the growing demand and given the fact that $\mathrm{AF}$ is a chronic condition, task substitution is one of the obvious answers ${ }^{10}$.

\section{EURO HEART SURVEY}

Important insights in the management of AF have been provided by the Euro Heart Survey (EHS). This multi-centre prospective observational study took place between 2003 and 2005 among cardiology practices in European Society of Cardiology (ESC) member countries. In total, 5333 AF patients in 182 hospitals among 35 countries were enrolled. The main aim of the study was to describe AF management in ESC member countries and to check cardiology practices against guidelines ${ }^{12}$. One of the major EHS conclusions was that AF management throughout Europe is suboptimal according to the ESC guidelines, in terms of performing diagnostic procedures and appropriate application of oral anticoagulation ${ }^{12,13}$, as recommended by contemporary guidelines ${ }^{14}$. As a result of non-adherence, the survey demonstrated increased morbidity and mortality rates and consequently worse cardiovascular prognosis in these patients ${ }^{15}$. Therefore the EHS researchers advocate guideline-adherent antithrombotic therapy and the use of stroke risk stratification schemes, to enhance appropriate antithrombotic treatment to prevent complications and save lives among AF patients ${ }^{13,15}$.

\section{Guidelines for the management of atrial fibrillation}

The ESC supports the distribution of knowledge regarding all facets of cardiovascular diseases by translating this evidence into guidelines for clinical practice, aiming at providing the best available guidance to practicing physicians and support them in every day clinical and medical decision making, in order to improve clinical practice. In 2001 the first guidelines for the management of patients with $\mathrm{AF}^{14}$ were presented. A committee of experts representing the American College of Cardiology (ACC), the American Heart Association (AHA), and the ESC conducted a comprehensive review of the literature relevant to AF. The use of diagnostic procedures and therapies in the management of AF were critically evaluated, as well as the relative benefits and risks of these procedures. The AF guidelines were revised in 2006, 2010 as well as in $2012^{1,16,17}$. This demonstrates the rapid developments of current insights and knowledge regarding the management of $\mathrm{AF}$ and the enormous efforts undertaken to provide physicians with the most updated evidence based information translated into recommended guidelines. From this point it should be noted that the 2006 
guidelines ${ }^{16}$ were used in this thesis, as these were the acting guidelines during the study. Notwithstanding the findings presented above, it is remarkable that the current, updated guidelines do not advocate integrated chronic care management for patients with AF yet.

\section{INTEGRATED CHRONIC CARE}

The number of patients with chronic diseases has evolved in the last decade and is growing at an enormous rate. In the Netherlands alone 4.5 million people are having a chronic disease, of whom 1.3 million are suffering from co-morbid conditions ${ }^{18}$. Causes of chronic diseases vary. The medical scientific knowledge is growing rapidly and more specific diagnostic and interventional procedures are available. The mean age at which a chronic disease manifests in Netherlands people is decreasing and is currently at 45 years. Patients live longer with a chronic diseases and consequently the population is aging ${ }^{18}$ and the burden of chronic cardiovascular diseases is rising. According to the World Health Organisation (WHO) $30 \%$ of deaths worldwide are due to heart disease or stroke ${ }^{19}$. This development has contributed to an increasing economic impact and the understanding that the fragmented nature of care for chronically ill patients is no longer being tenable ${ }^{20}$. In response to this, disease management programs have been recognized as a way to reorganize medical treatment for chronic illness, emphasising an integrated, patient-centred approach to care. Potential benefits of disease management may include improved health outcomes, greater patient satisfaction, better quality of life, and reduced healthcare costs $^{20,21}$. Disease management components include: population identification processes; evidence-based practice guidelines; collaborative practice models to include physician and support-service providers; patient self-management education; process and outcomes measurement, evaluation, and management; routine reporting and feedback loops ${ }^{22}$. Although disease management programs were disease specific from the start, their focus was mainly to save money which was associated with onesize fits all organisation of care. Consequently, in the initial programs patients often received care that they actually did not want or need ${ }^{23}$. In addition, long term beneficial effects were lacking, both concerning health outcomes as well as costs ${ }^{8,24}$.

As a response to these disease indiscriminate management programs, the Chronic Care Model (CCM) was developed to contribute to improved patient outcomes by changing the routine delivery of care. Wagner et al. advocate the provision of care by fusion of six interrelated elements, in order to deliver patient-centred, evidencebased care ${ }^{25,26}$. The CCM was developed as a synthesis of the best available evidence regarding system changes needed to improve quality of disease management, and covering the domains of 1) the entire community, 2) the healthcare system, and 3) the provider organisation ${ }^{25,27,28}$. By focusing on six interrelated elements, the CCM pursues high quality management of chronic diseases, with the elements being: 
1) self-management support, 2) delivery system design, 3) decision support, 4) clinical information systems, 5) health care organization, and 6) community resources ${ }^{29}$. These elements are meant to provide a practical system for restructuring the management of chronic care. By coordination activities in primary care rather than focusing on the roles of specific personnel, the CCM aims to improve organizational and health outcomes ${ }^{8,25,26}$. This 'integrated care' makes it possible to address overall healthcare efficiency (process) and effectiveness (impact) ${ }^{30}$, which is particularly important for multi-problem patients with high-risk conditions like patients with AF.

Therefore the challenge of integration is to coordinate the continuum of care across the relevant fields of interest. This requires simultaneously collaboration, differentiation and integration. Horizontal integration represents the integration of similar organisations/units at the same level (e.g. two hospitals, wards), whereas vertical integration involves the combination of different organizations/units at different levels (e.g. hospital, community health centre, home care agency and nursing home ${ }^{31}$.

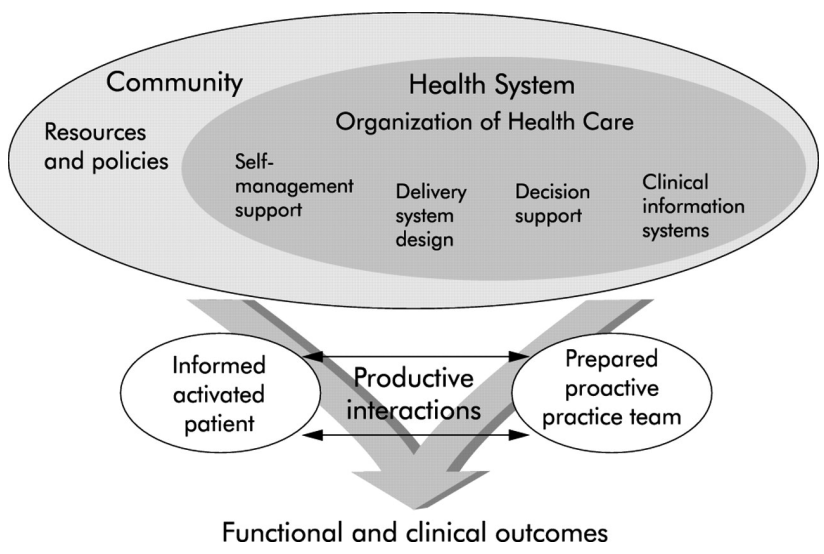

Figure 1.1 The chronic care model ${ }^{32}$.

Due to the variety of definitions and the interpretation and translation of disease management in terms of alternative care models, the AHA's Disease Management Taxonomy Writing Group was convinced of the importance of establishing a comprehensive, theory-based definition of disease management, and consequently developing a broad-based taxonomy that can adequately classify all types of disease management programs ${ }^{20}$. The taxonomy includes 8 domains representing a framework for the content that reports on disease management including: 1) patient population, 2) intervention recipient, 3 ) intervention content, 4) delivery personnel, 5) method of communication, 6) intensity and complexity, 7) environment, and 8) clinical outcomes (Figure 1.2). The system has been used as important input in heart failure disease management ${ }^{33,34}$, but has never been applied in AF before. 
In line with this, it is worth mentioning that integrated care interventions have been previously applied in other areas, e.g. coronary artery disease ${ }^{34}$, diabetes mellitus ${ }^{36-38}$, $\mathrm{COPD}^{39}$ and heart failure ${ }^{40-42}$. Comparing these disease management related interventions, in our opinion, is difficult because the wide variability of the content of the intervention provided (in terms of intensity, complexity, and location), the participating patients, the related diseases, and the number and capacity of disease management elements included in the intervention. Moreover, AF is a relatively new research area with respect to disease management and nurse-led interventions, which endorses the highly scientific relevance of the study in this thesis.

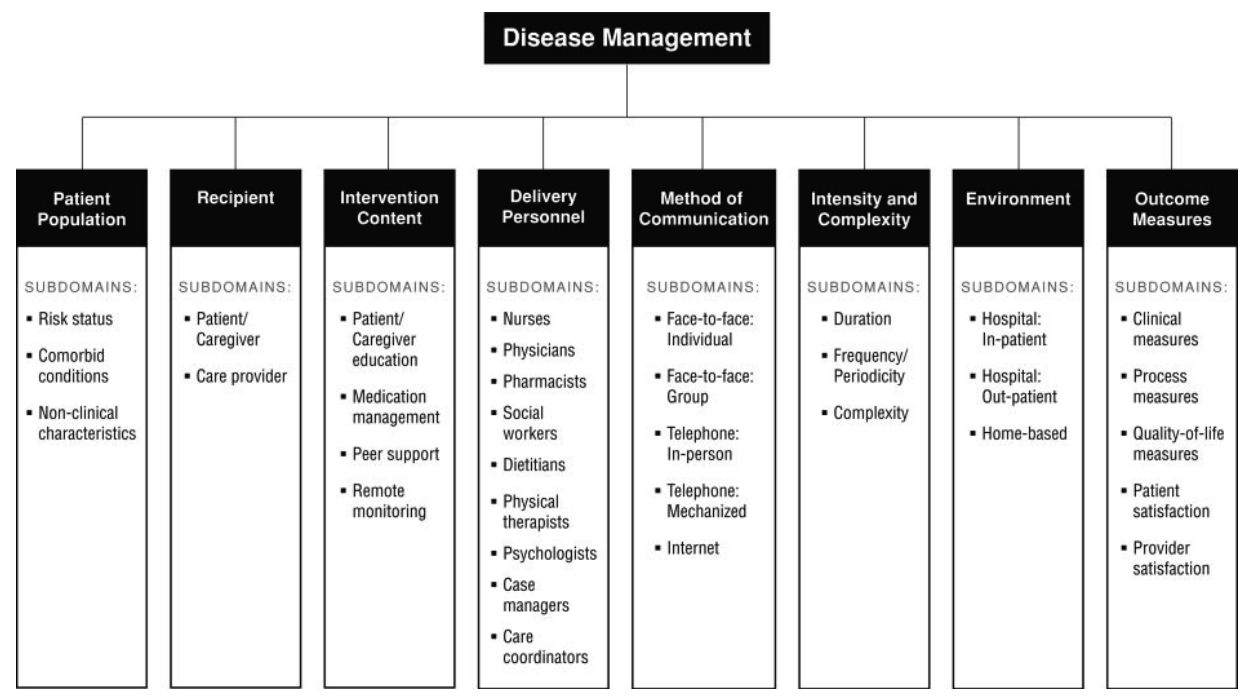

Figure 1.2 Disease management taxonomy ${ }^{20}$.

\section{DEVELOPMENT OF THE INTEGRATED CHRONIC CARE PROGRAM ON ATRIAL FIBRILLATION}

In response to the growing number of patients, the complexity of the disease and the frequent non-adherence to guidelines, there is a need for change in the management of AF. Nurse-led multidisciplinary heart failure clinics were shown to improve clinical outcomes $^{43,44}$, but no similar clinics for patients with AF do exist yet. Therefore, we developed an integrated chronic care program for patients with AF, in terms of a nurse-driven, guideline-based, software supported AF-Clinic. This outpatient clinic is based on the CCM and the framework of the disease management taxonomy. The domains and sub domains of the framework regarding the AF-Clinic are outlined below. 


\section{Patient population}

The target population in an AF-Clinic consists of patients with newly detected AF. This is an important patient population to consider for CCM since their risk is especially high compared to patients already known with $\mathrm{AF}^{45}$. The latter relates to underlying co-morbidities one of which may have triggered or worsened AF forcing the patient to come to the attention of the physician.

It is of utmost importance to check the thromboembolic Risk Status of this patient population. The risk assessment should not be too complicated. Fortunately, the $\mathrm{CHADS}_{2}{ }^{46}$ or $\mathrm{CHA}_{2} \mathrm{DS}_{2}-\mathrm{VASc}^{47}$ scoring system have become available over the previous years and they provide such an easy-to-use tool. The $\mathrm{CHADS}_{2}$ system is a stroke risk classification schema, using a point system ranging from 0 to 6 , to determine the

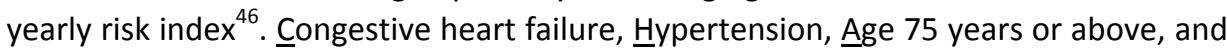

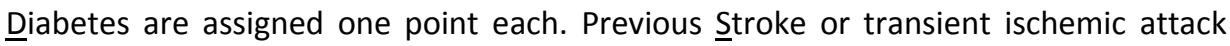
(TIA) is assigned two points. The score is calculated by summing all points for a patient. By using this schema it is possible to differentiate between low risk versus high risk patients. AF is associated with a diversity of Medical Comorbidities and therefore it is a disease state for which a disease management program is most appropriate ${ }^{12,48}$. Krumholz et al. state that some of the great challenges of caring for patients with multiple medical co-morbidities involves the complex interactions of different disease states $^{20}$. Thus, the treatment of AF must not be limited to management of the electrical problem only, especially since it foremost is a vascular disease $^{49}$. Indeed, as stated before, comprehensive management of underlying cardiovascular diseases should have priority ${ }^{15,50}$. Obviously, if such diverse problems coexist in one patient, including electrical, haemodynamic, coronary and valvular issues, management within a restrained time frame is extremely complex and asks for a well organized integrated chronic care model accommodating all the above aspects.

Also Non-clinical Characteristics of patients (e.g. education level, ethnicity, marital status) must be taken into account to enhance effectiveness of the CCM for management of AF. As an example, education determines the possibilities for selfmanagement, but the same holds e.g. for psychological status of the patient. To determine the patient profile concerning non-clinical characteristics, several tools including quality of life measurements, application of a knowledge scale $e^{51,52}$, the Hospital Anxiety and Depression Scale (HADS) ${ }^{53}$ and evaluation of patient satisfaction must be implemented. It is important to note that the information from non-clinical characteristics forms the basis for adapting education, counselling, and even medical therapy, but is also be of help in establishing effective self-management. Obviously, all of these items determine success of CCM in a complex way.

\section{Intervention recipient}

Patients with AF are expected to benefit directly from treatment, e.g. reduction of symptoms and prevention of complications. To obtain maximum beneficial effects, the intervention recipients must be activated in their role receptive for the 
intervention. AF patients in particular are most appropriate for activation of their selfmanagement role. Since recurrences in $\mathrm{AF}$ are most frequent, the population requires a large care demand (e.g. visits to outpatient clinic, emergency department, thrombosis centre). A decrease of these events will directly benefit the patients. When the benefit of decreased hospitalization is explained to them, then this may become an intrinsic motivator for patients to be included in a disease management program and perform self-management. In addition, the AF population seen in the AFClinic can be expected to efficiently perform self-management since they are relatively young (mean age is 67 years) and literacy is not a major problem (i.e. all patients are able to read and the majority has internet access). Whether the AF-Clinic will perform also in more elderly AF patients is in this respect an interesting issue which remains to be seen.

Apart from the above, the intervention recipient must be receptive for the intervention. For instance, the education offered must fit with the patients knowledge and needs. Obviously, patients may differ strongly in this respect. An education program should therefore have an adaptive educational approach, i.e. the information given should be tailored to the recipients capacities and interests. In itself this asks for pre-intervention evaluation of the patient's learning profile which may be done through questionnaires. In addition, specific health technology using counselling programs which adapt automatically to the level of knowledge gained-on-the-go may be helpful. This enables the amount and complexity of AF knowledge to be adapted to the level of knowledge a patient has gained a certain point in time in order to maintain self-management. In the intervention study presented in this thesis, we focused on enhancing patients' knowledge by verbal education during consulting hours as well as telephone calls as needed rather than using advanced telehealth systems which were unavailable at the time we performed the study.

\section{Intervention content and delivery personnel}

The heart of the disease management model within the AF-Clinic is a multidisciplinary approach to care, led by a nurse specialist, steered by decision support software based on the guidelines ${ }^{1,16}$ and supervised by a cardiologist ${ }^{54}$. The care delivery personnel must always be in close contact with the patients. Also the interaction with all involved care givers should be optimal. Special care should be paid to training of care delivery personnel concerning AF-specific communication, especially during didactic sessions. Attention should be paid that the intervention is acceptable for the patients, and feasible.

In general, before the first visit, patients undergo protocolized diagnostic procedures. At the first visit, a nurse specialist takes the patient's history and provides information about the pathophysiology of AF, its symptoms and possible complications, the results of the diagnostic tests and treatment options. Also patients are instructed about medication management (including strict anticoagulation monitoring), lifestyle interventions and about when to report to the hospital. This patient education is 
performed to further empower patients in their role and stimulate them to undertake self-management activities. The dedicated software is used to guide comprehensive AF management and associated cardiovascular conditions, since it can determine an individual patient profile and consequently propose the most appropriate treatment. This software is based on the guidelines and is updated by a national content board each time it is renewed. At the end of the consultation, the nurse specialist is supervised by a cardiologist, who approves the proposed diagnosis and treatments. These elements of care should be provided following a one-stop-shop approach. Patients can contact the nurse in person or by telephone between planned visits as needed. Special attention is given to verify if patients understand the principle of contacting the nurse as needed. During follow-up visits, psychosocial support and educational interventions are repeated by the nurse specialist. Besides the role of caregiver the nurse specialist fulfils the role of case manager (e.g. monitoring medication use, complaints and vital signs, collecting information regarding reported medication side effects, coordination of care also with other disciplines, communication of patient recommendations to the (general) physician and multidisciplinary communication).

In the AF-Clinic patients will benefit indirectly from the principle of 'influencing provider behaviour'. Nurse specialists in AF and cardiologists work closely together, creating a 'pilot / co-pilot construction'. This is most effective in implementing all diagnostic and therapeutic procedures AF patients need. The mutual feedback is instrumental in improving quality of care and clinical outcome. Finally, due to increased time scheduled during consultation with the nurse specialist, significant attention can be paid to patient education in order to teach patients how to fulfil and maintain self-management activities.

\section{Method of communication and environment}

In the AF-Clinic face-to-face contacts as well as telephone calls are used as the method of communication. Information sessions for patients and their relatives have not been established yet, but would be a significant complement to the contacts during consulting hours. Also, communication via multi-media can be considered, e.g. computerized remote follow-up, e-mail, or text messages. In heart failure a well known example is the Health Buddy ${ }^{55}$, a device connected to a landline phone at the patients' home, enabling remote communication. On a daily basis patients have to answer questions which will be sent to a server and the nurse desktop. In case of heart failure symptoms immediate responses by the heart failure nurse are triggered. Another example is the use of text messages in so-called mobile health. Supportive text messaging by mobile phone has potential to be a significant tool for influencing behavioral change, as was recently demonstrated in a smoking cessation trial ${ }^{56,57}$. The use of similar devices has not been established in the AF-Clinic yet but it is highly plausible that these interventions can improve communication processes and performance of self-management in patients with AF. 


\section{Intensity and complexity}

According to the framework of the Disease Management Taxonomy ${ }^{20}$, the relationship between individual key components within a disease management intervention and the intensity with which these components are delivered, are more important than the individual components alone $8,25,26,58$. Duration, frequency/periodicity and complexity are key elements in this respect. The standard duration of patients treated in the AF-Clinic is one year. However, the exact period depends on factors like stability of the disease, response to and toleration of medication, and co-morbid conditions. The latter also applies to the frequency of the visits to the outpatient clinic. Follow-up visits with the nurse specialist are pre-planned at 3, 6 and 12 months, and every 6 months thereafter. The complexity of the disease management program is considered to be high, as all recommended components of disease management are integrated in the AF-Clinic ${ }^{22}$. Obviously, since AF is complex and patients differ in their capacity to cope with this disease, tailoring to the patients' needs with more frequent visits and focused interventions are key to the success of integrated chronic care for more complicated forms of AF and vice versa.

\section{Outcomes}

The main aim of the AF-Clinic is to provide the best tailored care in order to improve cardiovascular morbidity and mortality. The main outcomes are therefore cardiovascular hospitalization and cardiovascular death. Non-clinical outcomes consist of guideline adherent management, the patients' experienced quality of life (including anxiety and depression), patient empowerment (e.g. patient education, knowledge, self-management, satisfaction), and cost-effectiveness.

\section{DEVELOPMENT OF THE AF-CLINIC IN THE PERSPECTIVE OF PRIOR AF RESEARCH}

AF is associated with an increased mortality and disabling cardiovascular diseases, and this goes hand in hand with increased AF-related hospitalizations ${ }^{59-61}$ and mortality ${ }^{62}$. Unfortunately, the large rate- and rhythm control studies have not shown any effect of rhythm control on cardiovascular events. As a general conclusion, rate control appeared not inferior to rhythm control ${ }^{63-67}$. In addition, the RACE I study demonstrated that even in the subset of patients maintaining sinus rhythm, vascular events are not reduced ${ }^{68}$. It must be noted that it was generally believed at that time, that the risk of stroke could be reduced by maintaining sinus rhythm alone, and that anticoagulation therapy could be stopped accordingly in patients with risk factors for stroke, in whom sinus rhythm was obtained (Shock-and-Forget paradigm). Therefore, the rate versus rhythm studies have taught us that continued anticoagulation is quite important irrespective of the approach taken. Considering the decrease of 
cardiovascular events over time, i.e. from RACE I to RACE II (Figure 1.3), it appears that adequate and continued anticoagulation pays off ${ }^{65,69}$. Figure 1.3 , comparing RACE I and RACE II indeed shows a clear reduction in stroke events and cardiovascular mortality (the latter possibly due to reduced stroke) and, by abandoning rhythm control in RACE II, also a reduction in adverse drug reactions and pacemakers. However, bleeding and heart failure events have remained high. Therefore, before one adopts the notion that anticoagulation is the key element in reducing cardiovascular events (Warfarinize-and-Forget paradigm) one must consider that other threats remain for patients with AF. In my opinion, this calls for comprehensive management of all vascular risks beyond stroke risk prevention: treatment of hypertension, coronary disease, heart failure and valvular disease. This notion is supported by the understanding that underlying cardiovascular diseases are potential risk factors in developing $A F$ and that $A F$ is a 'marker' of (future) vascular disease ${ }^{49,70}$. In addition to that, aggressive monitoring of anticoagulation or use of novel antithrombotic drugs that produce stable levels of anticoagulation may be needed to further enhance prognosis in the complex AF patient.

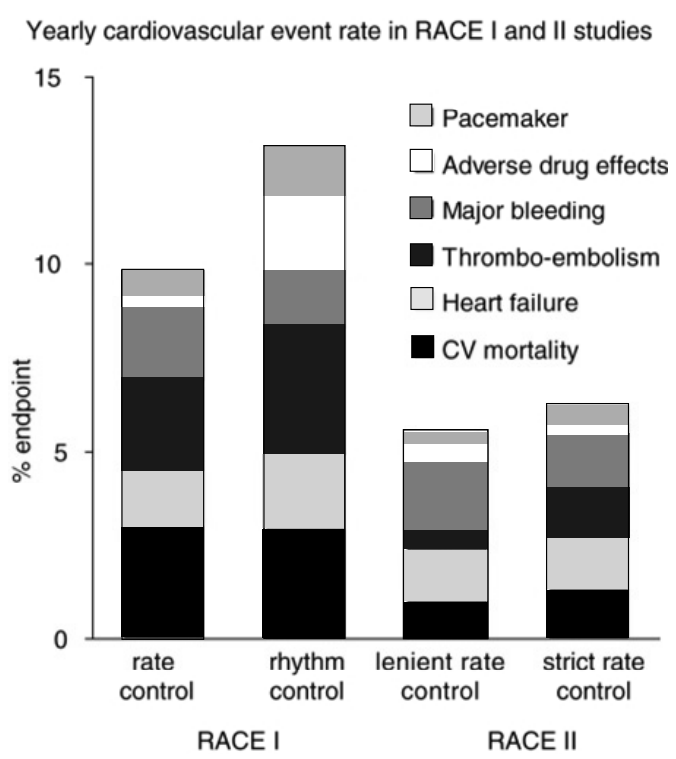

Figure 1.3 Yearly cardiovascular morbidity and mortality rate in the Rate Control Versus Electrical Cardioversion (RACE) I study and the Rate Control Efficacy in Permanent atrial fibrillation (RACE) II study ${ }^{65,69}$.

Physicians might assume that the management of AF is nearly complete by applying appropriate oral anticoagulation therapy and avoid rhythm control where possible. They may become distracted from the integral AF management process by focusing 
too much on rhythm and stroke risk prevention. In contrast, one should think beyond 'Shock-and-Forget' as well as beyond 'Warfarinize-and-Forget' and apply an integrated care approach, following the principles of the CCM and covering all facets of AF management.

\section{Conclusion}

In conclusion, AF can be a serious health threat due to underlying associated cardiovascular diseases and thromboembolic risk. Appropriate management of AF patients is difficult and influenced by numerous issues. Knowledge and awareness increased significantly over the last decades, but substandard management is still present in daily practice. Let's not 'forget' the patient by only focusing at the arrhythmia or stroke risk prevention. Our focus should be broader and consequently should take into account the possible underlying cardiovascular diseases, which can cause or worsen AF. Also, 'how' to manage patients is important in this perspective; not only the use of high-tech approaches, but also management tailored to the individual patient. The AF patient himself with all relevant facets; that is what management of AF should be all about. An integrated approach may be helpful in this respect by putting 'all lessons learned' into practice. 


\section{OUTLINE OF THIS THESIS}

The overall aim of this thesis is to evaluate a new integrated chronic care program on atrial fibrillation, featuring a nurse-driven, guideline-based, software supported outpatient clinic. The main hypothesis is that the management of AF patients within the integrated chronic care approach is associated with improved outcomes compared to usual care.

Section I (chapters 2 and 4) describes the protocol of the study and the preliminary results of a pilot in which the AF-Clinic is compared to a historical control group (patients from the same institution who participated in the Euro Heart Survey on AF). In chapter 3 the validation of the newly developed AF Knowledge Scale is described. This scale is able to measure knowledge in AF patients with a combined focus on disease, symptom recognition and therapy. Section II (chapter 5) concerns the randomized trial on effectiveness of the integrated chronic care program in comparison to the usual care by a cardiologist in the outpatient setting, in terms of cardiovascular hospitalization, cardiovascular death, and the extent to which the management of AF patients is in accordance with the evidence based guidelines. Section III (chapters 6 and 7) focuses on the patients' quality of life, as well as on costeffectiveness of treatment. Section IV presents an epilogue (chapter 8) containing a general discussion, including conceptual and methodological considerations as well as implications for clinical practice and recommendations for future research. 


\section{REFERENCES}

1. Camm AJ, Kirchhof P, Lip GY, Schotten U, Savelieva I, Ernst S, Van Gelder IC, Al-Attar N, Hindricks G, Prendergast B, Heidbuchel H, Alfieri O, Angelini A, Atar D, Colonna P, De Catarina R, De Sutter J, Goette A, Gorenek B, Heldal M, Hohloser SH, Kolh P, Le Heuzey JY, Ponikowski P, Rutten FH, European Heart Rhythm Association, European Association for Cardio-Thoracic Surgery. Guidelines for the management of atrial fibrillation of the European Society of Cardiology (ESC). Eur Heart J 2010;31:2369-429.

2. Go AS, Hylek EM, Phillips KA, Chang Y, Henault LE, Selby JV, Singer DE. Prevalence of diagnosed atrial fibrillation in adults: national implications for rhythm management and stroke prevention: the AnTicoagulation and Risk Factors in Atrial Fibrillation (ATRIA) Study. JAMA 2001;285:2370-5.

3. Heeringa J, van der Kuip DA, Hofman A, Kors JA, van Herpen G, Stricker BH, Stijnen T, Lip GY, Witteman JC. Prevalence, incidence and lifetime risk of atrial fibrillation: the Rotterdam study. Eur Heart J 2006;27:949-53.

4. Miyasaka Y, Barnes ME, Gersh BJ, Cha SS, Bailey KR, Abhayaratna WP, Seward JB, Tsang TS. Secular trends in incidence of atrial fibrillation in Olmsted County, Minnesota, 1980 to 2000, and implications on the projections for future prevalence. Circulation 2006;114: 119-25.

5. Wolowacz SE, Samuel M, Brennan VK, Jasso-Mosqueda JG, Van Gelder IC. The cost of atrial fibrillation: a systematic review of the recent literature. Europace 2011; 13:1375-85.

6. Ringborg A, Nieuwlaat R, Lindgren P, Jönsson B, Fidan D, Maggioni AP, Lopez-Sendon J, Stepinska J, Cokkinos DV, Crijns HJGM. Costs of atrial fibrillation in five European countries: results from the Euro Heart Survey on atrial fibrillation. Europace 2008;10:40311.

7. Heemstra HE, Nieuwlaat R, Meijboom M, Crijns HJ. The burden of atrial fibrillation in the Netherlands. Neth Heart J 2011;19:373-8.

8. Vrijhoef HJ. Chronically ill are the future (in Dutch: Chronisch zieken hebben de toekomst), Inaugural Speech. Tilburg, The Netherlands: Tilburg University; 2010.

9. Capaciteitsorgaan. Veel meer artsen nodig. Medisch Contact 2011;1.

10. Capaciteitsorgaan. Capaciteitsplan 2010. Available at: http://www.capaciteitsorgaan.nl/ Portals/0/capaciteitsorgaan/publicaties/capaciteitsplan2010/revisie\%201.1\%20\%20Capaci teitsplan\%202010.pdf. Accessed July 21, 2012.

11. Camm AJ, Kirchhof P, Lip GY, Savelieva I, Ernst S. Atrial Fibrillation. In: The ESC textbook of Cardiovascular Medicine, second edition. Oxford: Oxford University Press 2009;1069-131.

12. Nieuwlaat R, Capucci A, Camm AJ, Olsson SB, Andresen D, Davies DW, Cobbe S, Breithardt G, Le Heuzey JY, Prins MH, Levy S, Crijns HJ. Atrial fibrillation management: a prospective survey in ESC member countries: the Euro Heart Survey on Atrial Fibrillation. Eur Heart $J$ 2005;26:2422-34.

13. Nieuwlaat R, Capucci A, Lip GY, Olsson SB, Prins MH, Nieman FH, López-Sendón J, Vardaz $P E$, Aliot $E$, Santini M, Crijns HJGM. Antithrombotic treatment in real-life atrial fibrillation patients. Eur Heart J 2006;27:3018-26.

14. Fuster V, Ryden LE, Asinger RW, Cannom DS, Crijns HJ, Frye RL, Halperin JL, Kay GN, Klein WW, Levy S, McNamara RL, Prystowski EN, Wann LS, Wyse DG. ACC/AHA/ESC guidelines for the management of patients with atrial fibrillation. A report of the American College of Cardiology/American Heart Association Task Force on Practice Guidelines and the European Society of Cardiology Committee for Practice Guidelines and Policy Conferences (Committee to develop guidelines for the management of patients with atrial fibrillation) developed in collaboration with the North American Society of Pacing and Electrophysiology. Eur Heart J 2001;22:1852-923. 
15. Nieuwlaat R, Olsson SB, Lip GY, Camm AJ, Breithardt G, Capucci A, Meeder JG, Prins MH, Lévy $\mathrm{S}$, Crijns HJ. Guideline-adherent antithrombotic treatment is associated with improved outcomes compared with undertreatment in high-risk patients with atrial fibrillation: the Euro Heart Survey on Atrial Fibrillation. Am Heart J 2007;153:1006-12.

16. Fuster V, Rydén LE, Cannom DS, Crijns HJ, Curtis AB, Ellenbogen KA, Halperin JL, Le Heuzey JY, Kay GN, Lowe JE, Olsson SB, Prystowsky EN, Tamargo JL, Wann S, Task Force on Practice Guidelines, American College of Cardiology/American Heart Association; Committee for Practice Guidelines, European Society of Cardiology, European Heart Rhythm Association, Heart Rhythm Society. ACC/AHA/ESC 2006 guidelines for the management of patients with atrial fibrillation - executive summary: a report of the American College of Cardiology/American Heart Association Task Force on Practice Guidelines and the European Society of Cardiology Committee for Practice Guidelines (Writing Committee to revise the 2001 guidelines for the management of patients with atrial fibrillation). Eur Heart $J$ 2006;27:1979-2030.

17. Authors/Task Force Members, Camm AJ, Lip GY, De Caterina R, Savelieva I, Atar D, Hohnloser SH, Hindricks G, Kirchhof P, ESC Committee for Practice Guidelines (CPG), Bax JJ, Baumgartner H, Ceconi C, Dean V, Deaton C, Fagard R, Funck-Brentano C, Hasdai D, Hoes A, Kirchhof P, Knuuti J, Kolh P, McDonagh T, Moulin C, Popescu BA, Reiner Z, Sechtem $U$, Sirnes PA, Tendera $M$, Torbicki A, Vahanian A, Windecker S, Document Reviewers, Vardas P, Al-Attar N, Alfieri O, Angelini A, Blömstrom-Lundqvist C, Colonna P, De Sutter J, Ernst S, Goette A, Gorenek B, Hatala R, Heidbüchel H, Heldal M, Kristensen SD, Kolh P, Le Heuzey JY, Mavrakis H, Mont L, Filardi PP, Ponikowski P, Prendergast B, Rutten FH, Schotten U, Van Gelder IC, Verheugt FW. 2012 focussed update of the ESC Guidelines for the management of atrial fibrillation: An update of the 2010 ESC Guidelines for the management of atrial fibrillation * Developed with the special contribution of the European Heart Rhythm Association. European Heart Journal 2012;33:2719-47.

18. van der Lucht F, Polder JJ. Rijksinstituut voor Volksgezondheid en Milieu (RIVM), Ministerie van Volksgezondheid Welzijn en Sport. Report on Health Future Exploration; from health to better (in Dutch: Kernrapport Volksgezondheid Toekomst Verkenning; van gezond naar beter). Available at: http://www.rivm.nl/bibliotheek/rapporten/270061005.html. Accessed May 14, 2012.

19. Centers for Disease Control and Prevention. Chronic Disease, notes \& reports. Available at: http:www.cdc.gov/chronicdisease/resources/publications/cdnr/pdf/cdnr-feb-2009.pdf.

Accessed May 14, 2012.

20. Krumholz HM, Currie PM, Riegel B, Phillips CO, Peterson ED, Smith R, Yancy CW, Faxon DP, American Heart Association Disease Management Taxonomy Writing Group. A taxonomy for disease management: a scientific statement from the American Heart Association Disease Management Taxonomy Writing Group. Circulation 2006;114:1432-45.

21. Congressional Budget Office. An analysis of the literature on disease management programs. Available at: http://www.cbo.gov/ftpdocs/59xx/doc5909/10-13diseasemngmnt.pdf. Accessed May 14, 2012.

22. Care Continuum Alliance (CCA). Care Continuum Alliance (ACA) Definition of Disease Management. Available at: http://www.carecontinuum.org/dm_definition.asp Accessed May 14, 2012.

23. Coleman K, Austin BT, Brach C, Wagner EH. Evidence on the Chronic Care Model in the new millennium. Health Aff (Millwood) 2009;28:75-85.

24. Mattke S, Seid M, MA S. Evidence for the effect of disease management: is $\$ 1$ billion a year a good investment? Am J Manag Care 2007;13:670-6.

25. Wagner EH, Austin BT, Von Korff M. Organizing care for patients with chronic illness. Milbank Q 1996(b);74:511-44. 
26. Wagner EH, Austin BT, Von Korff M. Improving outcomes in chronic illness. Manag Care $Q$ 1996(a);4:12-25.

27. Wagner EH, Davis C, Schaefer J, Von Korff M, Austin B. A survey of leading chronic disease management programs: are they consistent with the literature? Manag Care Q 1999;7:5666.

28. Bonomi AE, Wagner EH, Glasgow RE, Von Korff M. Assessment of Chronic Illness Care (ACIC): a practical tool to measure quality improvement. Health Serv Res 2002;37:791-820.

29. Bodenheimer T, Wagner EH, Grumbach K. Improving primary care for patients with chronic illness. JAMA 2002;288:1775-9.

30. Kodner DL. All together now: a conceptual exploration of integrated care. Healthc $Q$ 2009;i3 Spec No:6-15.

31. Shortell SM, Gillies RR, Anderson DA. 1994. The New World of Managed Care: Creating Organized Delivery Systems. Health Affairs 1994;13: 46-64.

32. Improving chronic illness care. The chronic care model. Available at: http://www.improvingchroniccare.org/index.php?p=The_Chronic_Care_Model\&s=2.

Accessed July 21, 2012.

33. Riegel B, Lee CS, Sochalski J. Developing an instrument to measure heart failure disease management program intensity and complexity. Circ Cardiovasc Qual Outcomes 2010;3:324-30.

34. Konstam MA, Konstam V. Heart Failure Disease Management: A Sustainable Energy Source for the Health Care Engine. JACC 2010;56:379-81.

35. Voogdt-Pruis HR, Vrijhoef HJ, Beusmans GH, Gorgels AP. Quality improvement of nurse-led aftercare to outpatients with coronary heart disease: report of a case study. Int J Qual Health Care 2012;24:286-92.

36. Vrijhoef HJ, Diederiks JP, Spreeuwenberg C, Wolffenbuttel BH. Substitution model with central role for nurse specialist is justified in the care for stable type 2 diabetic outpatients. J Adv Nurs 2001;36:546-55.

37. Houweling ST, Kleefstra N, van Hateren KL, Kooy A, Groenier KH, Ten Vergert E, Meyboomde Jong B, Bilo HJ, Langerhans Medical Research Group. Diabetes specialist nurse as main care provider for patients with type 2 diabetes. Neth J Med 2009;67:279-84.

38. Steuten LM, Vrijhoef HJ, Landewé-Cleuren S, Schaper N, Van Merode GG, Spreeuwenberg C. A disease management programme for patients with diabetes mellitus is associated with improved quality of care within existing budgets. Diabet Med 2007;24:1112-20.

39. Steuten L, Palmer S, Vrijhoef B, van Merode F, Spreeuwenberg C, Severens H. Cost-utility of a disease management program for patients with asthma. Int J Technol Assess Health Care 2007;23:184-91.

40. Stromberg A, Martensson J, Fridlund B, Levin LA, Karlsson JE, Dahlstrom U. Nurse-led heart failure clinics improve survival and self-care behaviour in patients with heart failure: results from a prospective, randomised trial. Eur Heart J 2003;24:1014-23.

41. Jaarsma $\mathrm{T}$, van der Wal MH, Lesman-Leegte I. Effect of moderate or intensive disease management program on outcome in patients with heart failure: Coordinating Study Evaluating Outcomes of Advising and Counseling in Heart Failure (COACH). Arch Intern Med 2008;168:316-24.

42. Inglis SC, Clark RA, McAlister FA, Ball J, Lewinter C, Cullington D, Stewart S, Cleland JG. Structured telephone support or telemonitoring programmes for patients with chronic heart failure. Cochrane database Syst Rev 2010; 4:CD007228.

43. Rich MW, Beckham V, Wittenberg C, Leven CL, Freedland KE, Carney RM. A multidisciplinary intervention to prevent the readmission of elderly patients with congestive heart failure. N Engl J Med 1995;333:1190-5. 
44. Philips CO, Wright SM, Kern DE, Singa RM, Shepperd S, Rubin HR. Comprehensive discharge planning with postdischarge support for older patients with congestive heart failure: a meta-analysis. JAMA 2004;291:1358-67.

45. Nieuwlaat R, Prins MH, Le Heuzey JY, Vardas PE, Aliot E, Santini M, Cobbe SM, Widdershoven JW, Baur LH, Lévy S, Crijns HJ. Prognosis, disease progression, and treatment of atrial fibrillation patients during 1 year: follow-up of the Euro Heart Survey on atrial fibrillation. Eur Heart J 2008;29:1181-9.

46. Gage BF, Waterman AD, Shannon W, Boechler M, Rich MW, Radford MJ. Validation of clinical classification schemes for predicting stroke: results from the National Registry of Atrial Fibrillation. JAMA 2001;285:2864-70.

47. Lip GY, Nieuwlaat R, Pisters R, Lane DA, Crijns HJ. Refining clinical risk stratification for predicting stroke and thromboembolism in atrial fibrillation using a novel risk factor-based approach: the euro heart survey on atrial fibrillation. Chest 2010; 137:263-72.

48. Nabauer M, Gerth A, Limbourg T, Schneider S, Oeff M, Kirchhof P, Goette A, Lewalter T, Ravens $U$, Meinertz T, Breithardt G, Steinbeck G. The registry of the German competence NETwork on atrial fibrillation: patient characteristics and initial management. Europace 2009;11:423-34.

49. Weijs B, de Vos CB, Tieleman RG, Peeters FE, Limantoro I, Kroon AA, Cheriex EC, Pisters R, Crijns HJ. The occurrence of cardiovascular disease during 5-year follow-up in patients with idiopathic atrial fibrillation. Europace 2012; doi:10.1093/europace/eus203.

50. Du X, Ninomiya T, de Galan B, Abadir E, Chalmers J, Pillai A, Woodward M, Cooper M, Harrap S, Hamet P, Poulter N, Lip GY, Patel A, ADVANCE Collaborative Group. Risks of cardiovascular events and effects of routine blood pressure lowering among patients with type 2 diabetes and atrial fibrillation: results of the ADVANCE study. Eur Heart $J$ 2009;30:1128-35.

51. Linné $A B$, Liedholm $H$, Israelsson B. Effects of systematic education on heart failure patients' knowledge after 6 months. A randomised, controlled trial. Eur J Heart Fail 1999;1:219-27.

52. van der Wal MH, Jaarsma T, Moser DK, van Veldhuisen DJ. Development and testing of the Dutch Heart Failure Knowledge Scale. Eur J Cardiovasc Nurs 2005;4:273-7.

53. Zigmond AS, Snaith RP. The hospital anxiety and depression scale. Acta Psychiatr Scand 1983;67:361-70.

54. Hendriks JM, de Wit R, Vrijhoef HJ, Tieleman RG, Crijns HJ. An integrated chronic care program for patients with atrial fibrillation: study protocol and methodology for an ongoing prospective randomised controlled trial. Int J Nurs Stud 2010;47:1310-6.

55. Boyne JJ, Vrijhoef HJ, Crijns HJ, De Weerd G, Kragten J, Gorgels AP, TEHAF investigators. Tailored telemonitoring in patients with heart failure: results of a multicentre randomized controlled trial. Eur J Heart Fail 2012;14:791-801.

56. Free C, Knight R, Robertson S, Whittaker R, Edwards P, Zhou W, Rodgers A, Cairns J, Kenward MG, Roberts I. Smoking cessation support delivered via mobile phone text messaging (txt2stop): a single-blind randomised trial. Lancet 2011;378:49-55.

57. Bennett DA, Emberson JR. Text messaging in smoking cessation: the txt2stop trial. Lancet 2011;378:6-7.

58. Grol RP, Bosch MC, Hulscher ME, Eccles MP, Wensing M. Planning and studying improvement of care: the use of theoretical perspectives. Milbank Q 2007;85:93-138.

59. Wattigney WA, Mensah GA, Croft JB. Increasing trends in hospitalization for atrial fibrillation in the United States, 1985 through 1999: implications for primary prevention. Circulation 2003;108:711-16.

60. Friberg J, Buch P, Scharling H, Gadsbphioll N, Jensen GB. Rising rates of hospital admissions for atrial fibrillation. Epidemiology 2003;14:666-72. 
61. Miyasaka Y, Barnes ME, Gersh BJ, Cha SS, Bailey KR, Seward JB, Tsang TS. Changing trends of hospital utilization in patients after their first episode of atrial fibrillation. Am J Cardiol 2008;102:568-72.

62. Friberg L, Rosenqvist M. Cardiovascular hospitalization as a surrogate endpoint for mortality in studies of atrial fibrillation: report from the Stockholm Cohort Study of Atrial Fibrillation. Europace 2011;13:626-33.

63. Hohnloser $\mathrm{SH}$, Kuck $\mathrm{KH}$, Lilienthal J. Rhythm or rate control in atrial fibrillation Pharmacological Intervention in Atrial Fibrillation (PIAF): a randomised trial. Lancet 2000;356:1789-94.

64. Wyse DG, Waldo Al, DiMarco JP, Domanski MJ, Rosenberg Y, Schron EB, Kellen JC, Greene $\mathrm{HL}$, Mickel MC, Dalquist JE, Corley SD, Atrial Fibrillation Follow-up Investigation of Rhythm Management (AFFIRM) Investigators. A comparison of rate control and rhythm control in patients with atrial fibrillation. N Engl J Med 2002; 347:1825-33.

65. Van Gelder IC, Hagens VE, Bosker HA, Kingma JH, Kamp O, Kingma T, Said SA, Darmanata JI, Timmermans AJ, Tijssen JG, Crijns HJ, Rate Control versus Electrical Cardioversion for Persistent Atrial Fibrillation Study Group. A comparison of rate control and rhythm control in patients with recurrent persistent atrial fibrillation. N Engl J Med 2002;347:1834-40.

66. Carlsson J, Miketic S, Windeler J, Cuneo A, Haun S, Micus S, Walter S, Tebbe U, STAF Investigators. Randomized trial of rate-control versus rhythm-control in persistent atrial fibrillation: the Strategies of Treatment of Atrial Fibrillation (STAF) study. J Am Coll Cardiol 2003;41:1690-6.

67. Roy D, Talajic M, Nattel S, Wyse DG, Dorian P, Lee KL, Bourassa MG, Arnold JM, Buxton AE, Camm AJ, Connolly SJ, Dubuc M, Ducharme A, Guerra PG, Hohnloser SH, Lambert J, Le Heuzey JY, O'Harra G, Pedersen OD, Rouleau JL, Singh BN, Stevenson LW, Stevenson WG, Thibault B, Waldo AL, Atrial Fibrillation and Congestive Heart Failure Investigators. Rhythm control versus rate control for atrial fibrillation and heart failure. $N$ Engl J Med 2008;358:2667-77.

68. Rienstra M, Van Gelder IC, Hagens VE, Veeger NJ, Van Veldhuisen DJ, Crijns HJ. Mending the rhythm does not improve prognosis in patients with persistent atrial fibrillation: a subanalysis of the RACE study. Eur Heart J 2006; 27:357-64.

69. Van Gelder IC, Groenveld HF, Crijns HJ, Tuininga YS, Tijssen JG, Alings AM, Hillege HL, Bergsma-Kadijk JA, Cornel JH, Kamp O, Tukkie R, Bosker HA, Van Veldhuisen DJ, Van den Berg MP, RACE II investigators. Lenient versus strict rate control in patients with atrial fibrillation. N Engl J Med 2010;362:1363-73.

70. Weijs B, Pisters R, Haest RJ, Kragten JA, Joosten IA, Versteylen M, Timmermans CC, Pison L, Blaauw Y, Hofstra L, Nieuwlaat R, Wildberger J, Crijns HJ. Patients originally diagnosed with idiopathic atrial fibrillation more often suffer from insidious coronary artery disease compared to healthy sinus rhythm controls. Heart Rhythm 2012;doi.org/10.1016/ j.hrthm.2012.08.013. 



\section{SECTION}

Methodology and first results 



\title{
CHAPTER
}

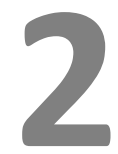

\begin{abstract}
An integrated chronic care program for patients with atrial fibrillation Study protocol and methodology for a prospective randomized controlled trial
\end{abstract}

Jeroen M Hendriks, Rianne de Wit, Hubertus J Vrijhoef, Robert G Tieleman, 


\section{ABSTRACT}

Background. Adherence to guidelines for the management of atrial fibrillation (AF) is often poor, although this is associated with improved morbidity and mortality in such patients. Increasing numbers of programs are designed to enhance appropriate counselling, treatment and coordinated care delivery including the nurse-led, guideline-based, software-supported integrated chronic care program (ICCP) for patients with AF reported here.

Objectives. This chapter outlines the study protocol and methodology that is used to evaluate the effectiveness of a newly developed nurse-led, guideline-based, software supported ICCP for patients with AF.

Design and Methods. Evaluation of the ICCP is carried out in the outpatient care setting known as the AF-Clinic. A prospective randomized controlled trial is performed in the outpatient AF-Clinic of a University Hospital in the Netherlands in cooperation with the collaborating university. The primary outcome measures are cardiovascular hospitalization and/or death. Secondary outcome measures include guideline adherence, patient knowledge about their condition, quality of life, satisfaction and other outcome measurements such as cost-effectiveness.

Participants. It was calculated that 698 participants are needed to demonstrate discernible outcomes in relation to the primary endpoint (349 patients in each group) with follow-up after one year.

Results. The study started in January 2007 and the first results are expected in the beginning of 2010 .

Conclusions. It is hypothesized that the ICCP may contribute towards closing the gap between guideline recommendations and current practice in the management of atrial fibrillation. Furthermore, it is hypothesized that the program has the potential to optimise the management of AF-patients and improve the efficiency and coordination of patient care. This may lead to better patient outcomes including improved quality of life and patient satisfaction in such patients. 


\section{BACKGROUND}

Atrial fibrillation (AF) is the most common cardiac arrhythmia in the western world. The prevalence is approximately $5.5 \%$ and increases with age ${ }^{1,2}$. AF leads to increased morbidity and mortality due to symptoms, the development of heart failure and stroke. Approximately $15-25 \%$ of ischaemic strokes are associated with AF. At diagnosis, it is estimated that $5.6 \%$ of patients have already suffered a stroke, followed by a $7.6 \%$ yearly stroke rate ${ }^{3}$. AF can result in symptoms such as palpitations, chest pain, shortness of breath, and is often accompanied by feelings of anxiety and depression. As a consequence, quality of life is significantly impaired in many patients $^{4-6}$.

A recent Euro Heart Survey (EHS) in 31 European countries investigated guideline adherence for the management of AF in 5333 patients. The study demonstrated poor guideline adherence in relation to the use of antithrombotic therapy leading to increased morbidity and mortality in such patients. Undertreatment caused by failure to adhere to published guidelines has also been associated with a higher chance of thromboembolism (odds ratio [OR] 1.97; 95\% composite interval [CI] 1.29-3.01; $P=0.004)$ and the combined endpoint of cardiovascular death, thromboembolism, or major bleeding (OR 1.54; 95\% Cl 1.14-2.10; $P=0.024)^{7,8}$. In the Netherlands, comparable results were found regarding guideline adherence in cardiologists (70\%), general practitioners $(58 \%)$ and internists $(55 \%)^{9}$. Many reasons underlie lack of adherence to the guidelines during routine clinical care, including lack of time and high workload for the physician. Even though these reasons are plausible, they do not replace the need to adhere to guidelines. To characterize AF patients effectively and install proper follow-up diagnostics and treatment is time-consuming, but should be done systematically. In this process there is a role for the nurse specialist.

In response to these problems, new healthcare models are being introduced to enhance appropriate treatment and to coordinate care delivery more effectively ${ }^{10}$. Trials in nurse-led management interventions show significant improvements, due mainly to improved application of clinical guidelines ${ }^{11-13}$. Boodhoo et al.'s ${ }^{14}$ longitudinal study demonstrated that a nurse-led cardioversion service is safe and effective whilst Inglis et al. ${ }^{15}$ demonstrated improved outcomes using a nurse-led, multidisciplinary, home-based intervention in relation to recurrent hospitalization and mortality in patients with chronic AF. To the best of our knowledge however, no nurse-led outpatient intervention services have been reported upon from Europe as yet.

We therefore developed an integrated chronic care program (ICCP) for patients with atrial fibrillation in our local University Hospital. The program, based upon the Chronic Care Model, is designed to help practices improve patient health outcomes by changing the routine delivery of ambulatory care through interrelated system changes designed to make patient-centred, evidence-based care easier to accomplish ${ }^{16}$. It has been shown that redesigning care using the Chronic Care Model leads to 
improvement in a variety of health outcomes ${ }^{17-19}$. The ICCP consists of multiple component interventions for patients with chronic disease and includes important professional and organisational changes, such as the transfer of tasks from physician to nurse specialists, the development of multidisciplinary teams, and treatment according to evidence based guidelines using computer based systems ${ }^{20,21}$. We suggest that a nurse specialist, delivering guideline-based care, using dedicated software and under supervision of a cardiologist can be reliable and effective in the process of care required by AF patients. As a result, the workload during the cardiologists' consulting hours may be lessened while the quality of care is maintained or even improved.

In a review regarding the cost-effectiveness of multi-component chronic care programs in COPD by Steuten et al. $2009^{22}$, stated that some papers only provided a limited description of their intervention. In this chapter we describe the content and study protocol for the newly developed nurse-driven, guideline-based, software supported ICCP for patients with atrial fibrillation in the outpatient care setting. By describing this protocol we aim to inform others about, what we believe, a multicomponent intervention should consist of. And also how effectiveness of the intervention should be evaluated.

\section{METHODS}

\section{Study population}

Patients referred to the outpatient clinic of the Cardiovascular Centre of the Maastricht University Hospital are being enrolled in the study using the following eligibility criteria: 1) newly diagnosed AF detected on electrocardiogram (ECG), 2) age $>18$ years and 3 ) capable of providing informed consent. Patients will be excluded from the study in case of any comorbidity which is unsatisfactorily treated, e.g. unstable and uncontrolled hypertension for which patients are treated by an internist, unstable heart failure defined as NYHA IV or heart failure necessitating hospital admission $<3$ months before inclusion, untreated hyperthyroidism or $<3$ months euthyroidism, current or foreseen pacemaker, internal cardioverter defibrillator, and/or cardiac resynchronisation therapy, cardiac surgery $<3$ months before inclusion.

\section{Study design}

A prospective, randomized controlled trial is being conducted. Newly diagnosed AF patients are randomized into two groups for clinical management by a cardiologist (usual care group) or management in the nurse-led, guideline-based, software supported AF-Clinic (intervention group). 


\section{Study hypothesis}

The hypothesis of the study is that treatment in the nurse-led ICCP service will be safe, efficient, and as effective as the usual care provided by cardiologists in terms of subsequent hospitalization for a cardiovascular event and/or death. Secondary outcomes include improved guideline adherence, patient quality of life, satisfaction and reduced cost.

\section{Primary objective}

The primary objective is to demonstrate the effectiveness of the nurse-led, guidelinebased, software supported ICCP in terms of the following medical outcomes: the number and length of hospital admissions for any cardiovascular reason and/or cardiovascular death (including heart failure, myocardial infarction, stroke, systemic emboli, bleeding, syncope, sustained ventricular tachycardia, cardiac arrest and, lifethreatening adverse effects of rate or rhythm control drugs).

\section{Secondary objectives}

Secondary objectives are:

1. To demonstrate process outcomes in terms of guideline adherence: the extent to which treatment is delivered according to the 2006 AHA/ACC/ESC AF guidelines ${ }^{23}$.

2. To demonstrate patient outcomes in terms of patient quality of life (including anxiety and depression), and patient satisfaction;

3. To demonstrate the benefits of a nurse-led, guideline-based, software supported ICCP in terms of cost-effectiveness expressed in quality adjusted life years (QALYS).

\section{Registration and ethical approval}

The study is registered as a clinical trial at Clinicaltrials.gov (identifier: NCT00753259) and ethical approval was obtained from the Institutional Review Board of the University Hospital Maastricht.

\section{INTERVENTION}

The intervention was developed on the basis of literature and the 2006 ACC/AHA/ESC guidelines $^{23}$ for the management of patients with AF. In addition, the intervention was based on identifying risk factors and potential problems in patients, and addressing needs through dynamic use of personalized education and adjustment of treatment. A nurse specialist was specially trained to educate and instruct patients with AF about the condition, its possible complications and treatment in order to improve patient empowerment. The nurse specialist was also trained how to treat AF patients during consulting hours using a dedicated software program aimed at guiding clinical 
decision making. A combination of structured and tailored components is used to identify relevant topics considered relevant to the patients' baseline knowledge of AF. Prior to the intervention, patients' education needs are determined by the nurse specialist using a checklist and questionnaire. Patients are then instructed about specific topics (e.g. smoking cessation, adherence to medication, weight loss etc.) when those topics are deemed applicable and when existing knowledge in respect of these is considered inadequate. This tailored information is provided during a 30 minute interview with the nurse specialist. Patients are then followed up for 1 year during visits to the outpatient clinic at 3, 6 and 12 month intervals.

\section{STUDY MEASURES}

\section{Primary endpoint}

The primary endpoint is defined as admission to hospital for any cardiovascular reason and/or cardiovascular death. The composite endpoints leading to hospitalization are therefore: (1) heart failure which is independent of LVEF (preferably confirmed by biomarker assessment using NT-pro-BNP), (2) thromboembolic complications such as stroke or systemic emboli (confirmed by a neurologist on the basis of computerized tomography or MRI), (3) bleeding (when patient haemoglobin decreases by more than $1,25 \mathrm{mmol} / \mathrm{l}$ and requires blood transfusion, hospitalization, or proves fatal), (4) syncope (including sudden temporary loss of consciousness with spontaneous recovery diagnosed by a cardiologist), (5) sustained ventricular tachycardia confirmed by ECG, (6) cardiac arrest, (7) lifethreatening adverse effects of rate or rhythm controlling drugs (including any proarrhythmia of class I and III anti-arrhythmic drugs, digitalis intoxication, drug-induced heart failure or conduction disturbances necessitating hospitalization), (8) STEMI/NSTEMI (ST segment elevation myocardial infarction/non-ST segment elevation myocardial elevation, respectively documented on ECG as well as/or only in blood levels of key chemical markers necessitating hospitalization).

\section{Secondary endpoints}

The secondary endpoints are: (1) the extent to which the treatment is in accordance to the $2006 \mathrm{AHA} / \mathrm{ACC} / \mathrm{ESC}$ guidelines for AF (including the protocolized diagnostic evaluation), (2) patient quality of life, (3) anxiety and/or depression (defined as an unpleasant feeling of oppression or stress accompanied with physiological signs such as the perception of fear), (4) patient satisfaction (measured by a number of questions within the questionnaire and reported experiences of patients during outpatient visits), (5) patients' knowledge of AF, (6) patients' self-reported adherence with medication and finally, (7) the cost of the intervention by means of a costeffectiveness analysis. 


\section{Instrumentation}

All patients are asked to fill out an extensive questionnaire at baseline $\left(T_{0}\right)$ and after a follow-up period of one year $\left(T_{1}\right)$. This evaluates their symptoms, use of medication, medical history, socio-demographic and cardiovascular risk factors, quality of life, daily and social activities, nutritional status and patients' knowledge of their disease; together with any complications related to their therapy. Quality of life is measured by means of the SF- $36^{24}$, and the Hospital Anxiety and Depression Scale (HADS) ${ }^{25}$. In addition, the ROSE questionnaire on Angina Pectoris and Coronary Calcification (Relevance Of Science Education) $^{26}$ and the RIVM nutrition questionnaire of the Netherlands Institute for Public Health and Environment (Rijksinstituut voor Volksgezondheid en Milieu) ${ }^{27}$ are used. Medication compliance is measured using Morisky's self-reporting medication taking scale which consists of items such as forgetting, being careless or stopping to take medication prescribed ${ }^{28}$. This has been translated into Dutch from the original English using the forward-backward translation technique and demonstrates good levels of concurrent validity, predictive validity and internal consistency. To measure knowledge regarding AF, the Netherlands Knowledge Scale on AF was developed.

The diagnostic process starts with a detailed focus on symptoms of AF and cardiovascular diseases (ROSE). Justifying the choice of the scales is related to the hypothesis and the secondary objectives and endpoints. If patients have knowledge about the disease, consequences and treatment, it is hypothesized that empowered patients will be more compliant. They might experience less symptoms and probably less relapse of $A F$, leading to improved quality of life. To evaluate the level of life style activities the nutrition questionnaire has been included. This also contains the use of alcohol, smoking en exercising.

Furthermore, medical review will be carried out. This is related to the process outcomes and includes protocolized diagnostic procedures and appropriate treatment, containing: trigger factors for AF recorded, echocardiogram made, laboratory testing of thyroid-stimulating hormone (TSH), appropriate prescription of antithrombotic treatment, inadvertent prescription of Vaughn-Williams class I drugs in patients with structural heart disease avoided, inadvertent application of rhythm control strategy to completely asymptomatic patients, and prescription of antiarrhythmic medication for rhythm control in patients with permanent AF avoided.

Medical note review will be carried out by reviewing all medical records of patients participating in the study, on baseline and after one year. The outcomes mentioned above will be searched for and documented in the database. This process will be accomplished by the researcher and help from medical students (Table 2.1). 
Table 2.1 Methods and questionnaires used in the study.

\begin{tabular}{lll}
\hline & Assessment & Method / Questionnaire \\
\hline CV hospitalisation / death & Baseline, 3, 6, 12 months & Interview \\
& Baseline, 3, 6, 12 months & Medical record \\
Baseline, 12 months & General questionnaire \\
Guideline adherence & Baseline, 3, 6, 12 months & Medical record \\
Quality of Life & Baseline, 3, 6, 12 months & Interview \\
Anxiety / Depression & Baseline, 12 months & SF-36 \\
Baseline, 3, 6, 12 months & Interview \\
Patient satisfaction & Baseline, 12 months & Hospital Anxiety and Depression Scale \\
& Baseline, 3, 6, 12 months & Interview \\
Knowledge & Baseline, 12 months & General questionnaire \\
& Baseline, 3, 6, 12 months & Interview \\
Compliance & Baseline, 12 months & Netherlands Knowledge Scale on AF \\
& Baseline, 3, 6, 12 months & Interview \\
Costs & Baseline, 12 months & Morisky's self-reported medication taking scale \\
& Baseline, 3, 6, 12 months & Interview \\
& Baseline, 3, 6, 12 months & Medical record \\
& Baseline, 12 months & General questionnaire \\
\hline
\end{tabular}

\section{Power}

A sample-size of 349 patients in both the intervention and control groups was calculated based on a reduction from $35 \%$ to $25 \%$ in hospitalization for any cardiovascular reason and/or cardiovascular death after 18 months using an alpha of 0.05 and a power of 0.80 .

\section{ASSESSMENT, RANDOMIZATION AND PROCEDURES}

\section{Assessment and randomization}

General Practitioners, cardiologist from other institutions, or physicians from our own institution send a referral letter to the triage-office. Patients who have AF on the ECG before referral are eligible for participation in the study. Based on the information in the letter the independent triage cardiologist will assess and allocate the patients to a specific pathway. Patients are then allocated to a specific care pathway (e.g. heart failure, heart rhythm disease, ischaemic heart disease) aiming to provide the most appropriate treatment. Following the confirmation of eligibility, patients are then randomized by a dedicated software system on a 1:1 basis to either the control group (usual care) or the intervention group (nurse-led AF-Clinic). Patients' baseline characteristics are assessed from the medical chart and patient questionnaire at $T_{0}$.

Follow-up data are assessed from the medical chart, the patient questionnaire, and patient interviews at $T_{1}$ one year later. Most patients have stable conditions after 6 to 12 months of treatment. The follow-up questionnaires are released after one year to 
measure differences between unstable (episode of AF at baseline) and stable conditions (sinus rhythm or accepted and treated AF after one year follow-up).

\section{Control group}

Patients in the control group receive care as usual from a cardiologist in the outpatient clinic. Patients do undergo standardized examinations if the triage cardiologist or treating cardiologist decides that these are necessary. The follow-up schedule is determined by the cardiologist.

\section{Intervention group}

The chronic care program consists of a nurse-led, guideline-based, software supported outpatient clinic for patients with AF. Before visiting the AF-Clinic, patients undergo protocolized laboratory testing, ECG, Holter registration, and echocardiography. These tests are performed before the patient's first visit to the AF-Clinic. If symptoms suggest cardiac ischaemia, an exercise test is requested. Follow-up visits are planned at baseline $\left(T_{0}\right), 3,6$ and 12 months. In case of unstable patient conditions, the frequency and time between visits will differ from this schedule according to protocol.

\section{Procedures}

During the first visit to the AF-Clinic, the nurse specialist takes the patient's history and informs the patient about the pathophysiology and symptoms of AF, its possible complications, the results of the diagnostic tests and treatment options. The supervising cardiologist then sees the patient to confirm the diagnosis, inform the patient about the treatment aims, and will initiate treatment. During follow-up visits, patients are seen by the nurse specialist under the supervision of the cardiologist. The nurse pays special attention to symptoms, drug side-effects, patient information needs and any questions they might have. The nurse then uses a dedicated software program (CardioConsult $\mathrm{AF}^{\circledR}$ ) to manage the patient's drug therapy and guides the patient through the care pathway. The software is based on the 2006 ACC/AHA/ESC guidelines for $\mathrm{AF}^{22}$ and aims to increase adherence by both physicians and nurse specialists.

The program was developed by Dutch cardiologists and is regularly updated under the supervision of a board of expert specialists. The software serves as an electronic patient record for documentation and correspondence, and also determines an individual patient profile (e.g. symptomatic vs. asymptomatic, type of AF, and stroke risk). Based upon the patient questionnaire, medical history and additional diagnostic tests, this individual patient profile also illustrates the patient's experienced health characteristics compared to the average experience of the population and suggests the most appropriate management plan for the nurse to implement (Figure 2.1). 

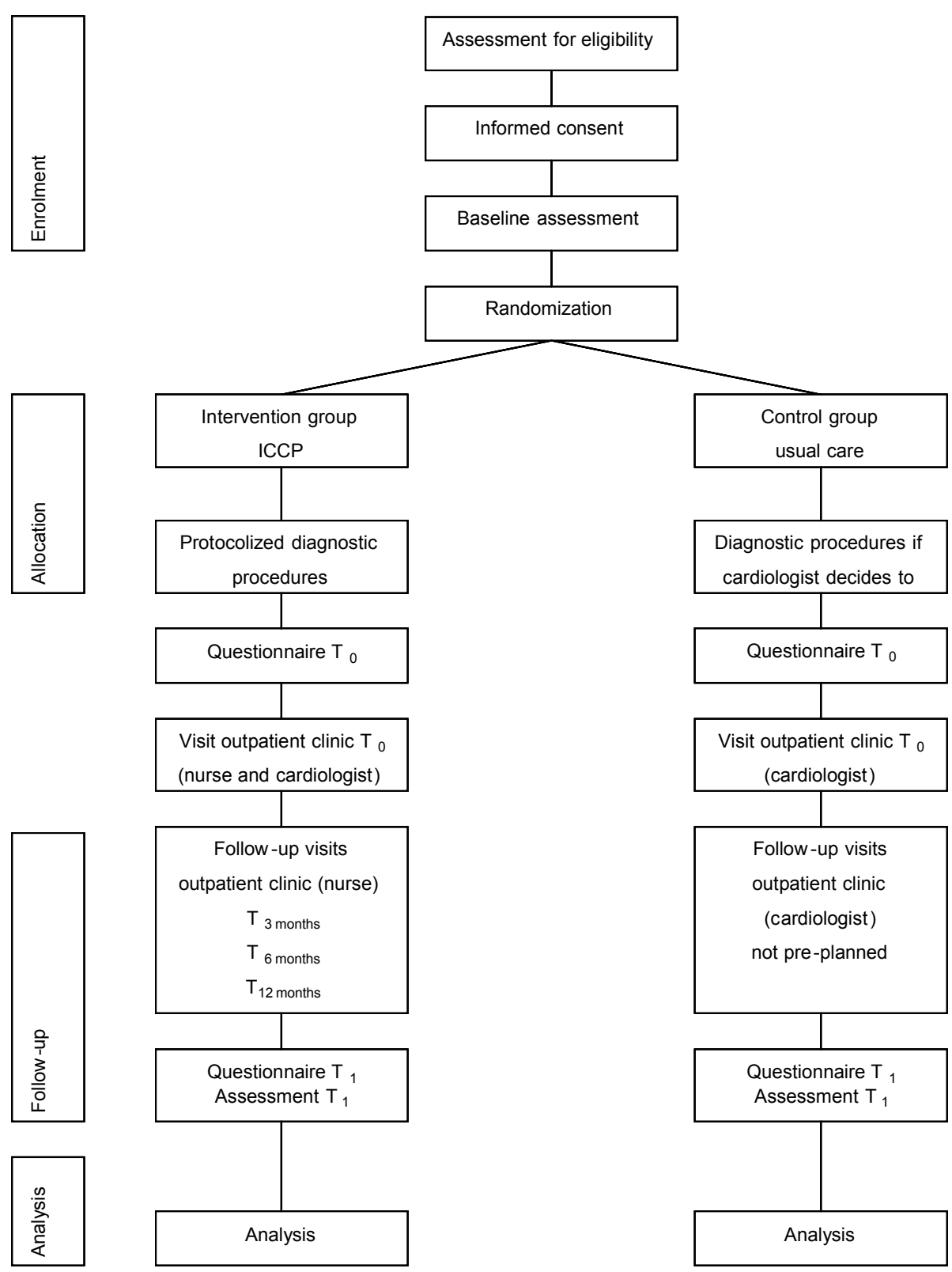

Figure 2.1 Study design. 


\section{Clinical Endpoint Committee}

An independent panel of specialists has been compiled to judge whether a documented hospitalization or death is related to cardiovascular disease under the terms of the study protocol. The panel consists of a cardiologist, an internal specialist, a neurologist and a vascular specialist who each have research and clinical expertise in the area. These review approximately 150-200 cases at each of their three face-toface meetings per annum during the study period. The Committee is blinded to assignment and interim study outcomes, and independently review each case in order to assign an admission or death as cardiovascular in nature. Their independent opinions are reconciled at each meeting, but if an endpoint is not unanimous, the case is reviewed further and discussed with the aim of developing a consensus. The committee terms of reference provide that in the event of a non-unanimous decision, the endpoint will be established by the study chair.

\section{STATISTICAL ANALYSIS}

Data analysis on the final data set will be performed using SPSS statistical software (SPSS, Inc., release 12.01) and according to the intention-to-treat principle. Continuous variables will be reported as the mean \pm standard deviation, and categorical variables as the observed number and percentage. The primary objective in the study, the number of hospitalization for any cardiovascular reason and/or cardiovascular death, will be evaluated by using Kaplan-Meier survival analysis. The secondary objectives in the study will be tested for differences with $\chi^{2}$ statistics of Fisher's exact test. Differences for continuous variables will be tested with independent t-test. Further multivariate techniques will be used to adjust for possible differences in baseline characteristics and scores. The $P$-value below 0.05 will be considered as statistically significant.

\section{ANTICIPATED FINDINGS}

There is a significant gap between guideline recommendations and current clinical practice in AF. This study aims to contribute towards closing this gap and optimising the management of AF patients by improved guideline adherence. It has been hypothesized that this will lead to less morbidity and mortality in AF patients. Furthermore, case management and counselling by a specially trained AF nurse may lead to improved efficiency and enhanced coordination, enhancing navigation of the patient care pathway for AF and improve multidisciplinary collaboration between physicians, nurse specialists and patients. To achieve this, important changes in daily practice are necessary, and this study may provide insight into these processes and support future developments in the delivery of services for patients with AF. 


\section{REFERENCES}

1. Go AS, Hylek EM, Phillips KA, Chang YC, Henault LE, Selby JV, Singer DE. Prevalence of diagnosed atrial fibrillation in adults: national implications for rhythm management and stroke prevention: the AnTicoagulation and Risk Factors in Atrial Fibrillation (ATRIA) Study. JAMA 2001;285:2370-5.

2. Heeringa J, Kuip van der DA, Hofman A, Kors JA, Herpen van G, Stricker BH, Stijnen T, Lip GY, Witteman JC. Prevalence, incidence and lifetime risk of atrial fibrillation: the Rotterdam study. Eur Heart J 2006;27:949-53.

3. Nieuwlaat R, Capucci A, Camm AJ, Olsson SB, Andresen D, Davies DW, Cobbe S, Breithardt G, Le Heuzey JY, Prins MH, Lévy S, Crijns HJ, European Heart Survey Investigators. Atrial fibrillation management: a prospective survey in ESC member countries: the Euro Heart Survey on Atrial Fibrillation. Eur Heart J 2005;26:2422-34.

4. Dorian P, Jung W, Newman D, Paquette M, Wood K, Ayers GM, Camm J, Akhtar M, Luderitz B. The impairment of health-related quality of life in patients with intermittent atrial fibrillation: implications for the assessment of investigational therapy. J Am Coll Cardiol 2000;36:1303-9.

5. Lane DA, Langman CM, Lip GY, Nouwen A. Illness perceptions, affective response, and health-related quality of life in patients with atrial fibrillation. I Psychosom Res 2009;66:203-10.

6. Thrall G, Lip GY, Carroll D, Lane D. Depression, anxiety, and quality of life in patients with atrial fibrillation. Chest 2007;132:1259-64.

7. Nieuwlaat R, Capucci A, Lip GY, Olsson SB, Prins MH, Nieman FH, López-Sendón J, Vardas $\mathrm{PE}$, Aliot E, Santini M, Crijns HJ, Euro Heart Survey Investigators. Antithrombotic treatment in real-life atrial fibrillation patients: a report from the Euro Heart Survey on Atrial Fibrillation. Eur Heart J 2006;27:3018-26.

8. Nieuwlaat R, Olsson SB, Lip GY, Camm AJ, Breithardt G, Capucci A, Meeder JG, Prins MH, Lévy $S$, Crijns HJ. Guideline-adherent antithrombotic treatment is associated with improved outcomes compared with undertreatment in high-risk patients with atrial fibrillation: the Euro Heart Survey on Atrial Fibrillation. Am Heart J 2007;153:1006-12.

9. Dinh T, Nieuwlaat R, Tieleman RG, Büller HR, Charante van NA, Prins MH, Crijns HJ. Antithrombotic drug prescription in atrial fibrillation and its rationale among general practitioners, internists and cardiologists in the Netherlands. The EXAMINE-AF study. A questionnaire survey. Int J Clin Pract 2007;61:24-31.

10. Vrijhoef HJ, Spreeuwenberg C, Eijkelberg IM, Wolffenbuttel BH, Merode van GG. Adoption of disease management model for diabetes in region of Maastricht. BMJ 2001;323:983-85.

11. Becker DM, Ragueno JV, Yook RM, Kral BG, Blumenthal RS, Moy TF, Bezirdjian PJ, Becker LC. Nurse-mediated cholesterol management compared with enhanced primary care in siblings of individuals with premature coronary disease. Arch Intern Med 1998;158:1533-9.

12. Logan AG, Milne BJ, Achber C, Campbell WP, Haynes RB. Work-site treatment of hypertension by specially trained nurses. Lancet 1979;2:1175-8.

13. Oakeshott $P$, Kerry $S$, Austin A, Cappuccio F. Is there a role for nurse-led blood pressure management in primary care? Fam Pract 2003;20:469-73.

14. Boodhoo L, Bordoli G, Mitchell AR, Lloyd G, Sulke N, Patel N. The safety and effectiveness of a nurse led cardioversion service under sedation. Heart 2004; 90:1443-6.

15. Inglis S, McLennan S, Dawson A, Birchmore L, Horowitz JD, Wilkinson D, Stewart S. A new solution for an old problem? Effects of a nurse-led, multidisciplinary, home-based intervention on readmission and mortality in patients with chronic atrial fibrillation. $J$ Cardiovasc Nurs 2004;19:118-27. 
16. Improving Chronic Illness Care. The Chronic Care Model. Available at: http://www. improvingchroniccare.org/index.php?p=CCM_Gallery\&s=149. Accessed September 18, 2009.

17. Coleman K, Austin BT, Brach C, Wagner EH. Evidence on the Chronic Care Model in the new millennium. Health Aff (Millwood) 2009;28:75-85.

18. Steuten LM, Vrijhoef HJ, Landewé-Cleuren S, Schaper N, Van Merode GG, Spreeuwenberg C. A disease management programme for patients with diabetes mellitus is associated with improved quality of care within existing budgets. Diabet Med 2007;24:1112-20.

19. Wagner EH, Austin BT, Davis C, Hindmarsh M, Schaefer J, Bonomi A. Improving chronic illness care: translating evidence into action. Health Aff (Millwood) 2001;20:64-78.

20. Vrijhoef HJ, Diederiks JP, Spreeuwenberg C, Wolffenbuttel BH. Substitution model with central role for nurse specialist is justified in the care for stable type 2 diabetic outpatients. J Adv Nurs 2001;36:546-55.

21. Wensing $M$, Wollersheim $H$, Grol R. Organizational interventions to implement improvements in patient care: a structured review of reviews. Implement Sci 2006;1:2.

22. Steuten LM, Lemmens KM, Nieboer AP, Vrijhoef HJ. Identifying potentially cost effective chronic care programs for people with COPD. Int J Chron Obstruct Pulmon Dis 2009;4: 87-100.

23. Fuster V, Rydén LE, Cannom DS, Crijns HJ, Curtis AB, Ellenbogen KA, Halperin JL, Le Heuzey JY, Kay GN, Lowe JE, Olsson SB, Prystowsky EN, Tamargo JL, Wann S, Smith SC Jr, Jacobs AK, Adams CD, Anderson JL, Antman EM, Halperin JL, Hunt SA, Nishimura R, Ornato JP, Page RL, Riegel B, Priori SG, Blanc JJ, Budaj A, Camm AJ, Dean V, Deckers JW, Despres C, Dickstein K, Lekakis J, McGregor K, Metra M, Morais J, Osterspey A, Tamargo JL, Zamorano JL. ACC/AHA/ESC 2006 Guidelines for the management of patients with atrial fibrillation: a report of the American College of Cardiology/American Heart Association Task Force on Practice Guidelines and the European Society of Cardiology Committee for Practice Guidelines (Writing Committee to revise the 2001 guidelines for the management of patients with atrial fibrillation): developed in collaboration with the European Heart Rhythm Association and the Heart Rhythm Society. Circulation 2006;114:e257-354.

24. Brazier JE, Harper R, Jones NM, O'Cathain A, Thomas KJ, Usherwood T, Westlake K. Validating the SF-36 health survey questionnaire: new outcome measure for primary care. BMJ 1992;305:160-4.

25. Zigmond AS, Snaith RP. The hospital anxiety and depression scale. Acta Psychiatr Scand 1983;67:361-70.

26. Oei HH, Vliegenthart R, Deckers JW, Hofman A, Oudekerk M, Witteman JC. The association of Rose questionnaire angina pectoris and coronary calcification in a general population: The Rotterdam Coronary Calcification Study. Ann Epidemiol 2004;14:431-6.

27. Brink van den $\mathrm{CL}$, Ocké $\mathrm{MC}$, Houben $\mathrm{AW}$, Nierop van $\mathrm{P}$, Droomers $\mathrm{M}$. Validering van standaardvraagstelling voeding voor Lokale en Nationale Monitor Volksgezondheid. RIVM rapport 260854008/2005. Available at: http://rivm.openrepository.com/rivm/bitstream/ 10029/7262/1/260854008.pdf. Accessed September 182009.

28. Morisky DE, Green LW, Levine DM. Concurrent and predictive validity of a self-reported measure of medication adherence. Med Care 1986;24:67-74. 



\section{CHAPTER}

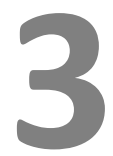

\section{The Atrial Fibrillation Knowledge Scale: development, validation and results}




\section{ABSTRACT}

Background. Patients' understanding of the nature and consequences of atrial fibrillation (AF) and appropriate therapy, is essential to optimize AF management. Currently, no valid instrument exists to measure knowledge in AF patients with a combined focus on disease, symptom recognition and therapy. Since there is a need for a specific instrument to detect gaps in the knowledge of AF patients, we developed and assessed the Atrial Fibrillation Knowledge Scale (AF knowledge scale).

Methods: The scale was developed based on a standard questionnaire in AF and existing knowledge scales in heart failure. Content validity was evaluated by a panel of 24 cardiology nurses, and 2 cardiologists. Face validity was assessed by judgment of 8 randomly selected AF patients, and construct validity was determined by performing an exploratory factor analysis with varimax rotation, based on 529 patients who completed the AF knowledge scale after one year follow-up. Internal consistency was calculated by means of Cronbach's $\alpha$. Finally the scale was tested for sensitivity, in terms of ability to distinguish patients' knowledge levels.

Results. The scale consists of 11 items concerning $\mathrm{AF}$ in general, symptom recognition, and treatment. Content-, face- and construct validity appeared to be acceptable. Cronbach's $\alpha$ was .58. The scale was able to differentiate between knowledge levels in patients with newly detected $\mathrm{AF}$ and after one year follow up.

Conclusion. The instrument is valid and able to distinguish knowledge levels in AF patients. Furthermore, it can be successfully used in an outpatient care setting as an important tool in the tailoring of patient education. (Clinicaltrials.gov identifier: NCT00753259) 


\section{INTRODUCTION}

In chronic diseases, such as diabetes ${ }^{1,2}$ and heart failure ${ }^{3}$, educational interventions have demonstrated significant improvements of knowledge in patients and emphasize the importance of self-management strategies to impact quality of life ${ }^{4}$. Also numerous studies have demonstrated a positive effect of educational and counseling programs in heart failure on readmission and mortality ${ }^{5-7}$. In contrast to these findings, little is known about patients' knowledge regarding atrial fibrillation (AF). AF is a very common cardiac rhythm disorder, occurring in $1-2 \%$ of the general population $^{8}$. It is associated with increased rates of stroke, heart failure and consequently increased hospitalization and death rates ${ }^{9,10}$ as well as degraded quality of life ${ }^{11}$ and increased costs ${ }^{12}$.

In the Maastricht University Medical Centre we developed a specialized AF-Clinic in terms of an integrated chronic care program for patients with AF, consisting of a nurse-driven, guideline-based, software supported outpatient clinic. In a randomized controlled trial (RCT) comparing the AF-Clinic with the usual care ${ }^{13}$, we demonstrated superiority in favour of the AF-Clinic in terms of cardiovascular hospitalization and death in these patients ${ }^{14}$. Within this AF-Clinic we focus on patient education in terms of information and instruction, as these components are expected to be important in the (self-) management of AF. We do believe that a therapy must be clinically acceptable in terms of proven benefit for the patient, but even more important: it must be tolerated and accepted by the patient ${ }^{15}$.

An extensive literature search showed numerous studies primarily focusing on knowledge related to anticoagulation therapy in AF patients ${ }^{15-19}$ or associated cardiovascular risks ${ }^{20,21}$. Overall patients' knowledge in these fields is poor. Lip et al. studied knowledge and perceptions of 119 patients with AF in different ethnical groups related to their anticoagulation therapy and found that only $63 \%$ were aware of their cardiac condition and only $52 \%$ were aware of the reason(s) of initiating oral anticoagulation therapy ${ }^{15}$. This gap in knowledge is confirmed by Nadar et al. demonstrating an average knowledge score of 5.5 out of 9, using a standardized questionnaire $^{16}$. The AF Aware group ${ }^{20}$ examined the level of understanding, perception, and attitudes of cardiovascular risks associated with AF in 825 patients and demonstrated that one in four patients felt unable to explain AF and $55 \%$ considered AF life-threatening. Despite the volume of research conducted in this field, no studies were found that focused specifically on knowledge related to a combination of items concerning AF in general, symptom recognition, and therapy including lifestyle interventions. According to Lane et al. ${ }^{22}$ understanding the nature and consequences of $\mathrm{AF}$ and appropriate therapy is essential to optimize AF management and allow patients to participate in maintaining their health, in consultation with health professionals. Information and instruction concerning patients' monitoring for symptoms of $\mathrm{AF}$, adherence to a medication regimen, and monitor for medication side effects is therefore required ${ }^{23}$. Currently, no valid 
instrument exists to measure knowledge in AF patients with a combined focus on disease, symptom recognition and therapy. To integrate these items, we developed the Atrial Fibrillation Knowledge Scale (AF knowledge scale). The instrument aims to measure AF related knowledge in patients with AF and to detect gaps in knowledge in order to provide the patients with the best tailored information and instructions.

With the development of the AF knowledge scale, we feel that we make a first step in providing a simple tool to measure this integrated item knowledge in AF patients. In this study we examined to what extent the AF knowledge scale is valid and reliable in measuring knowledge in patients with AF. In addition we studied to what extent the AF knowledge scale is able to distinguish differences in knowledge levels in patients with $A F$, to what extent the $A F$ knowledge scale contributes to the management of $A F$ and finally, to explore potential future testing and expansion of the AF knowledge scale.

\section{METHODS}

\section{Development of the scale}

The AF knowledge scale is based on a standard questionnaire as part of an educational intervention ${ }^{22}$ in $\mathrm{AF}$ and existing knowledge scales in heart failure ${ }^{24,25}$. The scale was developed in three phases; 1 ) concept analysis and first construction, 2) testing for face and content validity, and 3) testing of construct validity and reliability. After follow-up we tested for sensitivity of the instrument. The scale is a self-administered questionnaire and consists of 11 items concerning $A F$ in general ( 3 items), symptom recognition ( 3 items), and AF treatment ( 5 items). For each question patients can choose an answer out of three options, with one being the correct answer. The correct answer yields one point, while no points are added or subtracted to the score in case of an incorrect answer. The minimum score of the scale is 0 with a maximum score of 11 . The AF knowledge scale is portrayed in Figure 3.1.

\section{Participants and procedures}

The AF knowledge scale was applied in patients participating in the RCT to evaluate the specialized AF-Clinic ${ }^{13}$. All patients $\geq 18$ years referred for AF (documented on an electrocardiogram) by general practitioners (GP) or non-cardiology specialists to our outpatient department were eligible. In- and exclusion criteria have been described previously $^{13}$. Ethical approval was obtained from the Institutional Review Board. The study was registered at Clinicaltrials.gov (identifier: NCT00753259).

Recruitment of patients started prior to the development of the AF knowledge scale. As a consequence, only 300 patients received the AF knowledge scale at baseline. All patients $(n=712)$ received the 11 item AF knowledge scale after one year follow-up. Patients received the scale by regular mail two weeks prior to their appointment at 
the outpatient clinic and were asked to complete it using the paper form and a pencil, and send it back to the hospital. The answers were then entered by a nurse specialist into a dedicated software system (CardioConsult $\left.\mathrm{AF}^{\circledR}\right)^{13}$ which calculates the patients' scores directly.

In the AF-Clinic (intervention group) the nurse specialist discussed the scores with the patient during consultation. Based on incorrect or unknown answers in the AF knowledge scale or patients' additional questions, detailed information was provided. Also, patients received educational interventions, consisting of tailored information about AF in general, therapy instructions and lifestyle interventions aiming on further improvement of empowerment of patients in terms of self-management activities. Visits were scheduled to last 30 minutes and follow up visits were planned at 3,6 , and 12 months, and every 6 months thereafter. During these visits, psychosocial support and educational interventions were repeated. In the usual care (control group) the AF knowledge scale was not discussed. Visits were scheduled to last 20 minutes for the first visit and 10 minutes for follow-up visits.

\section{Demographic data}

During consultation patient demographic data were collected concerning, sex, age, ethnicity, marital status, highest level of education completed, $\mathrm{CHADS}_{2}$-score to determine the yearly risk of stroke ${ }^{26}$, and predominant AF pattern (paroxysmal, persistent or permanent).

\section{Validity}

Face validity was assessed through judgment by randomly selected AF patients in 2 phases, the first phase for initial adjustment of the scale and the second phase for a final check. We asked for the patients' impression about the scale and the particular items regarding readability and comprehensibility.

To determine content validity, the knowledge scale has been presented to a panel of 24 cardiology nurses, currently performing the Higher Vocational Education in Cardiovascular Nursing at the University of Applied Sciences Utrecht - in collaboration with the Netherlands Society of Cardiovascular Nursing - and 2 cardiologists who were involved in the management of AF patients.

Construct validity was determined by performing a factor analysis, based on the completed AF knowledge scales after one year follow-up. This method is used to describe variability among observed variables in terms of a potentially lower number of unobserved variables, called factors ${ }^{27}$. First an exploratory factor analysis was conducted by using the principal component method. A Kaiser-Meyer-Olkin Measure Sampling Adequacy above 0.6 was considered to be acceptable. Then the factor analysis was completed by using the principal component method with varimax rotation. Varimax rotation for independent items was used because of the notion that the 11 items were not dependently related. Factor loadings of 0.45 or above were considered to be acceptable. 


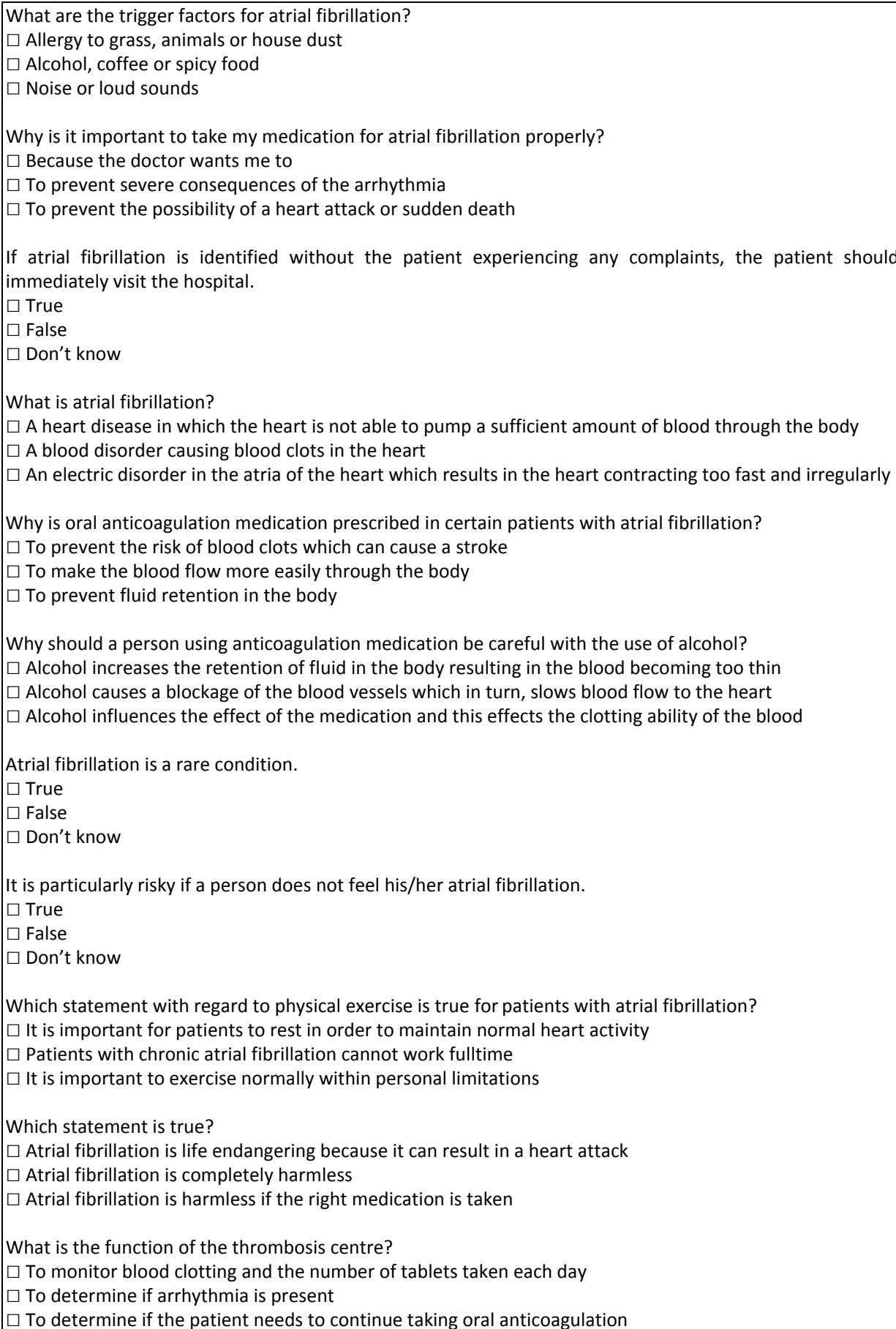

Figure 3.1 The Atrial Fibrillation Knowledge Scale translated into English from the original Netherlands version, using the forward - backward translation technique. 


\section{Sensitivity}

The sensitivity of an instrument refers to its ability to measure change in a specific state $^{28}$.

The aim was to investigate if the scale is able to distinguish differences in knowledge levels between patients with newly detected AF before (baseline) and after they were treated and consequently received education during consultations (one year followup). Therefore, we tested the sensitivity of the scale in 210 patients who were treated in the AF-Clinic or the usual care group and who filled out a baseline and a follow-up questionnaire.

\section{Reliability}

Internal consistency of an instrument determines the reliability of the observations by using the instrument. It measures the extent to which several items, that propose to measure the same general construct, produce similar scores. To determine internal consistency, Cronbach's $\alpha$ was calculated. A Cronbach's $\alpha$ of 0.7 or above was considered to be acceptable. The mean inter-item correlation (= Cronbach's $\alpha$ ) was included in the analysis. Clark and Watson (29) recommended using this as a criterion for internal consistency. To ensure uni-dimensionality of the scale, it should be between 0.15 and 0.50. Further, Spearman's correlation coefficient between each item was calculated to assess the strength between items. Spearman's correlation above 0.4 was considered to be acceptable.

\section{Statistics}

Data were retrieved from the CardioConsult $\mathrm{AF}^{\circledR}$ database and imported into SPSS. Data analyses were performed with SPSS, version 16.0 (SPSS, Chicago, Illinois). Demographic characteristics are described as number and percentage or mean \pm standard deviation (SD), as appropriate. Scores on the AF knowledge scale were described as means \pm SD. Continuous data were analyzed using 1-way ANOVA, and categorical data using the $\chi^{2}$. To evaluate construct validity of the AF knowledge scale, exploratory factor analysis was conducted by using the principal component method with varimax rotation. Reliability in terms of internal consistency was determined by calculation of inter-item correlation expressed in Cronbach's $\alpha$ and calculation of Spearman's correlation.

\section{RESULTS}

\section{Population}

A total of 712 patients were asked to fill out the AF knowledge scale at one year follow-up. In a total of 529 patients (74.3\%) completed the scale: 284 patients $(39.9 \%)$ of the AF-Clinic group and 245 patients (34.4\%) of the Usual Care group. Patients who 
did not send in their answers to the knowledge scale were significantly older (69 \pm 14 years) than those who completed the scale (66 \pm 12 years, $P=0.01$ ). Moreover, the prevalence of $\mathrm{CHADS}_{2}$-scores of 0 was higher in responders than in non-responders (30.4\% vs. $22.4 \%, P=0.045)$, whereas the reverse was true for prevalence of $\mathrm{CHADS}_{2}$ scores $>1$ ( $32.5 \%$ vs. $44.3 \%, P=0.005$, all respectively). The demographic characteristics are summarized in Table 3.1. The groups were well matched. Overall, sex was well distributed with $59 \%$ being male, mean age was $67 \pm 12$ years. Most patients (71\%) were married or co-habiting and of the Caucasian race (99\%). The educational level was well distributed between both groups. About $20 \%$ of the patients did not have any education or only primary school. The vast majority $(29 \%)$ had intermediate general education and $22 \%$ had higher vocational education or are academically educated. Patients with paroxysmal AF were over represented (58\%), compared to persistent or permanent AF. Finally, patients were well distributed according to $\mathrm{CHADS}_{2}$-score.

\section{Validity}

\section{Face and content validity}

Initially, the AF knowledge scale consisted of 14 items. To gain insight in the usefulness and face validity of the scale, we asked 38 AF patients who visited the outpatient clinic during three consecutive days and who were not involved in the AFClinic study, to fill out the original questionnaire and to comment on difficulty, readability, comprehensibility, and the number of items. In total 30 patients completed the questionnaire. Patients judged 3 items as being too easy and the scores on these items were accordingly. Therefore these 3 'easy' items were removed from the scale. These items were as follows: 1 . What symptoms / complaints can match AF? Answer a) palpitations, chest pain, fatigue, shortness of breath; b) vomiting and diarrhea, constipation, stomach-ache; c) fever, headache, pale appearance. 2. Which of the following statements is correct? a) if I cough a lot, it is better not to take my heart medication; b) if I have no complaints, I can stop taking my heart medication; c) it is important that I take my heart medication at fixed times. 3 . What is the function of the heart? a) absorption of nutrients from the blood, b) pumps blood through the body, c) provides the blood of oxygen. Subsequently, another 8 randomly selected AF patients were asked to do the same for a final check and face validity then was obtained.

The panel of 24 cardiology nurses and 2 cardiologists had only minor comments concerning clarification, but all facets were found present in the scale. No items were deleted or added to the scale and content validity was obtained. 
Table 3.1 Demographic characteristics of the total patient population and according to treatment group.

\begin{tabular}{|c|c|c|c|}
\hline Demographics & $\begin{array}{l}\text { Nurse-led Care } \\
(n=284)\end{array}$ & $\begin{array}{c}\text { Usual Care } \\
(\mathrm{n}=245)\end{array}$ & $\begin{array}{c}\text { Total population } \\
(n=529)\end{array}$ \\
\hline Age - yr (mean \pm SD) & $66 \pm 12$ & $67 \pm 11$ & $67 \pm 12$ \\
\hline Male sex - no(\%) of patients & $175(61.6)$ & $138(56.3)$ & $313(59.2)$ \\
\hline \multicolumn{4}{|l|}{ Ethnicity - no (\%) of patients } \\
\hline Caucasian & $283(99.6)$ & $242(98.8)$ & $525(99.2)$ \\
\hline \multicolumn{4}{|l|}{ Marital Status - no (\%) of patients } \\
\hline Single & $16(5.6)$ & $17(6.9)$ & $33(6.2)$ \\
\hline Married / co-habiting & $209(73.6)$ & $167(68.2)$ & $376(71.1)$ \\
\hline Widowed & $47(16.5)$ & $45(18.4)$ & $92(17.4)$ \\
\hline Divorced & $9(3.2)$ & $14(5.7)$ & $23(4.4)$ \\
\hline Other & $3(1.1)$ & $2(0.8)$ & $5(0.9)$ \\
\hline \multicolumn{4}{|l|}{$\begin{array}{l}\text { Highest level of education } \\
\text { completed }- \text { no (\%) of patients }\end{array}$} \\
\hline No education & $16(5.6)$ & $13(5.3)$ & $29(5.5)$ \\
\hline Primary school & $39(13.7)$ & 39 (15.9) & $78(14.8)$ \\
\hline Lower general secondary education & $52(18.3)$ & $46(18.8)$ & $98(18.5)$ \\
\hline $\begin{array}{l}\text { Intermediate general secondary } \\
\text { education }\end{array}$ & $81(28.5)$ & $72(29.4)$ & $153(28.9)$ \\
\hline Higher general secondary education & $21(7.4)$ & $18(7.3)$ & $39(7.4)$ \\
\hline Higher vocational education & $47(16.6)$ & $35(14.3)$ & $82(15.5)$ \\
\hline University education & $16(5.6)$ & $17(6.9)$ & $33(6.2)$ \\
\hline Other & $12(4.2)$ & $5(2.0)$ & $17(3.2)$ \\
\hline \multicolumn{4}{|l|}{$\mathrm{CHADS}_{2}$ score - no $(\%)$ of patients $\dagger$} \\
\hline 0 & $90(31.7)$ & $71(29.0)$ & $161(30.4)$ \\
\hline 1 & $103(36.3)$ & $93(38.0)$ & $196(37.1)$ \\
\hline$>1$ & $91(32.0)$ & $81(33.1)$ & $172(32.5)$ \\
\hline \multicolumn{4}{|l|}{ Type of AF - no (\%) of patients * } \\
\hline Paroxysmal & $159(56.0)$ & $149(60.8)$ & $308(58.2)$ \\
\hline Persistent & $55(19.4)$ & $35(14.3)$ & $90(17.0)$ \\
\hline Permanent & $58(20.4)$ & $54(22.0)$ & $112(21.2)$ \\
\hline
\end{tabular}

+ $\mathrm{CHADS}_{2}$-score is a stroke risk classification scheme, using a point system ranging from 0 to 6 , to determine the yearly risk index ${ }^{26}$. Congestive heart failure, hypertension, age 75 years or above, and diabetes are assigned one point each. Previous stroke or transient ischemic attack is assigned two points. The score is calculated by summing all points for a patient. * Atrial flutters were not considered for analysis.

\section{Construct validity}

To determine construct validity a factor analysis was performed, based on the completed AF knowledge scales $(n=529)$. First an exploratory factor analysis was conducted by using the principal component method. This resulted in a Kaiser-MeyerOlkin Measure of Sampling Adequacy of 0.69 and a Bartlett's Test of Sphericity being significant at a 0.01 level. Based on the eigenvalue above 1 (Keiser's criterion) 4 factors were selected. Then the factor analysis was completed by using the principal component method with varimax rotation with 4 factors. Table 2 shows the 11 items and the related factor loadings. All items loaded on one of the 4 factors. Item 5 and 7 had loadings in two different factors, in this case the strongest loadings were classified. The factors were named (e.g. atrial fibrillation in general, therapy, symptom 
recognition, and general attitudes) and the items of the scale were sorted, based on factor loadings (Table 3.2).

Table 3.2 Classification of the questions regarding the factors and factor loadings $(n=529)$.

\begin{tabular}{|c|c|c|c|c|}
\hline & Factor 1 & Factor 2 & Factor 3 & Factor 4 \\
\hline \multicolumn{5}{|l|}{ Atrial fibrillation in general } \\
\hline \multicolumn{5}{|l|}{$\begin{array}{l}\text { If atrial fibrillation is identified without the patient } \\
\text { experiencing any complaints, the patient should }\end{array}$} \\
\hline immediately visit the hospital (3) & 0.807 & & & \\
\hline \multicolumn{5}{|l|}{ It is particularly risky if a person does not feel his/her } \\
\hline atrial fibrillation (8) & 0.777 & & & \\
\hline Atrial fibrillation is a rare condition (7) & $0.574 *$ & & & \\
\hline \multicolumn{5}{|l|}{ Atrial fibrillation therapy } \\
\hline \multicolumn{5}{|l|}{ Why should a person using oral anticoagulation } \\
\hline medication be careful with the use of alcohol (6) & & 0.684 & & \\
\hline What is the function of the thrombosis centre (11) & & 0.623 & & \\
\hline $\begin{array}{l}\text { Why is oral anticoagulation medication prescribed in } \\
\text { certain patients with atrial fibrillation (5) }\end{array}$ & & $0.488^{*}$ & & \\
\hline \multicolumn{5}{|l|}{ Atrial fibrillation symptom recognition } \\
\hline What is atrial fibrillation (4) & & 0.464 & & \\
\hline What are the trigger factors for atrial fibrillation (1) & & & 0.756 & \\
\hline \multicolumn{5}{|l|}{ Why is it important to take my medication for atrial } \\
\hline fibrillation properly (2) & & & 0.690 & \\
\hline \multicolumn{5}{|l|}{ Atrial fibrillation general attitudes } \\
\hline Statements regarding physical exercise (9) & & & & 0.723 \\
\hline $\begin{array}{l}\text { Statements regarding to the level of danger associated } \\
\text { with atrial fibrillation (10) }\end{array}$ & & & & 0.702 \\
\hline
\end{tabular}

* Highest factor loading.

\section{Reliability}

Internal consistency was assessed in the 529 patients who filled out the AF knowledge scale after one year follow-up within the outpatient clinic (both groups). Cronbach's $\alpha$ in this population was 0.58 . This could not be improved by deleting one of the 11 items.

Spearman's correlation coefficient between each item and the overall score was calculated. The strongest association was $0.44(P<0.001)$ both in item 3 ('patient without complaints in whom AF is determined, should visit hospital') and item 8 ('It is particularly risky if a person does not feel his/her atrial fibrillation').

\section{Sensitivity}

The aim was to investigate if the AF knowledge scale is able to distinguish the differences in knowledge levels between patients with newly detected AF (baseline) and after a follow-up period of one year. The patients received the scale before their 
first visit to the hospital and were asked to fill out the scale, without using information sources. In total, 261 baseline scales (87\%) were returned. From these, 210 patients (70\%) also filled out the scale at one year follow-up.

The overall mean score of this sub-population at baseline was $7.08 \pm 2.41$ and at follow-up $7.98 \pm 2.14$. Comparing the knowledge levels of patients in the AF-Clinic expressed in mean scores before receiving care and education $(7.21 \pm 2.30)$ and after $(8.23 \pm 2.16)$ with knowledge levels of patients being treated in the Usual Care group before $(6.91 \pm 2.54)$ and after $(7.66 \pm 2.09)$, there is a significant difference between both groups at one year follow-up $(P=0.05)$.

\section{DISCUSSION}

Failure in the application of self-management activities may underlie many problems in patients with AF. Due to non-adherence to a therapeutic regimen it is reasonable to assume that recurrences of AF episodes, the occurrence of major complications resulting in (re-)hospitalization, and in some cases even death will occur. In the literature numerous studies and reviews demonstrate the importance of patient education in general. However, understanding persons' perceptions and attitudes towards the disease and the attended regimen is even more important. Specific AF-related education focusing on the use of medication for example, demonstrated the need of specific education programs. Aliot et al. investigated physicians' and patients' knowledge, perceptions and attitudes to AF and its contribution to cardiovascular morbidity and mortality in the AF AWARE group ${ }^{20}$. The findings in this survey confirm the fact that the patients' level of understanding AF and its management is often poor and insufficient. On the other hand, a study focusing at physicians' attitudes towards the use of antithrombotic drugs suggested uncertainties among general practitioners and cardiologists about the most appropriate use of drugs $^{31}$. Other studies and reviews reported lack of awareness and confidence in these treatments ${ }^{8,32}$, resulting in non-adherence to the evidence based guidelines. Therefore Aliot et al. correctly recommend a comprehensive international patient and professional information and support program on $\mathrm{AF}^{20}$.

Instruments to measure patients' knowledge and attitudes, mostly focus on the management of antithrombotic treatment in AF. Due to the fact that it is important for patients to understand the arrhythmia in general and to recognize symptoms, the AF knowledge scale focuses on all three items. This knowledge scale can be used as a tool to detect gaps in patients' knowledge or attitudes towards AF management. The scale may be difficult to complete, especially for elderly who may be cognitively impaired. However, if there is difficulty to complete the answers, this by itself indicates lack of knowledge and this signal may be used to tailor further counseling and education. To avoid a predominant focus on scores and distracting the care 
provider from the main purpose of the instrument - detecting gaps in patient knowledge - a cut-off is not considered helpful.

From there patients are provided with a tailored education program in terms of information and instruction, focusing on the development of patient selfmanagement activities. Hence it appears in our institution that patients' selfmanagement activities are evaluated during follow-up visits at the outpatient clinic, and if necessary the education will be repeated or adjusted.

Prior to the analysis it was assumed that the AF knowledge scale consisted of 3 subscales, according to the subject of the 11 items. These were: 1) AF in general; 2) AF symptom recognition; and 3) treatment of AF. However, factor analysis resulted in four factors. Therefore, we slightly changed the names of the factors, and divided the items according to the factor loadings. Nevertheless, the subject of the factors did not change. The loadings of factor 4 are considered to be 'general attitudes towards $\mathrm{AF}^{\prime}$ of patients. Prior to the factor analysis they were assumed to be part of the subscales 'AF in general' and 'symptom recognition'. By the generation of factor 4 the items related to attitudes regarding physical exercise (item 9) and to attitudes regarding the level of danger associated with AF (item 10) obtain more value in terms of understanding the patient's beliefs.

Concerning the reliability of the instrument, a Cronbach's $\alpha$ of 0.58 was found. Prior to the analysis a Cronbach's $\alpha$ of 0.7 or above was considered to be acceptable. Due to the fact that the AF knowledge scale is a rather small instrument (11 items) we consider the obtained Cronbach's $\alpha$ of 0.58 as a border-line case. It might be possible to improve the reliability by adding more questions to the scale, or add another answer to each question.

Regarding the sensitivity of the scale it can be concluded that the scale is able to differentiate patients who score minimal from patients who score moderate or high. Application of the scale in 210 patients with AF to detect gaps in knowledge and attitudes on baseline and after one-year follow up, was paralleled by a significant increase in knowledge in patients treated in the specialized AF-Clinic. This suggests that tailored information could be provided to specific patients and on relevant items on which the patients scored minimal. These findings were recently confirmed by Dennison et al. ${ }^{33}$ using the Dutch heart failure knowledge scale. Heart failure patients with inadequate health literacy are at increased risk for poor self-care and negative health outcomes such as hospital readmission. Dennison et al. demonstrated a high prevalence of inadequate health literacy. In a sample of 95 heart failure patients, health literacy seemed to be inadequate in $42 \%$, marginal in $19 \%$ and adequate in $39 \%$. Patients with adequate health literacy were younger and had a higher educational level, compared to patients in whom health literacy was marginal or inadequate.

A limitation of this study is that only half of the patients $(n=300)$ received a knowledge questionnaire at baseline. Out of these, 210 patients filled out a follow-up questionnaire. Analysis using all patients might have been more robust. 
Notwithstanding, a significant difference in knowledge level between treatment groups was demonstrated.

\section{Recommendations for future studies}

The AF knowledge scale performed well in this population of AF patients, according to patient assessment and the easiness to use in practice. However, additional research is needed to further determine the reliability and validity of the scale. Therefore, repeated measurements (test-retest) with larger samples could be used to investigate the reliability of the scale. Further validation of the scale could be accomplished by using Messick's ${ }^{34,35}$ sources of evidence to support the validity of a measurement: (a) content, (b) response process, (c) internal structure, (d) consequences, and (e) relations to other variables. Content (a) evaluates the relationship between the content of the test and the construct it is intended to measure ${ }^{35}$. Regarding this subject it could be helpful to study whether the questions of the AF knowledge scale adequately represent the above mentioned domains of $\mathrm{AF}$ and if the questions are well-written. Reviewing the response process (b) can yield insight in the fit between the construct and the performance in daily practice (e.g. influence of language barriers, differences in patients' understandings regarding the questions). Evidence on internal structure (c) is generally obtained by performing factor analysis and testretest reliability measurements.

Further validation of the scale could be achieved by testing the performance of the scale in a population with higher $\mathrm{CHADS}_{2}$-scores, in terms of Messick's consequences (item $d$, see above). The idea behind this is that patients with multiple co-morbid conditions might focus more on symptoms, might have numerous medications and, probably have more difficulties in focusing on the AF-related aspects. This might result in an inadequate development of self-management activities in terms of information and instruction, absorption or non-adherence to the medication regimen. Moreover, these patients are in need of more guidance regarding the management of AF in terms of education and counseling. By testing the scale in the above mentioned population it might be possible to determine score thresholds (e.g. score classification of symptom severity as low, moderate or high) aiming at assessing improvements in patient outcomes, like knowledge or clinical outcomes, after implementing the scale. On the other hand, it is recommended to test the AF knowledge scale in AF patients within general practitioner practices or AF patients admitted to the cardiology ward of a hospital. Environmental factors might be of important influence on the (absorption of) knowledge and attitudes of patients (e.g. reassurance, intensity of complaints or co-morbidity).

Finally, further research is needed to investigate whether the AF knowledge scale in terms of knowledge and self-management activities is able to contribute to other variables (item (e), see above) like the patients' experienced quality of life, the occurrence of feelings like anxiety and depression, and eventually to test the 
hypothesis if patients' hospital visits decrease in case adequate self-management is successfully provided.

\section{CONCLUSION}

We report the development and first validation of the AF knowledge scale. The analysis presented in this manuscript suggests that the AF knowledge scale is valid and able to distinguish knowledge levels in patients with AF, but further development is needed to enhance its performance. Using the instrument as a tool in daily practice may enhance the management of AF in terms of patient education and application of self-management activities.

\section{Clinical implications}

The AF knowledge scale can be successfully used in an outpatient care setting as an important tool in patient education. It can be utilized to get insight in the knowledge levels and attitudes of patients with AF, aiming to improve self-management activities as an important factor in managing AF.

In consequence, the instrument is able to identify gaps regarding different aspects of AF related knowledge in these patients. Therefore the instrument may appear useful in future research to determine the effect of educational programs. 


\section{REFERENCES}

1. Bruce DG, Davis WA, Cull CA, Davis TM. Diabetes education and knowledge in patients with type 2 diabetes form the community: the Freemantle diabetes study. I Diabetes Complicat 2003;17:82-9.

2. Mehuys E, Van Bortel L, De Bolle L, Van Tongelen I, Annemans L, Remon JP, Giri M. Effectiveness of a community pharmacist intervention in diabetes care: a randomized controlled trial. J Clinical Pharm Ther 2011;36:602-13.

3. Boyde M, Turner C, Thompson DR, Stewart S. Educational Interventions for Patients with Heart Failure: A Systematic Review of Randomized Controlled Trials. J Cardiovasc Nurs 2011;26:E27-35.

4. Wright SP, Walsh H, Ingley KM, Muncaster SA, Gamble GD, Pearl A, Whalley GA, Sharpe N, Doughty RN. Uptake of self-management strategies in a heart failure management programme. Eur J Heart Fail 2003;5:371-80.

5. Gonseth J, Guallar-Castillón P, Banegas JR, Rodríguez-Artalejo F. The effectiveness of disease management programmes in reducing hospital re-admission in older patients with heart failure: a systematic review and meta-analysis of published reports. Eur Heart $J$ 2004;25:1570-95.

6. McAlister FA, Stewart S, Ferrua S, McMurray JJ. Multidisciplinary strategies for the management of heart failure patients at high risk for admission: a systematic review of randomized trials. J Am Coll Cardiol 2004;44:810-9.

7. Davidson PM, Cockburn J, Newton PJ, Webster JK, Betihavas V, Howes L, Owensby DO. Can a heart failure-specific cardiac rehabilitation program decrease hospitalizations and improve outcomes in high-risk patients? Eur J Cardiovas Prev Rehabil 2010;17:393-402.

8. Camm AJ. Safety considerations in the pharmacological management of atrial fibrillation. Int J Cardiol 2008;127:299-306.

9. Stewart S, Hart CL, Hole DJ, McMurray JJ. A population-based study of the long-term risks associated with atrial fibrillation: 20-year follow-up of the Renfrew/Paisley study. Am J Med 2002;113:359-64.

10. Kirchhof P, Auricchio A, Bax J, Crijns H, Camm J, Diener HC, Goette A, Hindricks G, Hohnloser S, Kappenberger L, Kuck KH, Lip GY, Olsson B, Meinertz T, Priori S, Ravens U, Steinbeck G, Svernhage E, Tijssen J, Vincent A, Breithardt G. Outcome parameters for trials in atrial fibrillation: recommendations from a consensus conference organized by the German Atrial Fibrillation Competence NETwork and the European Heart Rhythm Association. Europace 2007;9:1006-23.

11. Thrall G, Lip GY, Carroll D, Lane D. Depression, anxiety, and quality of life in patients with atrial fibrillation. Chest 2007;132:1259-64.

12. Ringborg $A$, Nieuwlaat $R$, Lindgren $P$, Jönsson $B$, Fidan $D$, Maggioni AP, Lopez-Sendon J, Stepinska J, Cokkinos DV, Crijns HJ. Costs of atrial fibrillation in five European countries: results from the Euro Heart Survey on Atrial Fibrillation. Europace 2008;10:403-11.

13. Hendriks JM, de Wit R, Vrijhoef HJ, Tieleman RG, Crijns HJ. An integrated chronic care program for patients with atrial fibrillation: study protocol and methodology for an ongoing prospective randomised controlled trial. Int J Nurs Stud 2010;47:1310-6.

14. Hendriks JM, de Wit R, Crijns HJ, Vrijhoef HJ, Prins M, Pisters R, Pison LA, Blaauw Y, Tieleman RG. Nurse-led care vs. usual care for patients with atrial fibrillation: results of a randomized trial of integrated chronic care vs. routine clinical care in ambulatory patients with atrial fibrillation. Eur Heart J 2012;33:2692-9.

15. Lip GY, Kamath S, Jafri M, Mohammed A, Bareford D. Ethnic differences in patient perceptions of atrial fibrillation and anticoagulation therapy: The West Birmingham Atrial Fibrillation Project. Stroke 2002;33:238-42. 
16. Nadar S, Begum N, Kaur B, Sandhu S. Patients' understanding of anticoagulant therapy in a multiethnic population. J $R$ Soc Med 2003;96:175-9.

17. Smith DE, Xuereb CB, Pattison HM, Lip GY, Lane DA. Trial of an educational intervention on patients' knowledge of atrial fibrillation and anticoagulant therapy, INR control, and outcome of treatment with warfarin (TREAT). BMC Cardiovasc Disord 2010;10:21.

18. Smith MB, Christensen N, Wang S, Strohecker J, Day JD, Weiss JP, Crandall BG, Muhlestein JB, Lappe DL, Moss H, Oliver J, Viau K, Bunch TJ. Warfarine knowledge in patients with atrial fibrillation: implications for safety, efficacy, and education strategy. Cardiology 2010;116:61-9.

19. Rewiuk K, Bednarz S, Faryan P, Grodzicki T. Knowledge of antithrombotic prophylaxis among patients with atrial fibrillation. Cardiol J 2007;14:44-9.

20. Aliot E, Breithardt G, Brugada J, Camm J, Lip GY, Vardas PE, Wagner M; Atrial Fibrillation AWareness And Risk Education group; Atrial Fibrillation Association; European Heart Rhythm Association; Stroke Alliance for Europe; World Heart Federation. An international survey of physician and patient understanding, perception, and attitudes to atrial fibrillation and its contribution to cardiovascular disease morbidity and mortality. Europace 2010;12:626-33.

21. Sloma A, Backlund LG, Strender LE, Skanér Y. Knowledge of stroke risk factors among primary care patients with previous stroke or TIA: a questionnaire study. BMC Fam Pract 2010;11:47.

22. Lane DA, Ponsford J, Shelley A, Sirpal A, Lip GY. Patient knowledge and perceptions of atrial fibrillation and anticoagulant therapy: Effects of an educational intervention programme. The West Birmingham Atrial Fibrillation Project. Int J Cardiol 2006;110:354-8.

23. Barlow J, Wright C, Sheasby J, Turner A, Hainsworth J. Self-management approaches for people with chronic conditions: a review. Patient Educ Couns 2002;48:177-87.

24. Linné $A B$, Liedholm $H$, Israelsson $B$. Effects of systematic education on heart failure patients' knowledge after 6 months. A randomised, controlled trial. Eur J Heart Fail 1999;1:219-27.

25. Wal van der HM, Jaarsma T, Moster DK, Veldhuisen van DJ. Development and testing of the Dutch Heart Failure Knowledge Scale. Eur J Cardiovsc Nurs 2005;4:273-7.

26. Gage BF, Waterman AD, Shannon W, Boechler M, Rich MW, Radford MJ. Validation of clinical classification schemes for predicting stroke: results from the National Registry of Atrial Fibrillation. J Am Med Assoc 2001;285:2864-70.

27. Gorsuch RL. Exploratory factor analysis: its role in item analysis. $J$ Pers Assess 1997;68:532-60.

28. Liang $\mathrm{MH}$. Longitudinal construct validity: establishment of clinical meaning in patient evaluative instruments. Med Care 2000;38:II84-90.

29. Clarke LA, Watson D. Constructing validity: basic issues in objective scale development. Psychol Assessment 1995;7:309-19.

30. Shewan LG, Coats AJ. Ethics in the authorship and publishing of scientific articles. Int J Cardiol 2010;144:1-2.

31. Peterson GM, Boom K, Jackson SL, Vial JH. Doctors' belief on the use of antithrombotic therapy in atrial fibrillation: identifying barriers to stroke prevention. Int Med J 2002;32:15-23.

32. Deplanque D, Leys D, Parnetti L, Schmidt R, Ferro J, De Reuck J, Mas JL, Gallai V, SAFE II Investigators. Stroke prevention and atrial fibrillation: reasons leading to an inappropriate management. Main results of the SAFE II study. Br J Clin Pharmacol 2004;57:798-806.

33. Dennison CR, McEntee ML, Samuel L, Johnson BJ, Rotman S, Kielty A, Russel SD. Adequate health literacy is associated with higher heart failure knowledge and self-care confidence in hospitalized patients. J Cardiovasc Nurs 2011;26:359-67. 
34. Messick S. Validity. In: Linn RL, editor. Educational Measurement. 3rd ed. New York: American Council on Education and Macmillan; 1989.

35. Cook DA, Beckman TJ. Current concepts in validity and reliability for psychometric instruments: theory and application. Am J Med 2006;119:166 e7-16. 



\section{CHAPTER 4}

\section{Improving guideline adherence in the treatment of atrial fibrillation by implementing an integrated chronic care program}

Jeroen M Hendriks, Robby Nieuwlaat, Hubertus J Vrijhoef, Rianne de Wit, Harry J Crijns, Robert G Tieleman 


\section{ABSTRACT}

Background / Objectives. Atrial fibrillation (AF) is a very frequent and complex disease often associated with other medical conditions. The Euro Heart Survey (EHS) on AF showed that adherence to guidelines may reduce morbidity and mortality in AF patients. Therefore a nurse-driven, guideline-based, software supported integrated chronic care program (ICCP) was developed and implemented in daily practice. The objective of this study is to evaluate the clinical feasibility of the ICCP, with guideline adherence as the endpoint.

Methods. 111 ambulant patients referred for treatment of their AF were enrolled in the ICCP. In this group, patients underwent standardized clinical testing and were subsequently managed by a nurse, supported by a dedicated ICT-program and supervised by cardiologists. For comparison, we used a recent historical control group of 102 patients who participated in the Maastricht part of the Euro Heart Survey (EHS) on $\mathrm{AF}$.

Results. Guideline adherence was excellent within the ICCP and compared favourably to the EHS-AF data concerning both clinical testing (trigger factors recorded $100 \%$ vs. $44 \%$, echocardiogram performed $99 \%$ vs. $88 \%$; thyroid stimulating hormone level recorded $96 \%$ vs. $63 \%$ ) as well as treatment (antithrombotic therapy $90 \%$ vs. $78 \%$; rhythm control avoided in completely asymptomatic patients, $100 \%$ vs. $54 \%$; class I drugs avoided in patients with structural heart disease, $90 \%$ vs. $95 \%$; rhythm control avoided in permanent AF patients, $100 \%$ vs. $92 \%$ ).

Conclusion. The high level of guideline adherence suggests that a nurse-driven, guideline-based, software supported ICCP for AF patients is feasible. 


\section{INTRODUCTION}

Atrial fibrillation (AF) is a very frequent ${ }^{1,2}$ and complex disease often associated with other medical conditions. Not only the arrhythmia itself but also the underlying medical conditions determine the patients' long-term prognosis ${ }^{3}$. Physicians' focus on the arrhythmia frequently distracts their attention from the true problems AF patients face, leading to lack of anticoagulation and heart failure treatment, and futile installment of rhythm control in asymptomatic patients ${ }^{4,5}$. The Euro Heart Survey (EHS) on AF showed that adherence to guidelines may reduce morbidity and mortality in $\mathrm{AF}$ patients ${ }^{6}$ and may also reduce costs ${ }^{7,8}$.

Guideline adherence and outpatient care may be enhanced by implementing innovative integrated chronic care programs (ICCP) ${ }^{9}$. The effectiveness of ICCPS is related to interventions that are multifaceted and comprised of various organizational changes such as redefined professional roles, multidisciplinary teams, and use of computer systems and components of quality management ${ }^{10}$. The ICCP is derived from the Chronic Care Model, which is a synthesis of evidence-based organizational changes intended to guide quality improvement and disease management activities $^{11-13}$. Implementation of changes from traditional care to these new models requires a staged approach aimed at more productive interactions between healthcare providers and patients.

In the present study we report the feasibility of a new collaborative practice model for AF patients for which we developed a nurse-driven, guideline-based, software supported ICCP, with guideline adherence as the endpoint.

\section{PATIENTS AND METHODS}

Patients referred to the outpatient clinic of the Maastricht University Hospital between June 2006 and April 2007, were enrolled in the ICCP. All patients were 18 years or older and had AF recorded on ECG or Holter before visiting the outpatient clinic. To compare the degree of guideline adherence, we used a recent historical control group consisting of the Maastricht patients included in the EHS in 2003 and 2004. For the present study, we recorded all baseline and follow-up data contained within the inclusion visit.

\section{Procedures}

The patients in the EHS control group were routinely seen by a cardiologist and received usual care without the support of a nurse specialist. All diagnostic and therapeutic procedures were managed by the attending cardiologist.

Patients enrolled in the ICCP underwent standardized diagnostic procedures (electrocardiogram, echocardiogram, Holter recording, laboratory testing) before visiting the outpatient clinic. During the inclusion visit, the nurse specialist took the patient's history and informed the patient about pathophysiology, symptoms of AF, its 
possible complications, and treatment options. The nurse specialist uses a dedicated software program (CardioConsult $\mathrm{AF}^{\circledR}$ ) which directs medical therapy based upon the patient's profile and clinical guidelines. The supervising cardiologist sees the patient at the end of the visit before the start of treatment, confirms the medical diagnosis and informs the patient about the treatment aims and program.

\section{Variables}

Adherence to the guidelines was evaluated by calculating the percentage of patients in whom the following was present: (a) trigger factors for AF recorded; (b) echocardiogram performed; (c) laboratory testing of thyroid-stimulating hormone (TSH); (d) appropriate prescription of antithrombotic treatment; (e) inadvertent prescription of Vaughn-Williams class I drugs in patients with structural heart disease avoided; (f) inadvertent application of rhythm control strategy to completely asymptomatic patients avoided; and (g) no anti-arrhythmic medication for rhythm control in patients with permanent AF. These variables were chosen since they are unambiguously indicated in the 2006 guidelines ${ }^{14}$. Assessment of AF trigger factors is needed to guide targeted preventive treatment. Two-dimensional Doppler echocardiography is part of the initial evaluation of AF patients since it may reveal associated medical conditions related to $A F$, which may be amenable to treatment. The TSH level should be evaluated at least once to detect hyper- or hypothyroidism (also when the patient is given amiodarone treatment). Antithrombotic treatment was considered appropriate for ICCP patients (2006/2007) as outlined in the 2006 guidelines ${ }^{14}$, using the $\mathrm{CHADS}_{2}$ stroke risk score ${ }^{15}$. The $\mathrm{CHADS}_{2}$ model is a stroke risk classification scheme, using a point system to determine the yearly risk index. With a $\mathrm{CHADS}_{2}$-score 2 or higher consideration for a vitamin $\mathrm{K}$ antagonist (VKA) is strongly recommended. In case of a score of 1 , either aspirin or a VKA is recommended. In these patients, the presence of one or more so-called less well established risk factors, including age between 65 and 75 years, coronary artery disease, or female gender may tip the scale towards use of a VKA, but patient preference should also be considered. With a $\mathrm{CHADS}_{2}$-score of 0 , it is appropriate to give either aspirin or no antithrombotic therapy. Appropriate antithrombotic treatment for EHS patients was considered to be adherence to the 2001 guidelines $^{16}$, with VKA recommended for all patients with a $\mathrm{CHADS}_{2}$-score of 1 , but was also similar to the 2006 guidelines. Concerning the use of Vaughn-Williams class I or class III antiarrhythmic drugs, the guidelines advise avoiding class I drugs in patients with structural heart disease, i.e. coronary artery disease, heart failure, valvular heart disease, and thyroidism; to refrain from rhythm control (including ablation) in asymptomatic patients; and to avoid class I and III drugs in permanent AF. Those with permanent AF should receive only classical rate control drugs including beta-blockers, digitalis, or non-dihydropyridine calcium antagonists as needed. Class I and III drugs should be stopped in case permanent AF develops in paroxysmal or persistent AF patients under rhythm control. 


\section{Data collection and analysis}

Permission to perform this research was obtained from the Institutional Review Board of the University Hospital Maastricht. Data was retrieved from the CardioConsult $\mathrm{AF}^{\circledR}$ database. Data from the EHS were retrieved from the original EHS database available at our institution ${ }^{4}$. Data analyses were performed with SPSS statistical software (SPSS, Inc., release 12.01). Continuous variables are reported as the mean \pm standard deviation, and categorical variables as the observed number and percentage. The number and percentages of patients with guideline adherent treatment were compared between the ICCP and EHS control group and were tested for differences with $\chi^{2}$ statistics or Fisher's exact test. Differences for continuous variables were tested with independent t-test.

\section{RESULTS}

\section{Patient characteristics}

ICCP patients were slightly younger and had a lower burden of individual associated cardiovascular diseases, but had lone AF slightly less often (Table 4.1). This indicates that EHS patients had multiple associated diseases more often and consequently a higher stroke risk, as depicted by the higher $\mathrm{CHADS}_{2}$-score. Hypertension was by far the most prevalent stroke risk factor, followed by age over 75 years and congestive heart failure. AF types were similar among the groups.

\section{Guideline adherence}

The average percentage of patients treated according to the guidelines was $96 \%$ in the ICCP group compared with $70 \%$ in the control group $(P<0.001)$. Figure 4.1 shows the percentage adherence per number of recommendations in both groups. Guideline adherence in the ICCP group was much better when three or more recommendations should have been followed.

\section{Clinical diagnostic investigation}

In the control group, AF trigger factors were recorded in only 45 cases (44\%) whereas these were reported for all ICCP patients. An echocardiogram was recorded during the EHS in 90 patients (88\%). All but one of the ICCP patients (99\%) underwent echocardiogram as a routine evaluation $(P<0.001)$. TSH level was measured in only 64 patients $(63 \%)$ in the control group, while TSH level was measured at least once in 107 ICCP patients $(96 \%)(P<0.001)$. 


\section{Antithrombotic therapy}

Figure 4.2 shows the use of antithrombotic therapy per $\mathrm{CHADS}_{2}$-score in both study groups. In the ICCP patients, antithrombotic treatment was largely in accordance with recommendations. Most ICCP patients without stroke risk factors received aspirin or no antithrombotic drugs as recommended by the guidelines, and $18 \%$ ( 6 patients) received VKA because of a scheduled cardioversion. On the other hand, 39\% (7 patients) of all risk-free patients in the control group used VKA and only 2 of these patients were in preparation for a cardioversion.

Table 4.1 Characteristics of the patients enrolled in the Integrated Chronic Care Program versus patients enrolled in the Euro Heart Survey control group.

\begin{tabular}{|c|c|c|c|}
\hline & $\begin{array}{c}\text { ICCP } \\
n=111\end{array}$ & $\begin{array}{c}\text { EHS } \\
n=102\end{array}$ & $p$-value \\
\hline \multicolumn{4}{|l|}{ Demographics } \\
\hline Age, mean $\pm S D, y$ & $67 \pm 13$ & $70 \pm 11$ & 0.051 \\
\hline Age $>75$ y, n (\%) & $37(33)$ & 39 (39) & 0.456 \\
\hline Males, n (\%) & $66(59)$ & $62(61)$ & 0.844 \\
\hline \multicolumn{4}{|l|}{ Underlying Disease, n (\%) } \\
\hline Hypertension & $50(45)$ & $58(57)$ & 0.085 \\
\hline Coronary artery disease & $15(14)$ & $41(41)$ & 0.000 \\
\hline Congestive heart failure & $12(11)$ & $30(29)$ & 0.000 \\
\hline Previous stroke / TIA & $12(11)$ & $10(10)$ & 0.809 \\
\hline Diabetes mellitus & $9(8)$ & $14(14)$ & 0.187 \\
\hline Hyperthyroidism & $9(8)$ & $6(6)$ & 0.526 \\
\hline Valvular heart disease & $7(6)$ & $30(29)$ & 0.000 \\
\hline Lone AF & $19(17)$ & $24(24)$ & 0.244 \\
\hline \multicolumn{4}{|l|}{$\mathrm{CHADS}_{2}$-score, $\mathrm{n}(\%)$} \\
\hline 0 & $34(31)$ & $18(18)$ & \multirow{3}{*}{0.014} \\
\hline 1 & $39(35)$ & $30(29)$ & \\
\hline$>1$ & $38(34)$ & $54(53)$ & \\
\hline \multicolumn{4}{|l|}{ Type of $A F * 1,2$} \\
\hline Paroxysmal & $59(53 \%)$ & $42(41 \%)$ & \multirow{4}{*}{0.000} \\
\hline Persistent & $29(26 \%)$ & $30(29 \%)$ & \\
\hline Permanent & $23(21 \%)$ & $13(13 \%)$ & \\
\hline Missing & 0 & $17(17 \%)$ & \\
\hline
\end{tabular}

* ${ }^{1}$ unknown type of $A F(E H S, n=3)$ and first detected AF (EHS, $\left.n=14\right)$ is not reported and is labelled as missing; ${ }^{*}{ }^{2}$ in contrast with the EHS, first detected AF in the ICCP $(n=55)$ is not calculated as part of the $3 \mathrm{P}$ classification on type of AF.

AF: atrial fibrillation; $\mathrm{CHADS}_{2}$-score: stroke risk classification scheme representing congestive heart failure, hypertension, age 75 years or older, diabetes, and prior stroke or TIA; EHS: Euro Heart Survey on atrial fibrillation; ICCP: Integrated Chronic Care Program; TIA: Transient Ischaemic Attack. 


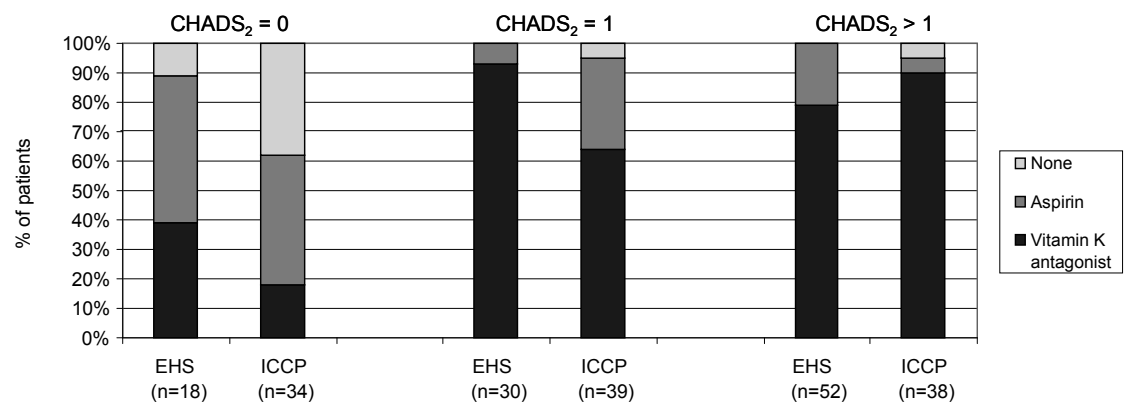

Figure 4.2 Antithrombotic therapy per $\mathrm{CHADS}_{2}$-score. The therapy per $\mathrm{CHADS}_{2}$-score is significantly different in the ICCP group compared with the EHS group $(P \leq 0.001)$.

In ICCP patients with only one stroke risk factor $\left(\mathrm{CHADS}_{2}\right.$-score of 1 ) there was a balanced mix between aspirin and VKA use, again steered by the presence of non$\mathrm{CHADS}_{2}$ risk factors ${ }^{14}$. In this subgroup, 23 of 25 VKA users (92\%) had at least one additional non-CHADS 2 stroke risk factor compared with 5 of 14 (36\%) of the aspirin/no antithrombotic drugs users. In the control group, almost all patients were on VKA and 23 out of these 28 patients (82\%) had additional non-CHADS 2 risk factors ( $P=$ non-significant compared with $92 \%$ in the ICCP). When the EHS data was collected, the 2001 guidelines were active ${ }^{16}$, suggesting that antithrombotic guidelines were well followed at the time.

In 34 out of 38 (90\%) ICCP high-risk patients ( $\mathrm{CHADS}_{2}$-scores $\left.>1\right)$, VKA was prescribed. In $2(5 \%)$, aspirin was given, and in another $2(5 \%)$, no antithrombotic therapy was given because of a moderate to high risk of bleeding.

According to the 2006 guidelines ${ }^{14}$, appropriate antithrombotic treatment was administered to 37 (97\%) of the high-risk ICCP patients. On the other hand, according to the 2001 guidelines $^{16}$, appropriate treatment was given to 41 (79\%) of the high-risk control group patients $(P<0.05)$. 


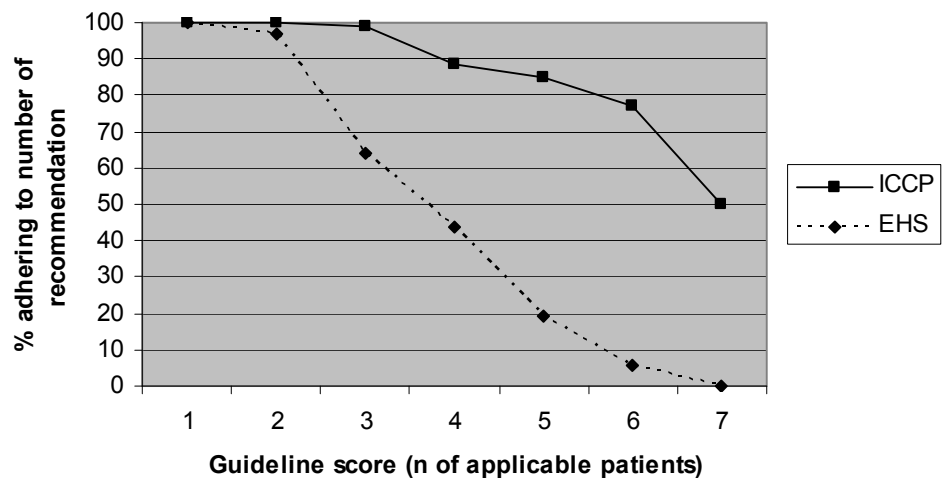

\begin{tabular}{lccccccc}
\hline & 1 & 2 & 3 & 4 & 5 & 6 & 7 \\
\hline ICCP & $(n=111)$ & $(n=111)$ & $(n=111)$ & $(n=111)$ & $(n=66)$ & $(n=13)$ & $(n=2)$ \\
& $100 \%$ & $100 \%$ & $99.10 \%$ & $88.30 \%$ & $84.80 \%$ & $76.90 \%$ & $50 \%$ \\
& & & & & & & \\
\multirow{2}{*}{ EHS } & $(n=98)$ & $(n=98)$ & $(n=98)$ & $(n=98)$ & $(n=77)$ & $(n=34)$ & $(n=4)$ \\
& $100 \%$ & $96.90 \%$ & $64.30 \%$ & $43.90 \%$ & $19.50 \%$ & $5.90 \%$ & 0 \\
\hline
\end{tabular}

Figure 4.1 Guideline adherence per number of recommendations, as calculated among patients in whom the number of recommendations concerned should be followed, in the EHS control group versus the ICCP group.

\section{Antiarrhythmic medication}

Inadvertent use of class I antiarrhythmic agents in patients with underlying cardiovascular disease (UHD)(Table 4.2) was seen in 2 of the ICCP patients (7\%) versus 2 patients $(5 \%)$ in the control group ( $P=$ non-significant).

Table 4.2 Use of rhythm-control drugs in ICCP and EHS control.

\begin{tabular}{lcccc}
\hline & \multicolumn{2}{c}{ ICCP $\mathrm{n}(\%)$} & \multicolumn{2}{c}{ EHS $\mathrm{n}(\%)$} \\
\cline { 2 - 5 } & UHD & $\mathrm{non}-\mathrm{UHD}$ & $\mathrm{UHD}$ & $\mathrm{non}-$ UHD \\
& $\mathrm{n}=29$ & $\mathrm{n}=82$ & $2(5)$ & $\mathrm{n}=65$ \\
\hline Flecainide & $2(7)$ & $15(18)$ & $3(5)$ \\
Sotalol & $1(3)$ & $11(13)$ & $6(16)$ & $9(14)$ \\
Amiodarone & 0 & $3(4)$ & $5(14)$ & $14(22)$ \\
\hline
\end{tabular}

There were 14 asymptomatic patients in the ICCP, none of whom were on rhythm control (no anti-arrhythmic drugs, no ablation). In contrast, 24 of 52 (46\%) asymptomatic patients $(P<0.001)$ in the control group received rhythm control (19 class I or III drugs, 12 planned cardioversion, 2 planned ablations). However, the 2001 guidelines ${ }^{16}$ were active during the EHS data collection, which did not stringently recommend avoiding rhythm control in asymptomatic patients. 
In the ICCP group, permanent AF was present in 23 (21\%) patients. All patients were on appropriate rate control drugs and no class I or III anti-arrhythmic medication was prescribed (Table 4.3). In the control group, permanent AF was present in 13 patients (13\%), who also received rate control medication; however, sotalol was inappropriately prescribed in 1 patient (8\%) ( $P=$ non-significant).

Table 4.3 Use of rhythm-control and rate-control medication in 36 patients with permanent (accepted) AF.

\begin{tabular}{lcc}
\hline & ICCP $\mathrm{n}(\%)$ & EHS $\mathrm{n}(\%)$ \\
& $\mathrm{n}=23$ & $\mathrm{n}=13$ \\
\hline Flecainide & 0 & 0 \\
Sotalol & 0 & $1(8)$ \\
Amiodarone & 0 & 0 \\
Verapamil & $2(11)$ & 0 \\
Diltiazem & 0 & 0 \\
Beta blocker & $13(68)$ & $10(77)$ \\
Digitalis & $6(32)$ & $7(54)$ \\
\hline
\end{tabular}

Proportions add up to $>100 \%$ due to combinations of prescribed drugs.

\section{DISCUSSION}

This report shows that ACC/AHA/ESC AF guideline adherence for AF patients within an ICCP compares favourably with that seen in general clinical practice. Considering that guideline adherence was only $70 \%$ with general practice in the EHS, a remarkable $96 \%$ of ICCP patients were completely diagnosed and treated according to all major recommendations of the current guidelines, which is most likely because of the systematic approach we implemented. This finding supports the notion that an ICCP is highly feasible.

Integrated systematic care protects patients from the risks of incomplete diagnostic and therapeutic procedures. Too often, medical specialists take an approach that is too narrowly focused. In the EHS it appeared that when AF occurred in the setting of heart failure, the recommendations provided by AF and HF guidelines were followed in only $13 \%$ of patients with both conditions ${ }^{6}$. Not only in clinical practice, but also in well-known randomized trials, incomplete treatment may be observed ${ }^{17-19}$. Our study as well as previous ones ${ }^{20-22}$ suggest that integrated care leads to an improved application of diagnostic procedures and therapy which may save lives, improve quality of life, and enhance patient compliance.

Cost-effectiveness was not part of the study. However, it is most likely that implementing the ICCP increases initial costs. On the other hand, improved evidencebased care with the ICCP is likely to enhance quality of life and prevent mortality, strokes and hospitalizations. We anticipate that cost savings related to these beneficial effects will eventually overrule the increased cost burden related to implementing the ICCP. 
Many reasons underlie lack of adherence to the guidelines during routine clinical care, including lack of time and high workload for the physician. 'Time is money' seems most applicable to this subject. To characterize AF patients effectively and install proper follow-up diagnostics and treatments is time-consuming, but should be done systematically. For installing proper therapy, following the guidelines, and informing and instructing patients, there is a role for the nurse specialist. Trials in nurse-led management interventions show significant improvements mainly due to rigorous application of guidelines ${ }^{23-25}$. Systematic reviews indicate that involving a nurse specialist to control blood pressure ${ }^{26}$ and to help patients stop smoking ${ }^{27}$ is beneficial. Our results suggest that a nurse specialist can also be reliable and effective in the more complex process of care required by AF patients. As a result, the workload during the cardiologists' consulting hours may be lessened while the quality of care is maintained or improved.

\section{Study limitations}

The baseline characteristics of the study groups differed. The historical EHS control group was observed three years before the implementation of the ICCP. In addition, ICCP patients were all new referrals to the outpatient clinic, whereas the EHS included both new and existing outpatients and inpatients. If anything, the longer arrhythmia history for most of these patients, as well as the fact that many were already known for some time within our department, should have increased rather than decreased guideline adherence in the EHS control group.

Because the EHS was performed at our institution a few years previously, this may have led to improved awareness and adherence. It is hard to separate the actual effect of an intervention from temporal changes in any before-after study. We considered the present results as an indication that the ICCP can work and feel that the ICCP contributed significantly to the adherence figures.

\section{CONCLUSION}

An ICCP driven by a nurse specialist, supervised by a cardiologist and supported by a dedicated software program, may be implemented safely while maintaining and potentially improving cardiac care for patients with AF. 


\section{REFERENCES}

1. Furberg CD, Psaty BM, Manolio TA, Gardin JM, Smith VE, Rautaharju PM. Prevalence of atrial fibrillation in elderly subjects (the Cardiovascular Health Study). Am J Cardiol 1994;74:236-41.

2. Go AS, Hylek EM, Phillips KA, Chang YC, Henault LE, Selby JV, Singer DE. Prevalence of diagnosed atrial fibrillation in adults: national implications for rhythm management and stroke prevention: the AnTicoagulation and Risk Factors In Atrial Fibrillation (ATRIA) study. JAMA 2001;285:2370-5.

3. Roy D, Talajic M, Nattel S, Wyse DG, Dorian P, Lee KL, Bourassa MG, Arnold JM, Bruxton AE, Camm AJ, Connolly SJ, Dubuc M, Ducharme A, Guerra PG, Hohnloser SH, Lambert J, Le Heuzey JY, O'Hara G, Pedersen OD, Rouleau JL, Singh BN, Stevenson LW, Stevenson WG, Thibault B, Waldo AL; Atrial Fibrillation and Congestive Heart Failure Investigators. Rhythm control versus rate control for atrial fibrillation and heart failure. $N$ Engl J Med 2008;358:2667-77.

4. Nieuwlaat R, Capucci A, Camm AJ, Olsson SB, Andresen D, Davies DW, Cobbe S, Breithardt G, Le Heuzey JY, Prins MH, Lévy S, Crijns HJ; European Heart Survey Investigators. Atrial fibrillation management: a prospective survey in ESC member countries: the Euro Heart Survey on Atrial Fibrillation. Eur Heart J 2005;26:2422-34.

5. Nieuwlaat R, Prins MH, Le Heuzey JY, Vardas PE, Aliot E, Santini M, Cobbe SM, Widdershoven JW, Baur LH, Lévy S, Crijns HJ. Prognosis, disease progression, and treatment of atrial fibrillation patients during 1 year: follow-up of the Euro Heart Survey on atrial fibrillation. Eur Heart J 2008;29:1181-9.

6. Nieuwlaat R, Olsson SB, Lip GY, Camm AJ, Breithardt G, Capucci A, Meeder JG, Prins MH, Lévy S, Crijns HJ; Euro Heart Survey Investigators. Guideline-adherent antithrombotic treatment is associated with improved outcomes compared with undertreatment in highrisk patients with atrial fibrillation: the Euro Heart Survey on Atrial Fibrillation. Am Heart $J$ 2007;153:1006-12.

7. Le Heuzey JY, Paziaud O, Piot O, Said MA, Copie X, Lavergne T, Guize L. Cost of care distribution in atrial fibrillation patients: the COCAF study. Am Heart J 2004;147:121-6.

8. Ringborg A, Nieuwlaat R, Lindgren P, Jönsson B, Fidan D, Maggioni AP, Lopez-Sendon J, Stepinska J, Cokkinos DV, Crijns HJ. Costs of atrial fibrillation in five European countries: results from the Euro Heart Survey on atrial fibrillation. Europace 2008;10:403-11.

9. Institute Of Medicine. Crossing the quality chasm 2001 (26 May 2005). Available from: www.iom.edu/?id=12736. Accessed October 11, 2008.

10. Wensing $M$, Wollersheim $H$, Grol R. Organizational interventions to implement improvements in patient care: a structured review of reviews. Implement Sci 2006;1:2.

11. Casalino LP. Disease management and the organization of physician practice. JAMA 2005;293:485-8.

12. Wagner EH. Chronic disease management: what will it take to improve care for chronic illness? Eff Clin Pract 1998;1:2-4.

13. Wagner EH, Austin BT, Davis $\mathrm{C}$, Hindmarsh $\mathrm{M}$, Schaefer J, Bonomi A. Improving chronic illness care: translating evidence into action. Health Aff 2001;20:64-78.

14. Fuster V, Rydén LE, Cannom DS, Crijns HJ, Curtis AB, Ellenbogen KA, Halperin JL, Le Heuzey JY, Kay GN, Lowe JE, Olsson SB, Prystowsky EN, Tamargo JL, Wann S, Smith SC Jr, Jacobs AK, Adams CD, Anderson JL, Antman EM, Halperin JL, Hunt SA, Nishimura R, Ornato JP, Page RL, Riegel B, Priori SG, Blanc JJ, Budaj A, Camm AJ, Dean V, Deckers JW, Despres C, Dickstein K, Lekakis J, McGregor K, Metra M, Morais J, Osterspey A, Tamargo JL, Zamorano $\mathrm{JL}$; American College of Cardiology/American Heart Association Task Force on Practice Guidelines; European Society of Cardiology Committee of Practice Guidelines; European 
Heart Rhythm Association; Heart Rhythm Society. ACC/AHA/ESC 2006 guidelines for the management of patients with atrial fibrillation: a report of the American College of Cardiology/American Heart Association Task Force on Practice Guidelines and the European Society of Cardiology Committee for Practice Guidelines (writing committee to revise the 2001 guidelines for the management of patients with atrial fibrillation): developed in collaboration with the European Heart Rhythm Association and the Heart Rhythm Society. Circulation 2006;114:e257-354.

15. Gage BF, Waterman AD, Shannon W, Boechler M, Rich MW, Radford MJ. Validation of clinical classification schemes for predicting stroke: results from the National Registry of Atrial Fibrillation. JAMA 2001;285:2864-70.

16. Fuster V, Rydén LE, Asinger RW, Cannom DS, Crijns HJ, Frye RL, Halperin JL, Kay GN, Klein WW, Lévy S, McNamara RL, Prystowski EN, Wann LS, Wyse DG, Gibbons RJ, Antman EM, Alpert JS, Faxton DP, Fuster V, Gregoratos G, Hiratzka LF, Jacobs AK, Russell RO, Smith SC Jr, Klein WW, Alonso-Garcia A, Blomström-Lundqvist C, de Backer G, Flather M, Hradec J, Oto A, Parkhomenko A, Silber S, Torbicki A; American College of Cardiology/American Heart Association Task Force on Practice Guidelines; European Society of Cardiology Committee for Practice Guidelines and Policy Conferences (Committee to Develop Guidelines for the Management of Patients With Atrial Fibrillation); North American Society of Pacing and Electrophysiology. ACC/AHA/ESC guidelines for the management of patients with atrial fibrillation: executive summary: a report of the American College of Cardiology/American Heart Association Task Force on Practice Guidelines and the European Society of Cardiology Committee for Practice Guidelines and Policy Conferences (Committee to develop guidelines for the management of patients with atrial fibrillation) developed in collaboration with the North American Society of Pacing and Electrophysiology. Circulation 2001;104:2118-50.

17. Moss AJ. MADIT-I and MADIT-II. J Cardiovasc Electrophysiol 2003;14:S96-8.

18. Pratt CM, Moyé LA. The cardiac arrhythmia suppression trial: casting suppression in a different light. Circulation 1995;91:245-7.

19. Wachtell K, Hornestam B, Lehto M, Slotwiner DJ, Gerdts E, Olsen MH, Aurup P, Dahlöf B, Ibsen $\mathrm{H}$, Julius S, Kjeldsen SE, Lindholm LH, Nieminen MS, Rokkedal J, Devereux RB. Cardiovascular morbidity and mortality in hypertensive patients with a history of atrial fibrillation: the Losartan Intervention For End Point Reduction in Hypertension (LIFE) study. JACC 2005; 45:705-11.

20. Akosah KO, Schaper AM, Haus LM, Mathiason MA, Barnhart SI, McHugh VL. Improving outcomes in heart failure in the community: long-term survival benefit of a diseasemanagement program. Chest 2005;127:2042-8.

21. De la Porte PW, Lok DJ, Van Veldhuisen DJ, Van Wijngaarden J, Cornel JH, Zuithoff NP, Badings $\mathrm{E}$, Hoes AW. Added value of a physician-and-nurse-directed heart failure clinic: results from the Deventer-Alkmaar heart failure study. Heart 2007;93:819-25.

22. Liem SS, Van der Hoeven BL, Oemrawsingh PV, Bax JJ, Van der Bom JG, Bosch J, Viergever EP, van Rees C, Padmos I, Sedney MI, van Exel HJ, Verwey HF, Atsma DE, van der Velde ET, Jukema JW, van der Wall EE, Schalij MJ. MISSION!: optimization of acute and chronic care for patients with acute myocardial infarction. Am Heart J 2007;153:14.e1-11.

23. Becker DM, Ragueno JV, Yook RM, Kral BG, Blumenthal RS, Moy TF, Bezirdjian PJ, Becker LC. Nurse-mediated cholesterol management compared with enhanced primary care in siblings of individuals with premature coronary disease. Arch Intern Med 1998;158:1533-9.

24. Logan AG, Milne BJ, Achber C, Campbell WP, Haynes RB. Work-site treatment of hypertension by specially trained nurses. Lancet 1979;2:1175-8.

25. Oakeshott P, Kerry S, Austin A, Cappuccio F. Is there a role for nurse-led blood pressure management in primary care? J Fam Pract 2003;20:469-73. 
26. Fahey T, Schroeder K, Ebrahim S. Interventions used to improve control of blood pressure in patients with hypertension. Cochrane Database Syst Rev 2006; CD005182.

27. Rice VH, Stead LF. Nursing interventions for smoking cessation. Cochrane Database Syst Rev 2008; CD001188. 



\section{SECTION}

A randomized comparison 



\title{
CHAPTER
}

\begin{abstract}
Nurse-led care versus usual care for patients with atrial fibrillation: results of a randomized trial of integrated chronic care versus routine clinical care in ambulatory patients with atrial fibrillation
\end{abstract}

Jeroen ML Hendriks, Rianne de Wit, Harry JGM Crijns, Hubertus JM Vrijhoef, Martin H Prins, Ron Pisters, Laurent AFG Pison, Yuri Blaauw, Robert G Tieleman 


\section{ABSTRACT}

Aims. The management of patients with atrial fibrillation (AF) is often inadequate due to deficient adherence to the guidelines. A nurse-led AF-Clinic providing integrated chronic care to improve guideline adherence and activate patients in their role, may effectively reduce morbidity and mortality but such care has not been tested in a large randomized trial. Therefore we performed a randomized clinical trial to compare the AF-Clinic with routine clinical care in patients with AF.

Methods and results. We randomly assigned 712 patients with AF to nurse-led care and usual care. Nurse-led care consisted of guideline-based, software supported integrated chronic care supervised by a cardiologist. The primary endpoint was a composite of cardiovascular hospitalization and cardiovascular death. Duration of follow-up was at least 12 months.

Adherence to guideline recommendations was significantly better in the nurse-led care group. After a mean of 22 months the primary endpoint occurred in $14.3 \%$ of 356 patients of the nurse-led care group compared to $20.8 \%$ of 356 patients receiving usual care (hazard ratio $0.65 ; 95 \%$ confidence interval $[\mathrm{Cl}] 0.45$ to $0.93 ; P=0.017$ ). Cardiovascular death occurred in $1.1 \%$ in the nurse-led care versus $3.9 \%$ in the usual care group (hazard ratio $0.28 ; 95 \% \mathrm{Cl} 0.09$ to $0.85 ; P=0.025$ ). Cardiovascular hospitalization amounted $(13.5 \%$ versus $19.1 \%$, respectively, hazard ratio $0.66 ; 95 \% \mathrm{Cl}$ 0.46 to $0.96, P=0.029$ ).

Conclusions. Nurse-led care of patients with AF is superior to usual care provided by a cardiologist in terms of cardiovascular hospitalization and cardiovascular mortality. (Clinicaltrials.gov identifier: NCT00753259) 


\section{INTRODUCTION}

Atrial fibrillation (AF) is the most common cardiac arrhythmia and increasing in prevalence with age $\mathrm{e}^{1,2}$. It is becoming an extremely costly public health problem ${ }^{3,4}$, with hospitalization as the primary cost driver $^{5}$. AF is often inadequately managed due to deficient adherence to guidelines ${ }^{6,7}$. Non-adherence relates to disease complexity with large differences between patients concerning risks of stroke, heart failure and coronary syndromes. The growing number of patients, the complexity of the disease and the frequent non-adherence ask for a change in management of AF. Nurse-led multidisciplinary heart failure clinics were shown to improve clinical outcomes, ${ }^{8,9}$. In contrast, it has never been investigated whether a multidisciplinary AF-Clinic may likewise improve cardiovascular outcomes in patients with AF. Also, to our knowledge, the effects of decision support software in the management of these patients has not been described. Previously we demonstrated that a nurse-led multidisciplinary AFClinic can be implemented safely ${ }^{10}$, but a prospective comparison with standard care is lacking. Therefore, we performed a randomized trial to compare nurse-led care with usual care to prevent cardiovascular hospitalization or death in patients with AF in the outpatient setting. We hypothesized that nurse-led care is superior to usual care.

\section{METHODS}

\section{Study design}

This prospective randomized clinical trial took place in the Maastricht University Medical Centre and recruited patients between January 2007 and December 2008. Follow-up was at least 1 year. The design of the study has been described previously ${ }^{11}$. The study complies with the Declaration of Helsinki and ethical approval was obtained from the Institutional Review Board. The study was registered at Clinicaltrials.gov (identifier: NCT00753259). The steering committee was responsible for the design and conduct of the study, data analysis and manuscript preparation. All authors reviewed previous versions of the manuscript and vouch for accuracy and completeness of data and analyses.

\section{Study participants and randomization}

All patients $\geq 18$ years referred for AF (documented on an electrocardiogram) by general practitioners or non-cardiology specialists to our outpatient department, were eligible $^{11}$. Patients were asked permission for use of their personal clinical data to be collected during their future visits. At the same time we informed them about the AFClinic and nurse-led care, as well as the possibility of participation in a clinical trial. Patients were then randomly assigned to nurse-led care or usual care, following a computerized 1 to 1 randomization. Patients were excluded in case of any comorbidity which is unsatisfactorily treated, e.g. unstable and uncontrolled 
hypertension, unstable heart failure defined as NYHA IV or necessitating hospital admission <3 months before inclusion, untreated hyperthyroidism, current or foreseen pacemaker, internal cardioverter defibrillator or cardio resynchronization therapy, or cardiac surgery $<3$ months before inclusion ${ }^{11}$.

\section{Treatment}

The care provided in the AF-Clinic was based on the Chronic Care Model ${ }^{12,13}$. It consisted of nurse-led outpatient care steered by decision support software based on the guidelines ${ }^{2}$ and supervised by a cardiologist ${ }^{11}$. Before the first visit, patients underwent laboratory testing, electrocardiogram, Holter monitoring and echocardiography. At the first visit, a nurse specialist took the patient's history and informed them about the pathophysiology of $\mathrm{AF}$, its symptoms and possible complications, the results of the diagnostic tests and treatment options. The dedicated software CardioConsult $\mathrm{AF}^{\circledR}$ (Curit BV - Groningen, The Netherlands) was used to guide comprehensive management of $\mathrm{AF}$ and associated cardiovascular conditions. The software determined the individual patient profile based on symptoms, type of AF, and stroke risk. Thereafter, it proposed the most appropriate management. To further empower patients they were instructed about rate and rhythm control as well as prophylactic vascular therapy (including strict anticoagulation monitoring), and about when to report to the hospital. At the end of the consultation, the nurse specialist was supervised by a cardiologist, endorsing the proposed diagnoses and treatments. Visits to the nurse were scheduled to last 30 minutes. Follow up visits were planned at 3, 6 and 12 months, and every 6 months thereafter. Patients could contact the nurse in person or by telephone between planned visits as needed. During follow-up visits, psychosocial support and educational interventions were repeated.

Patients in the control group received usual care by a cardiologist in the outpatient clinic during visits scheduled to last 20 minutes for the first visit and 10 minutes for follow-up visits.

During follow-up visits patients were questioned for major adverse cardiovascular events and hospitalizations. Also all medical records were reviewed for such events after 1 and 2 years, and at the end of follow-up.

\section{Outcomes}

The primary outcome was a composite of death from cardiovascular causes, and cardiovascular hospitalization (i.e. hospitalization with an overnight stay) for heart failure, ischaemic stroke, acute myocardial infarction, systemic embolism, major bleeding, severe arrhythmic events and life-threatening adverse effects of drugs. All primary outcome events were adjudicated on the basis of pre-specified criteria by an independent clinical endpoint committee that was not aware of the randomized treatment assignments. Cardiovascular deaths were classified according to a modified Hinkle and Thaler classification ${ }^{14}$. Heart failure was defined as heart failure 
independent of left ventricular ejection fraction, preferably confirmed by $\mathrm{N}$-terminal pro-brain natriuretic peptide assessment, and necessitating hospitalization. Thromboembolic complications included stroke (sudden onset of focal deficit caused by occlusion of major cerebral artery, confirmed by a neurologist on the basis of computerized tomography or magnetic resonance imaging), systemic embolization (acute occlusion of an extremity or organ, confirmed by imaging or surgery) and myocardial infarction ( 2 of 3 characteristics: chest pain, ischemic electrocardiographic changes, elevated blood levels of key biochemical markers), all necessitating hospitalization. Major bleeding: fatal bleeding, or intracranial bleeding, or a reduction in the haemoglobin level $>1.25 \mathrm{mmol} / \mathrm{l}$ and requiring blood transfusion with hospitalization. Arrhythmic events included AF, cardiac syncope, sustained ventricular tachycardia and cardiac arrest, all associated with hospitalization. Life-threatening adverse effects of rate or rhythm controlling drugs included pro-arrhythmia of Vaughan Williams classes I and III anti-arrhythmic drugs, digitalis intoxication, druginduced heart failure or conduction disturbances, all necessitating hospitalization.

\section{Statistical analysis}

The primary analysis was performed to test whether nurse-led care was superior to usual care. A sample size of 349 patients in both the intervention and control groups was calculated on a reduction from $35 \%$ to $25 \%$ for the primary endpoint, using an alpha of 0.05 and a power of 0.80 . All analyses were performed on an intention-totreat basis. We calculated Kaplan-Meier estimates and their $95 \%$ confidence intervals [Cls]. To assess the risk for cardiovascular hospitalization or cardiovascular death in both groups, Cox proportional hazards modelling was used to calculate hazard ratios and their $95 \% \mathrm{Cls}$, both crude and adjusted for sex, age, and the presence of cardiovascular disease at the time of the patient's referral. The latter included heart failure, hypertension, diabetes and prior stroke or transient ischemic attack. The assumptions of the Cox proportional hazards model was checked by visual inspection of the log-log survivor function-by-time curve. To assess implementation of care as recommended by the AF guidelines in both groups we tested for differences using Fisher's exact test after calculating the cumulative percentage of patients in whom 1 through 6 recommendations were followed. We did all calculations with SPSS, version 16.0 (SPSS, Chicago, Illinois).

\section{RESULTS}

\section{Patients and implementation of care}

A total of 712 patients were enrolled in the study: 356 in the nurse-led care group and 356 in the usual care group (Figure 5.1). The groups were well matched without significant differences in baseline characteristics (Table 5.1). None of the patients was 
lost to follow-up. Figure 5.2 shows the adherence to guidelines recommendations. At the end of the first visit appropriate prescription of anti-thrombotic treatment was seen in $99 \%$ and $83 \%$ of patients in the nurse-led care and usual care groups, respectively. Thyroid function testing was done in $91 \%$ versus $54 \%$, and echocardiography in $91 \%$ versus $82 \%$ of patients, in both treatment groups, respectively. Appropriate application of rhythm control was more frequent in the nurse-led care group, i.e. it was not applied in asymptomatic patients (95\% versus $85 \%$ ), no rhythm control drugs were prescribed if contra-indicated ( $87 \%$ versus $82 \%)$, and no such drugs in patients with permanent AF (97\% versus 93\%, respectively). In total 2732 outpatient department visits, 551 first heart aid visits and 362 telephone contacts were produced from inclusion to end of follow-up. In the nurse-led care arm an estimated 407 hours were spent in total by the nurse specialist and 265 hours by the supervising cardiologist. In the control group, an estimated 436 hours were spent in total by the cardiologist. The level of knowledge the patients had of their disease and its management was scored using a heart failure questionnaire ${ }^{15}$ modified for AF. At 1 year after inclusion, patients in the nurse-led group scored significantly better than usual care patients (data not shown).

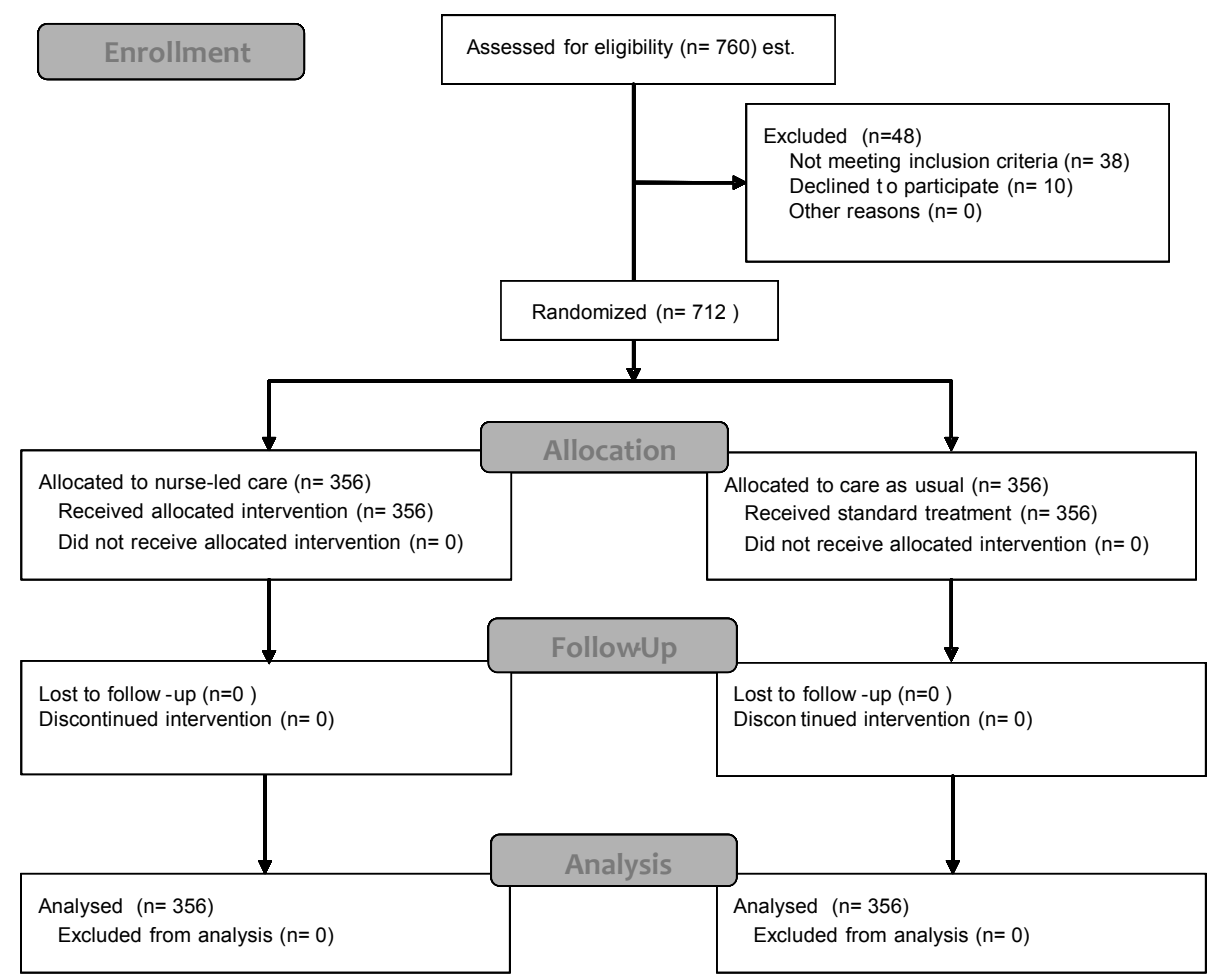

Figure 5.1 CONSORT flow diagram showing flow of patients and reasons for exclusion and protocol deviations. 
Table 5.1 Characteristics of the patients according to treatment group.

\begin{tabular}{|c|c|c|}
\hline Characteristic & Nurse-led Care $(n=356)$ & Usual Care $(n=356)$ \\
\hline Age - yr & $66 \pm 13$ & $67 \pm 12$ \\
\hline Male sex - no (\%) of patients & $197(55.3)$ & $221(62.1)$ \\
\hline \multicolumn{3}{|l|}{ Type of AF - no (\%) of patients } \\
\hline Paroxysmal & $190(53.4)$ & $203(57.0)$ \\
\hline Persistent & $68(19.1)$ & $44(12.4)$ \\
\hline Permanent & $75(21.1)$ & $84(23.6)$ \\
\hline Symptomatic - no (\%) of patients & 294 (82.6) & $296(83.1)$ \\
\hline \multicolumn{3}{|l|}{ History of underlying disease - no (\%) of patients } \\
\hline Hypertension & $187(52.5)$ & $193(54.2)$ \\
\hline Diabetes mellitus & $50(14.0)$ & $46(12.9)$ \\
\hline Previous stroke /TIA & $44(12.4)$ & $45(12.6)$ \\
\hline Coronary artery disease & $33(9.3)$ & $38(10.7)$ \\
\hline Myocardial infarction & $19(5.3)$ & $22(6.2)$ \\
\hline Chronic obstructive lung disease & $29(8.1)$ & $31(8.7)$ \\
\hline Congestive heart failure & $25(7.0)$ & $25(7.0)$ \\
\hline Peripheral vascular disease & $13(3.7)$ & $20(5.6)$ \\
\hline Hyperthyroidism & $12(3.4)$ & $12(3.4)$ \\
\hline Mitral valve heart disease & $7(2.0)$ & $10(2.8)$ \\
\hline Aortic valve heart disease & $5(1.4)$ & $11(3.1)$ \\
\hline No underlying heart disease & $6(1.7)$ & $7(2.0)$ \\
\hline \multicolumn{3}{|l|}{$\mathrm{CHADS}_{2}$-score - no (\%) of patients $\dagger$} \\
\hline 0 & $107(30.0)$ & $95(26.7)$ \\
\hline 1 & $122(34.3)$ & 135 (37.9) \\
\hline$>1$ & $127(35.7)$ & $126(35.4)$ \\
\hline \multicolumn{3}{|l|}{ Treatment - no (\%) of patients } \\
\hline Beta-blocker & $164(46.1)$ & $187(52.5)$ \\
\hline Digitalis & $59(16.6)$ & $43(12.1)$ \\
\hline Verapamil & $44(12.4)$ & $18(5.1)$ \\
\hline Vaughan-Williams class I \& III antiarrhythmic Drugs & $105(29.1)$ & $88(24.7)$ \\
\hline \multicolumn{3}{|l|}{ Other medication - no (\%) of patients } \\
\hline Angiotensin receptor blocker & $88(24.7)$ & $80(22.5)$ \\
\hline Angiotensin converting enzyme inhibitor & $72(20.2)$ & $67(18.8)$ \\
\hline Diuretic & $56(15.7)$ & $67(18.8)$ \\
\hline Statin & $119(33.4)$ & $99(27.8)$ \\
\hline Vitamin $\mathrm{K}$ antagonist & $218(61.2)$ & $188(52.8)$ \\
\hline Aspirin & $118(33.1)$ & $108(30.3)$ \\
\hline \multicolumn{3}{|l|}{ Heart rate } \\
\hline Mean - beats / min & $80 \pm 22$ & $85 \pm 26$ \\
\hline$>100$ beats $/ \mathrm{min}-$ no $(\%)$ of patients & $54(15.2)$ & 78 (21.9) \\
\hline Body-mass index $-\mathrm{Kg} / \mathrm{m}^{2}$ & $27.1 \pm 4.9$ & $27.3 \pm 5.2$ \\
\hline \multicolumn{3}{|l|}{ Blood pressure $-\mathrm{mmHg}$} \\
\hline Systolic & $141 \pm 20.6$ & $143 \pm 24.7$ \\
\hline Diastolic & $79 \pm 10.8$ & $83 \pm 13.7$ \\
\hline \multicolumn{3}{|l|}{ Echocardiographic findings } \\
\hline Size of left atrium, long axis $-\mathrm{mm}$ & $42 \pm 6$ & $43 \pm 8$ \\
\hline Left ventricular end-diastolic diameter - mm & $49 \pm 6$ & $49 \pm 6$ \\
\hline Left ventricular end-systolic diameter - mm & $34 \pm 6$ & $34 \pm 6$ \\
\hline Septal thickness - mm & $9 \pm 1$ & $9 \pm 1$ \\
\hline Posterior wall thickness $-\mathrm{mm}$ & $9 \pm 1$ & $9 \pm 1$ \\
\hline Left ventricular ejection fraction - \% & $57 \pm 10$ & $56 \pm 12$ \\
\hline
\end{tabular}

+ $\mathrm{CHADS}_{2}$-score is a stroke risk classification scheme, using a point system ranging from 0 to 6 , to determine the yearly risk index ${ }^{31}$. Congestive heart failure, hypertension, age 75 years or above, and diabetes are assigned one point each. Previous stroke or transient ischemic attack is assigned two points. The score is calculated by summing all points for a patient. 

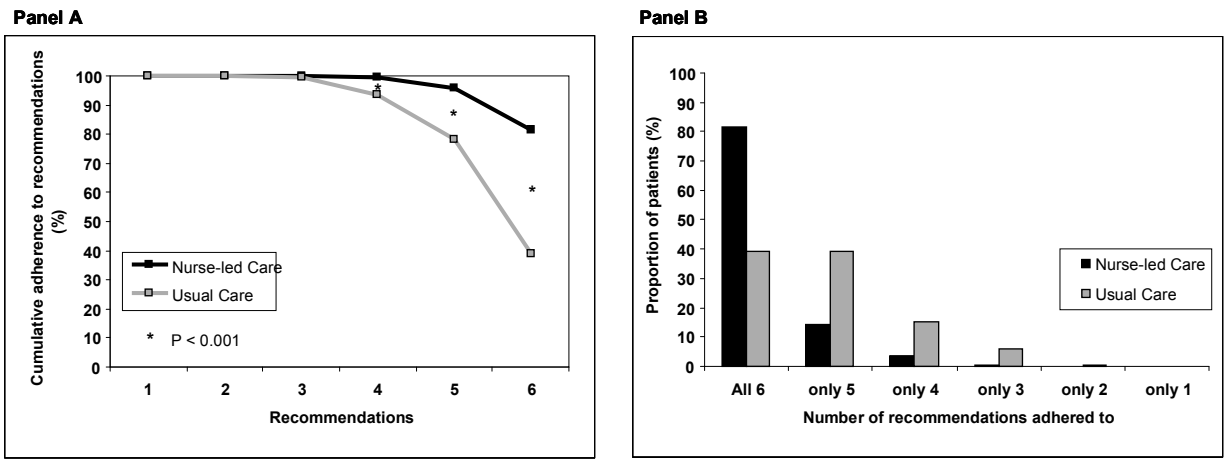

Figure 5.2 Panel A shows the cumulative adherence to 6 guidelines recommendations in the nurse-led care group versus the usual group, see text for details concerning recommendations tested. $P$-values represent statistical differences concerning guidelines implementation between the 2 groups. Panel B shows the distribution of the proportion of patients adhering to only 1 through all 6 guidelines recommendations in the 2 arms of the study.

\section{Primary outcome}

During a mean follow-up of 22 months, the primary outcome was reached in 125 patients: 51 patients (14.3\%) in the nurse-led care and $74(20.8 \%)$ in the control group (hazard ratio $0.65 ; 95 \% \mathrm{Cl} 0.45$ to 0.93 ) (Table 5.2). After adjustment the hazard ratio was $0.63 ; 95 \% \mathrm{Cl} 0.44$ to 0.90 . Therefore, nurse-led care was superior to usual care with regard to prevention of a composite of cardiovascular hospitalization and mortality. Figure 5.3 shows Kaplan-Meier curves for the estimates of the first occurrence of the primary outcome over time in both groups.

\section{Other outcomes}

The rate of cardiovascular death was significantly lower in the nurse-led care group compared to the usual care group $(1.1 \%$ and $3.9 \%$, respectively, hazard ratio 0.28 ; $95 \% \mathrm{Cl} 0.09$ to 0.85 ) (Table 5.2). Heart failure death was seen in 1 patient in the nurseled care group compared to 4 in usual care. One and 2 patients died suddenly, one and 3 patients had fatal pulmonary embolism and 0 and 3 patients suffered from fatal stroke, in the nurse-led care and usual care groups, respectively. One nurse-led care patient succumbed from subdural haematoma. Fatal gastro-intestinal bleeding and unspecified cardiovascular mortality in a vascular compromized patient occurred in one patient each and only in the usual care group. Also the number of cardiovascular hospitalizations was significantly lower in the nurse-led care group (13.5\% versus $19.1 \%$, respectively, hazard ratio $0.66 ; 95 \% \mathrm{Cl} 0.46$ to 0.96 ). The adjusted hazard ratio is $0.64 ; 95 \% \mathrm{Cl} 0.44$ to 0.93 . Some patients were hospitalized twice or more for cardiovascular reasons leading to a total number of 55 and 87 hospitalizations in the nurse-led care and usual care groups, respectively. In total 453 hospitalisations and 
42 deaths were reported during follow-up, including 269 non-cardiovascular hospitalizations and 24 non-cardiovascular deaths.

Table 5.2 Incidence of the primary outcome and its components according to treatment group.*

\begin{tabular}{lccc}
\hline End Point & $\begin{array}{c}\text { Nurse-led Care } \\
(\mathrm{n}=356)\end{array}$ & $\begin{array}{c}\text { Usual Care } \\
(\mathrm{n}=356)\end{array}$ & $\begin{array}{c}\text { Hazard Ratio ** } \\
(95 \% \mathrm{Cl})\end{array}$ \\
\hline Composite end point & $51(14.3 \%)$ & $74(20.8 \%)$ & $0.65(0.45-0.93)$ \\
& $4(1.1 \%)$ & $14(3.9 \%)$ & $0.28(0.09-0.85)$ \\
Cardiovascular death & $1(0.3 \%)$ & $2(0.6 \%)$ & \\
Cardiac arrhythmic & $1(0.3 \%)$ & $4(1.1 \%)$ & \\
Cardiac non-arrhythmic & $2(0.6 \%)$ & $8(2.3 \%)$ & \\
Vascular non-cardiac & & & \\
& $48(13.5 \%)$ & $68(19.1 \%)$ & $0.66(0.46-0.96)$ \\
Cardiovascular hospitalization & $18(5.1 \%)$ & $33(9.3 \%)$ & \\
Arrhythmic events & $15(4.2 \%)$ & $23(6.5 \%)$ & \\
$\quad$ Atrial fibrillation & $3(0.8 \%)$ & $7(2.0 \%)$ & \\
$\quad$ Syncope & - & $1(0.3 \%)$ & \\
$\quad$ Sustained ventricular tachycardia & - & $2(0.6 \%)$ & \\
Cardiac arrest & $14(3.9 \%)$ & $19(5.3 \%)$ & \\
Heart failure & $4(1.1 \%)$ & $2(0.6 \%)$ & \\
Acute myocardial infarction & $3(0.8 \%)$ & $5(1.4 \%)$ & \\
Stroke & - & - & \\
Systemic emboli & $6(1.7 \%)$ & $6(1.7 \%)$ & \\
Major bleeding & $3(0.8 \%)$ & $3(0.8 \%)$ & \\
Life-threatening effects of drugs & &
\end{tabular}

* The tabulation of the composite primary outcome includes the first event for each patient, whereas the tabulations of component events include all such events. ** Hazard ratios from the univariate analysis.

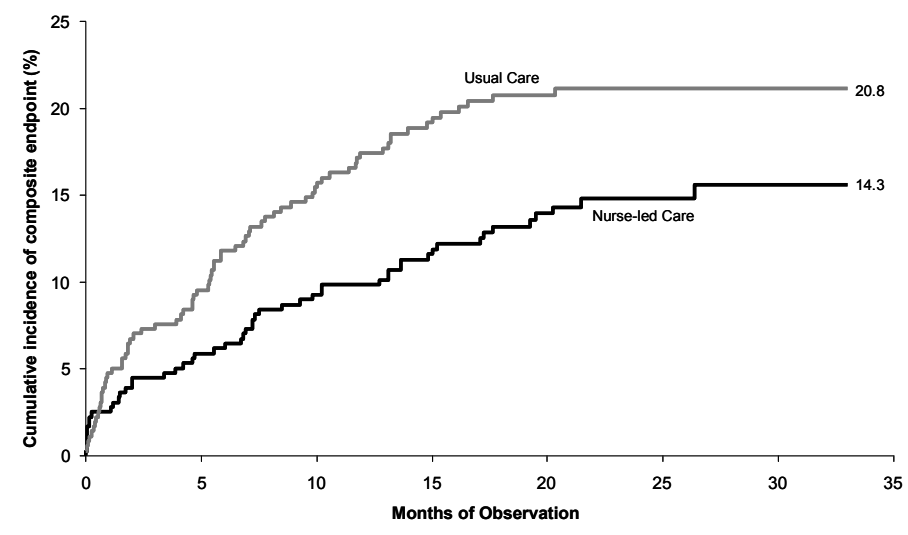

No. At Risk

NLC $\quad 356$

UC $\quad 356$

355

323

285

229

126

55

$321 \quad 300$

265

206

107

$37 \quad 3$

Figure 5.3 Kaplan-Meier estimates of the cumulative incidence of the primary outcome in both groups. The primary outcome is a composite of the first occurrence of cardiovascular hospitalization or cardiovascular death. NLC denotes nurse-led care and UC usual care. 
The hazard ratios and their 95\% confidence intervals for the treatment effect on the primary outcome according to subgroups are presented in Figure 5.4. It shows that the relative effect between nurse-led care and usual care was consistent among subgroups, with the exception of female patients.

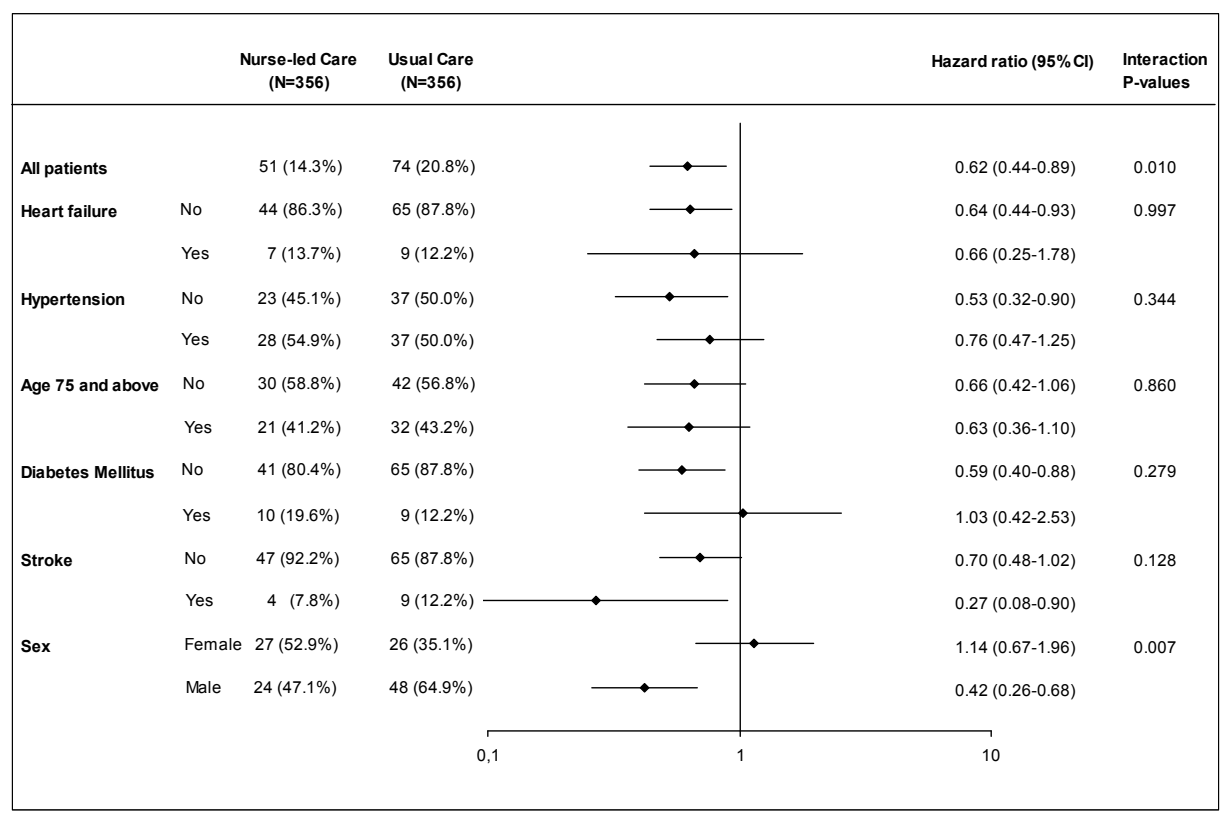

Figure 5.4 Hazard ratios and their 95\% Confidence Intervals $(\mathrm{Cl})$ of the treatment effect on the primary outcome according to subgroups. See text for details.

\section{DISCUSSION}

We compared nurse-led care with usual care for stable patients with AF in the outpatient setting. Nurse-led care was associated with a higher relative efficacy with respect to prevention of the composite of cardiovascular death and cardiovascular hospitalization. The primary outcome occurred in $14.3 \%$ of patients with nurse-led care compared to $20.8 \%$ when usual care was delivered. The relative risk reduction of $35 \%$ by nurse-led care was substantial and represents the combined beneficial effects of our disease management system. Nurse-led care patients were better informed about their disease and its management. Also, guidelines recommendations were more comprehensively implemented in the intervention group representing the impact of the decision support software we used.

To the best of our knowledge this is the first large outcomes study in nurse-led care for patients with AF. In a pilot study, Inglis et al. suggested that a nurse-led, 
multidisciplinary home-based-intervention - using a heart failure algorithm - reduces hospital readmission and mortality in patients with AF but results were only convincing in the subset with heart failure ${ }^{16}$. Obviously, this may relate to low number of patients, but also to lack of an integrated approach specifically directed to AF. Even though we included on average less sick patients who were not recently discharged from the hospital like in the study by Inglis et al., we still were able to demonstrate favourable effects of our intervention.

The rate of the primary endpoint was lower than expected. Nevertheless, we were able to show superiority of nurse-led care because of a slightly larger than expected relative risk reduction in outcome events in the intervention group. The rate of the primary endpoint was also lower than in previous reports with a similar composite endpoint ${ }^{17,18}$, presumably because we included stable patients and did not exclusively select high risk patients. Nonetheless, nurse-led care retained its beneficial effects in complex AF patients since our post-hoc analysis shows that it is effective in elderly with heart failure and previous stroke (Figure 5.4). However, the trend in favour of nurse-led care was not seen in female patients (interaction $P$-value 0.007). Female patients had similar characteristics at baseline, a similar level of knowledge of their disease and similar implementation of guideline recommendations compared to male patients (data not shown). All the same, compared to men, women receiving usual care had a relatively low event rate for which we lack an explanation but which may have been a matter of chance. Similarly, the trend in favour of nurse-led care in patients with diabetes did not seem as strong as compared to the other medical conditions in the analysis but the number of events was low and the interaction appeared non-significant. Of note, all of these post-hoc subanalyses should be interpreted with caution for low numbers of patients per subgroup.

Atrial fibrillation is a complex condition and frequently associated with admissions for stroke, heart failure and $A F$, as well as cardiovascular death ${ }^{17,18}$. Also in the present study the composite primary endpoint was driven by these clinical events. Rhythm control is not helpful in this respect ${ }^{19,20}$, although dronedarone may be an exception ${ }^{18}$. In stead, comprehensive management of underlying cardiovascular disease should come first ${ }^{21,22}$. Nevertheless, rhythm control is often applied when not indicated ${ }^{23}$. Even attaining the optimal heart rate in permanent AF may be difficult, and expectedly - recent new data will not find their way easily into clinical practice ${ }^{24,25}$. Also, many patients in whom AF is associated with heart failure do not receive recommended drug treatment ${ }^{6}$. We reasoned that - like in other chronic conditions ${ }^{26}$ - the use of an electronic patient record with incorporated dedicated decision support software based on the guidelines may downsize complexity and improve adherence to recommendations. In addition, a multi-disciplinary approach in which cardiologists and nurses work closely together and have to justify reciprocally deviations from the protocol may largely preclude treatment decisions which do not comply with the guidelines. Moreover, using an electronic patient record in the outpatient setting challenges information transfer between multiple care providers, and medication 
safety $^{27,28}$. The outcomes of the present study justify the notion that like in the aviation industry, modern medicine benefits from protocolized procedures and presence of a co-pilot, thereby preventing medical accidents. From the present study we cannot tell whether straightforward application of checklists by stand-alone cardiologists would have yielded the same results as nurse-led co-piloted care, but for now it seems appropriate to strongly advocate the use of checklists whatever the care program type.

The American Heart Association developed an eight domain classification system for disease management programs for chronic diseases ${ }^{29}$. AF is such a chronic condition. We studied the effects of disease management in consecutive stable outpatients with electrocardiographically documented AF. Key to the success of our approach, we believe, was the comprehensive intervention focusing on patient education, reassurance, prophylactic measures guided by electronic decision support based on the guidelines, time spent with the patients, and the teamwork between the nurse specialist and the cardiologist. These elements are essential in the Chronic Care Model on which we based our intervention ${ }^{11,13}$. The relative contribution of the different elements to lowering the composite primary endpoint is difficult to establish, but most tangible is the improved adherence to guidelines recommendations (Figure 5.2). Presumably, the intervention content may improve from involving general practitioners' practices and intensifying education and peer support for patients. Novel communication systems may further ameliorate morbidity in AF but results may be disappointing - if used too much in isolation - as was recently the case with telemonitoring for heart failure ${ }^{30}$. From the above it is clear that disease management programs trigger costs which relates among others to increased time spent with the patients. The latter was also the case in the present study. However, in the end these systems also save costs by preventing complications and hospitalizations. Obviously, it is this balance which will drive decisions to implement disease management systems like that presented here for AF.

\section{Study Limitations}

The mechanisms through which the beneficial effect of nurse-led AF care was obtained are not immediately clear. Traditionally, stroke prevention using antithrombotic drugs has received much attention, including the major bleedings associated with it. Implementation of appropriate antithrombotic treatment was indeed more comprehensive in the nurse-led care group, but that did not lead to significantly fewer strokes and expectedly also not to fewer major bleeds. On the other hand, the enhanced implementation of appropriate antithrombotic treatment may have contributed to fewer vascular deaths. Nevertheless, our findings must be interpreted with caution, also because they derive from cardiology practice and may not hold for the general AF population. 


\section{CONCLUSION}

Nurse-led care for stable atrial fibrillation is superior to usual care in terms of major clinical events. These findings should trigger disease management for atrial fibrillation similar to other chronic cardiovascular conditions like heart failure and diabetes. 


\section{REFERENCES}

1. Go AS, Hylek EM, Philips KA, Chang YC, Henault LE, Selby JV, Singer DV. Prevalence of diagnosed atrial fibrillation in adults: national implications for rhythm management and stroke prevention: the AnTicoagulation and Risk Factors in Atrial Fibrillation (ATRIA) study. JAMA 2001;285:2370-5.

2. Fuster V, Rydén LE, Cannom DS, Crijns HJ, Curtis AB, Ellenbogen KA, Halperin JL, Le Heuzey JY, Kay GN, Lowe JE, Olsson SB, Prystowsky EN, Tamargo JL, Wann S; Task Force on Practice Guidelines, American College of Cardiology/American Heart Association; Committee for Practice Guidelines, European Society of Cardiology; European Heart Rhythm Association; Heart Rhythm Society. ACC/AHA/ESC 2006 Guidelines for the management of patients with atrial fibrillation - executive summary: a report of the American College of Cardiology / American Heart Association Task Force on Practice Guidelines and the European Society of Cardiology Committee for Practice Guidelines (Writing Committee to revise the 2001 guidelines for the management of patients with atrial fibrillation). Eur Heart $J$ 2006;27:1979-2030.

3. LeHeuzey JY, Paziaud O, Piot O, Said MA, Copie X, Lavergne T, Guize L. Cost of care distribution in atrial fibrillation patients: the COCAF study. Am Heart J 2004;147:121-6.

4. Stewart S, Murphy NF, Walker A, McGuire A, McMurray JJ. Cost of an emerging epidemic: an economic analysis of atrial fibrillation in the UK. Heart 2004;90:286-92.

5. Ringborg A, Nieuwlaat R, Lindgren P, Jönsson B, Fidan D, Maggioni AP, Lopez-Sendon J, Stepinska J, Cokkinos DV, Crijns HJ. Costs of atrial fibrillation in five European countries: results from the Euro Heart Survey on Atrial Fibrillation. Europace 2008;10:403-11.

6. Nieuwlaat R, Eurlings LW, Cleland JG, Cobbe SM, Vardas PE, Capucci A, López-Sendòn JL, Meeder JG, Pinto YM, Crijns HJ. Atrial fibrillation and heart failure in cardiology practice: reciprocal impact and combined management from the perspective of atrial fibrillation: results of the Euro Heart Survey on atrial fibrillation. J Am Coll Cardiol 2009;53:1690-8.

7. Waldo AL, Becker RC, Tapson VF, Colgan KJ; NABOR Steering Committee. Hospitalized patients with atrial fibrillation and a high risk of stroke are not being provided with adequate anticoagulation J Am Coll Cardiol 2005;46:1729-36.

8. Rich MW, Beckham V, Wittenberg C, Leven CL, Freedland KE, Carney RM. A multidisciplinary intervention to prevent the readmission of elderly patients with congestive heart failure. N Engl J Med 1995;333:1190-5.

9. Phillips CO, Wright SM, Kern DE, Singa RM, Shepperd S, Rubin HR. Comprehensive discharge planning with postdischarge support for older patients with congestive heart failure: a meta-analysis. JAMA 2004;291:1358-67.

10. Hendriks JML, Nieuwlaat R, Vrijhoef HJM, de Wit R, Crijns HJGM, Tieleman RG. Improving guideline adherence in the treatment of atrial fibrillation by implementing an integrated chronic care program. Neth Heart J 2010;18:471-6.

11. Hendriks JML, de Wit R, Vrijhoef HJM, Tieleman RG, Crijns HJGM. An integrated chronic care program for patients with atrial fibrillation: study protocol and methodology for an ongoing prospective randomised controlled trial. Int J Nurs Stud 2010;47:1310-6.

12. Wagner EH, Austin BT, Von Korff M. Organizing care for patients with chronic illness. Millbank Q 1996;74:511-44.

13. Wagner EH, Austin BT, Davis C, Hindmarsh M, Schaefer J, Bonomi A. Improving chronic illness care: translating evidence into action. Health Aff (Millwood) 2001;20:64-78.

14. Hinkle LE Jr, Thaler HT. Clinical classification of cardiac deaths. Circulation 1982;65:457-64.

15. van der Wal MH, Jaarsma T, Moser DK, Van Veldhuisen DJ. Development and testing of the Dutch Heart Failure Knowledge Scale. Eur J Cardiovasc Nurs 2005;4:273-7. 
16. Inglis S, McLennan S, Dawson A, Birchmore L, Horowitz JD, Wilkinson D, Stewart S. A new solution for an old problem? Effects of a nurse-led, multidisciplinary, home-based intervention on readmission and mortality in patients with chronic atrial fibrillation. $J$ Cardiovasc Nurs 2004;19:118-27.

17. Nieuwlaat R, Prins MH, Le Heuzey JY, Vardas PE, Aliot E, Santini M, Cobbe SM, Widdershoven JW, Baur LH, Lévy S, Crijns HJ. Prognosis, disease progression and treatment of atrial fibrillation patients during 1 year: follow-up of the Euro Heart Survey on atrial fibrillation. Eur Heart J 2008;29:1181-9.

18. Hohnloser SH, Crijns HJ, van Eickels M, Gaudin C, Page RL, Torp-Pedersen C, Connolly SJ; ATHENA Investigators. Effects of dronedarone on cardiovascular events in atrial fibrillation. N Engl J Med 2009;360:668-78.

19. Van Gelder IC, Hagens VE, Bosker HA, Kingma JH, Kamp O, Kingma T, Said SA, Darmanata JI, Timmermans AJ, Tijssen JG, Crijns HJ; Rate Control versus Electrical Cardioversion for Persistent Atrial Fibrillation Study Group. A comparison of rate control and rhythm control in patients with recurrent persistent atrial fibrillation. $N$ Engl J Med 2002; 347:1834-40.

20. Wyse DG, Waldo AL, DiMarco JP, Domanski MJ, Rosenberg Y, Schron EB, Kellen JC, Greene HL, Mickel MC, Dalquist JE, Corley SD; Atrial Fibrillation Follow-up investigators of Rhythm Management (AFFIRM) investigators. A comparison of rate control and rhythm control in patients with atrial fibrillation. N Engl J Med 2002;347:1825-33.

21. Nieuwlaat R, Olsson SB, Lip GY, Camm AJ, Breithardt G, Capucci A, Meeder JG, Prins MH, Lévy S, Crijns HJ; Euro Heart Survey Investigators. Guideline-adherent antithrombotic treatment is associated with improved outcomes compared with undertreatment in highrisk patients with atrial fibrillation: the Euro Heart Survey on Atrial Fibrillation. Am Heart J 2007;153:1006-12.

22. Du X, Ninomiya T, de Galan B, Abadir E, Chalmers J, Pillai A, Woodward M, Cooper M, Harrap S, Hamet P, Poulter N, Lip GY, Patel A; ADVANCE Collaborative Group. Risks of cardiovascular events and effects of routine blood pressure lowering among patients with type 2 diabetes and atrial fibrillation: results of the ADVANCE study. Eur Heart $J$ 2009;30:1128-35.

23. Nieuwlaat R, Capucci A, Camm AJ, Olsson SB, Andersen JL, Davies DW, Cobbe S, Breithardt G, Le Heuzey JY, Prins MH, Lévy S, Crijns HJ; Euro Heart Survey Investigators. Atrial fibrillation management: a prospective survey in ESC member countries: the Euro Heart Survey on Atrial Fibrillation. Eur Heart J 2005;26:2422-34.

24. Van Gelder IC, Groenveld HF, Crijns HJ, Tuininga YS, Tijssen JG, Alings AM, Hillege HL, Bergsma-Kadijk JA, Cornel JH, Kamp O, Tukkie R, Bosker HA, Van Veldhuisen DJ, Van den Berg MP; RACE II Investigators. Lenient versus strict rate control in patients with atrial fibrillation. N Engl J Med 2010;362:1363-73.

25. Van Gelder IC, Wyse DG, Chandler ML, Cooper HA, Olshansky B, Hagens VE, Crijns HJ; RACE and AFFIRM Investigators. Does intensity of rate-control influence outcome in atrial fibrillation? An analysis of pooled data from the RACE and AFFIRM studies. Europace 2006;8:935-42.

26. Coleman K, Austin BT, Branch C, Wagner EH. Evidence on the chronic care model in the new millennium. Health Aff 2009;28:75-85.

27. Gandhi TK, Lee TH. Patient safety beyond the hospital. N Engl J Med 2010;363:1001-3.

28. Katon WJ, Lin EH, Von Korff M, Ciechanowski P, Ludman EJ, Young B, Peterson D, Rutter $\mathrm{CM}$, McGregor M, McCulloch D. Collaborative care for patients with depression and chronic illnesses. N Engl J Med 2010;363:2611-20. 
29. Krumholz HM, Currie PM, Riegel B, Phillips CO, Peterson ED, Smith R, Yancy CW, Faxon DP; American Heart Association Disease Management Taxonomy Writing Group. A taxonomy for disease management: a scientific statement from the American Heart Association Disease Management Taxonomy Writing Group. Circulation 2006;114:1432-45.

30. Chaudhry SI, Mattera JA, Curtis JP, Spertus JA, Herrin J, Lin Z, Phillips CO, Hodshon BV, Cooper LS, Krumholz HM. Telemonitoring in patients with heart failure. $N$ Engl J Med 2010;363:2301-9.

31. Gage BF, Waterman AD, Shannon W, Boechler M, Rich MW, Radford MJ. Validation of clinical classification schemes for predicting stroke: results form the National Registry of Atrial Fibrillation. JAMA 2001;285:2864-70. 


\section{SECTION [II}

Quality of life and cost-effectiveness 



\section{CHAPTER 6}

The impact of a nurse-led integrated chronic care approach on quality of life in patients with atrial fibrillation

Jeroen ML Hendriks, Hubertus JM Vrijhoef, Harry JGM Crijns, Hans Peter Brunner-La Rocca

Submitted 


\section{ABSTRACT}

Aims. Quality of life (QoL) is often impaired in patients with atrial fibrillation (AF). A novel nurse-led integrated chronic care approach demonstrated superiority compared to usual care in terms of cardiovascular hospitalization and mortality. Consequently, we hypothesized that this approach may also improve QoL and AF-related knowledge, which in turn may positively correlate with QoL.

Methods and results. In this randomized controlled trial, 712 patients were randomly assigned to nurse-led care versus usual care. Nurse-led care consisted of guidelinebased, software supported care, supervised by cardiologists. Usual care was provided by cardiologists in the regular outpatient setting. QoL was assessed by means of the Medical Outcomes Study 36-Item Short Form Survey Instrument (SF-36). The Hospital Anxiety and Depression Scale (HADS) was used to assess anxiety and depression scores. The AF Knowledge Scale was used to gain insight in patients' AF-knowledge levels. Baseline QoL scores were relatively high in both groups. QoL significantly improved over time in both groups with no significant differences between both groups. AF-related knowledge improved over time and was significantly higher at follow-up in the intervention group, compared to the usual care group ( $8.23 \pm 2.16$ vs. $7.66 \pm 2.09 P<0.05)$.

Conclusion. QoL including anxiety and depression improved over time, regardless of treatment group. The AF-related knowledge level was better in the nurse-led care group at follow-up.

Trial registration information: Clincaltrials.gov identifier number NCT00753259. 


\section{INTRODUCTION}

Atrial fibrillation (AF) is the most common arrhythmia in the Western world, occurring in $1-2 \%$ of the general population and increasing with age. Recurrences are common in patients with AF and consequently it is considered as a chronic condition ${ }^{1,2}$. The clinical impact differs among patients, depending on the arrhythmia pattern and presence of related symptoms ${ }^{3}$, but many patients are highly symptomatic (e.g. palpitations, chest pain, shortness of breath, fatigue $)^{4}$. Symptoms are often accompanied by anxiety and depression as well as reduced quality of life $e^{5,6}$. Anxiety and depression can further impair quality of life $(\mathrm{Q} o \mathrm{~L})^{7,8}$, with depression reported as the strongest independent predictor of QoL in AF patients ${ }^{5}$.

Patients with AF have a poorer QoL compared to healthy controls, the general population and even patients with coronary heart disease ${ }^{9}$. However, most studies focussed on highly selected patients undergoing interventional procedures, AF-related surgery or pharmacologic therapy. QoL in a more 'general' AF population, however, has only been assessed scarcely ${ }^{9}$.

Furthermore, AF management is often not adequate ${ }^{10,11}$, although improved QoL was seen by applying appropriate rate or rhythm control, respectively ${ }^{9}$. Significantly better QoL has been demonstrated in patients with controlled versus uncontrolled $\mathrm{AF}^{12}$, mainly due to fewer symptoms and prevention of complications ${ }^{13}$.

In the Maastricht University Medical Centre, we developed a novel integrated chronic care program for patients with $\mathrm{AF}^{14}$, aiming to provide appropriate management according to current AF guidelines ${ }^{2}$. This program, based on the Chronic Care Model ${ }^{15}$ consists of a nurse-led, guideline-based, software supported outpatient clinic. In a randomized controlled effectiveness trial, we recently demonstrated superiority of this program in terms of cardiovascular hospitalization and death, and guideline adherent management compared to usual care ${ }^{16}$.

This study evaluated $\mathrm{QoL}$ in an all-comer AF population and the impact of the integrated approach thereon, including anxiety and depression, and AF-related knowledge. We hypothesized that this approach may improve QoL, including anxiety and depression, and AF-related knowledge, compared to the usual care group.

\section{METHODS}

\section{Study design and participants}

This study was performed in patients who participated in the AF effectiveness trial ${ }^{16}$. In this randomized controlled trial, 712 patients with newly diagnosed AF were included and randomized to nurse-led care versus usual care. All patients $\geq 18$ years referred for AF - documented on electrocardiogram - to our outpatient department, were eligible for the study. Patients were excluded for the study in case of any unsatisfactorily treated co-morbidity (e.g. uncontrolled hypertension or unstable 
heart failure for which patients were treated by a physician $<3$ months before inclusion, untreated hyperthyroidism or $<3$ months euthyroidism, current or foreseen pacemaker, internal cardioverter defibrillator, and/or cardiac resynchronisation therapy, cardiac surgery $<3$ months before inclusion). Follow-up was at least one year. The design of the trial has been previously described in more detail ${ }^{14}$. The trial took place at the Maastricht University Medical Centre, the Netherlands. Ethical approval was obtained from the Institutional Review Board. The study was registered at Clinicaltrials.gov (identifier: NCT00753259).

\section{Procedures}

Patients allocated to the nurse-led care, underwent protocolized diagnostic procedures prior to their first visit to the outpatient clinic. A nurse specialist then took the patients' medical history and extensively informed the patient about the arrhythmia, symptoms and possible complications as well as results of diagnostic tests and treatment options. The nurse specialist was supervised by a cardiologist, who saw the patient and supervised the nurse specialist at the end of the first consultation to approve medical diagnosis - suggested by dedicated software, i.e. Cardio Consult $\mathrm{AF}^{\circledR}{ }^{14}$ - and to start treatment. The software was based on the then prevailing $\mathrm{ACC} / \mathrm{AHA} / \mathrm{ESC}$ guidelines for $\mathrm{AF}^{4}$ to ensure comprehensive management of $\mathrm{AF}$ and its associated co-morbidity. Visits to the nurse specialist were scheduled for 30 minutes and follow-up visits were planned at 3, 6 and 12 months. Patients in the usual care group received care from a cardiologist in the outpatient clinic, who neither collaborated with the nurse specialist nor used the software program. Visits to the cardiologist were scheduled 20 minutes for a first consultation and 10 minutes for follow-up, and were not predefined per protocol. Patient characteristics were assessed in terms of mean age, gender, ethnicity, marital status, highest level of education, type of AF, history of associated diseases and $\mathrm{CHADS}_{2}$-score ${ }^{17}$.

\section{OUTCOMES AND INSTRUMENTATION}

Patients were asked to complete questionnaires at baseline $\left(T_{0}\right)$ and at one year follow-up $\left(T_{1}\right)$ evaluating the following outcomes for this study ${ }^{14}$ :

\section{Quality of life}

QoL was measured by means of the Medical Outcomes Study 36-Item Short Form Survey Instrument (SF-36), a standardized, generic health survey ${ }^{18}$. The SF-36 consists of 36 questions and standardized response choices, which are organized into multiitem scales: physical functioning (PF), social functioning (SF), role limitations due to physical health problems (RP), role limitations due to emotional problems (RE), mental health $(\mathrm{MH})$, vitality (VT), bodily pain (BP), and general health perceptions $(\mathrm{GH})$. The raw item scale scores are recoded and linearly converted to a 0 to 100 point 
scale. Higher scores indicate higher levels of functioning or well-being. Detailed background information on the SF-36 and scoring algorithms are available elsewhere ${ }^{19,20}$. Moreover, SF-36 scores were compared with a Netherlands healthy reference population ${ }^{21,22}$.

\section{Anxiety and depression}

Anxiety and depression was measured by means of the Hospital Anxiety and Depression Scale (HADS) ${ }^{7}$. The questionnaire consists of a 7-item depression scale and a 7-item anxiety scale. The item scores are on a 4-point scale [0-3]. Scores are obtained by summing up the scores of the seven items, accounting values between 0 and 21 . Higher scores indicate worse levels of anxiety and depression and scores $\geq 8$ were considered as diagnostic value ${ }^{7}$.

\section{Patients' knowledge on AF-related topics}

It has been demonstrated that low disease related knowledge is associated with poor QoL in patients with heart failure ${ }^{23}$. To examine if the same holds true regarding AFrelated knowledge and QoL (e.g. AF in general, symptom recognition and, therapy) in patients with $A F$, the recently developed Atrial Fibrillation Knowledge Scale ${ }^{24}$ (AF knowledge scale) was used to gain insight in the patients' AF knowledge levels, and to encourage self-management activities as important factors in managing AF. The questionnaire consists of 11 items concerning $A F$ in general ( 3 items), symptom recognition (3 items), and AF treatment (5 items). For each question patients could choose an answer out of three options, with one being the correct answer. Scores were obtained by summing up the individual item scores, ranging between 0 and 11, and higher scores indicating higher knowledge levels.

\section{Statistical analysis}

Data were retrieved from the CardioConsult $\mathrm{AF}^{\circledR}$ database and imported into SPSS. Data analyses were performed with SPSS, version 20.0 (SPSS, Chicago, Illinois). Demographic characteristics were checked for baseline differences between treatment groups, continuous variables were examined with $t$ test or Mann-Whitney $U$ test, as appropriate, and categorical variables with $\chi^{2}$ tests. Demographic characteristics, as well as scores on QoL, anxiety and depression, and knowledge are described as number and percentage, mean \pm standard deviation (SD) or median and inter quartile range (IQR), as appropriate. Analyses were performed in patients only who completed the questionnaires (SF-36, HADS, and AF Knowledge Scale) both on baseline and after one year follow-up. To score each SF-36 scale, we used Linkert's method for summated rating scales ${ }^{25}$. All scales were linearly transformed to a 0 to 100 scale, with 100 representing the most favourable health state and 0 the least favourable. A missing scale score was allocated if over one-half of the items per scale were missing. If one-half or fewer items were missing, values for the missing items 
were substituted by using the mean of the non-missing items. In case of a single missing item on a subscale of the HADS, the score has been inferred by the mean score of the remaining six items. If more than one item was missing, the subscale was assessed as invalid.

QoL scores were also compared with QoL scores of a Netherlands reference population. The reference population was derived from a national surveys representatives in terms of age and gender ${ }^{21,22}$. Since it has been shown that QoL is dependent on age and gender ${ }^{19}$ we defined these variables, including patients' AFrelated knowledge, as co-variates. Bivariate correlation was used to study possible associations between QoL and age or knowledge. These associations are expressed in Spearman's rank correlation coefficient ( $\mathrm{rs}$ ). To assess correlations between gender and QoL the Mann-Whitney $U$ test was used. $P$-values $<0.05$ were considered statistically significant.

\section{RESULTS}

\section{Patients / population}

Patients ( $n=178$ ) who did not complete the SF-36 at both time points were excluded. These patients were significantly older, and a history of coronary artery disease (including myocardial infarction) was significantly more common compared to patients in analysis (Table 6.1). Quality of life was significantly lower in these patients (Table 6.2).

The present analysis was performed on the remaining 534 patients (75\%). The two treatment groups were well matched for patient baseline characteristics without significant differences (Table 6.1).

\section{Quality of Life}

Baseline QoL scores were relatively high in both groups. Thus, they were only slightly if at all lower than in the general population ${ }^{21,22}$ and were comparable with the general population at follow-up (Figure 6.1). Despite randomization, patients in the nurse-led care had better QoL scores at baseline than the control group, which differed significantly for the subscales physical functioning, role limitations due to physical problems, vitality, bodily pain, and general health (Table 6.3). After one year, significant improvement in subscales of role limitations due to emotional problems $(P=0.004)$, mental health $(P=0.001)$ and vitality $(P=0.008)$ were seen in the intervention group. The latter two also significantly improved in the usual care group (mental health $P=0.002$, vitality $P<0.001$ ), as well as role limitations due to physical problems $(P=0.004)$. Over time, no statistically significant differences were demonstrated between both groups (Table 6.3). 


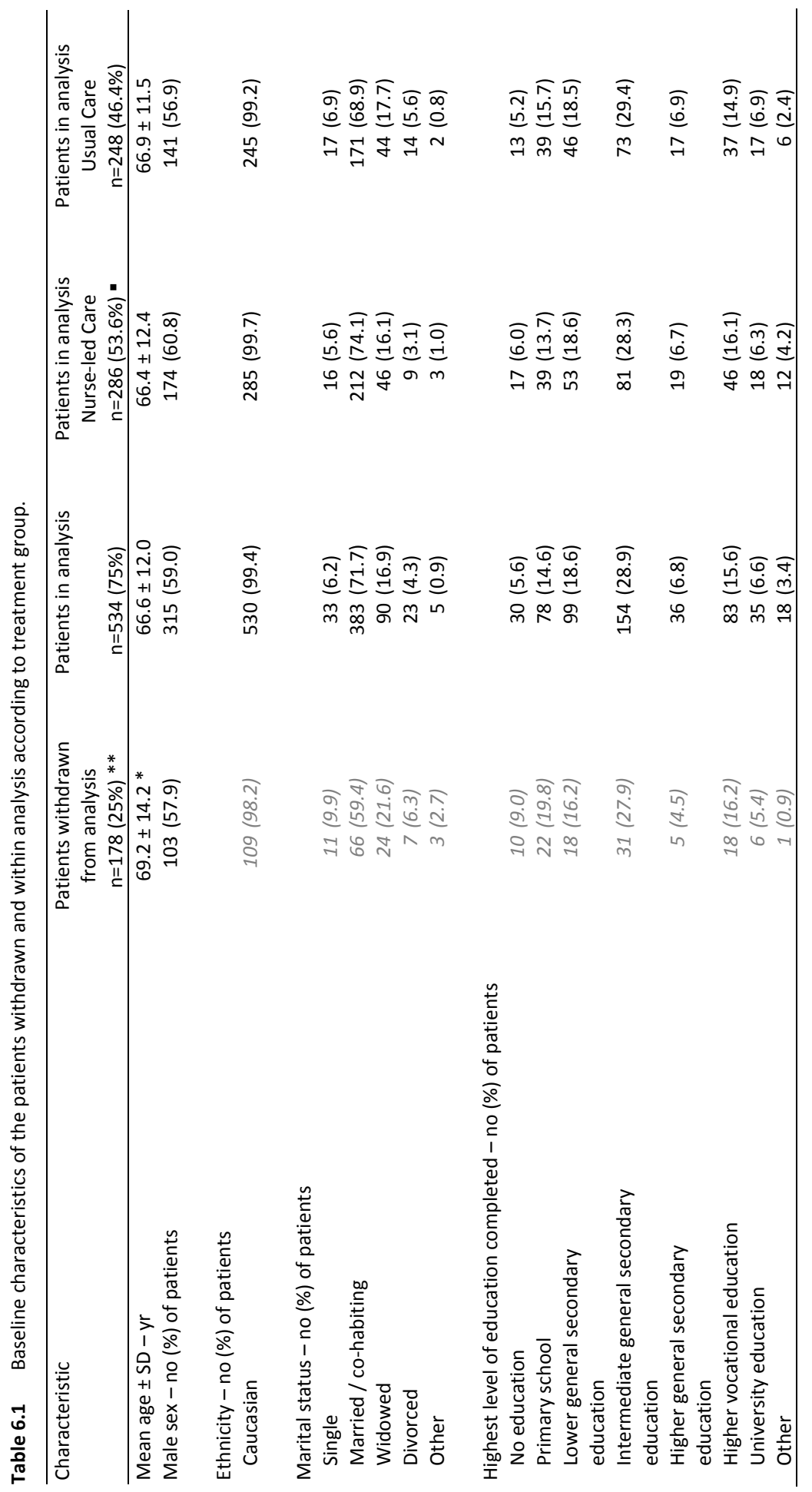




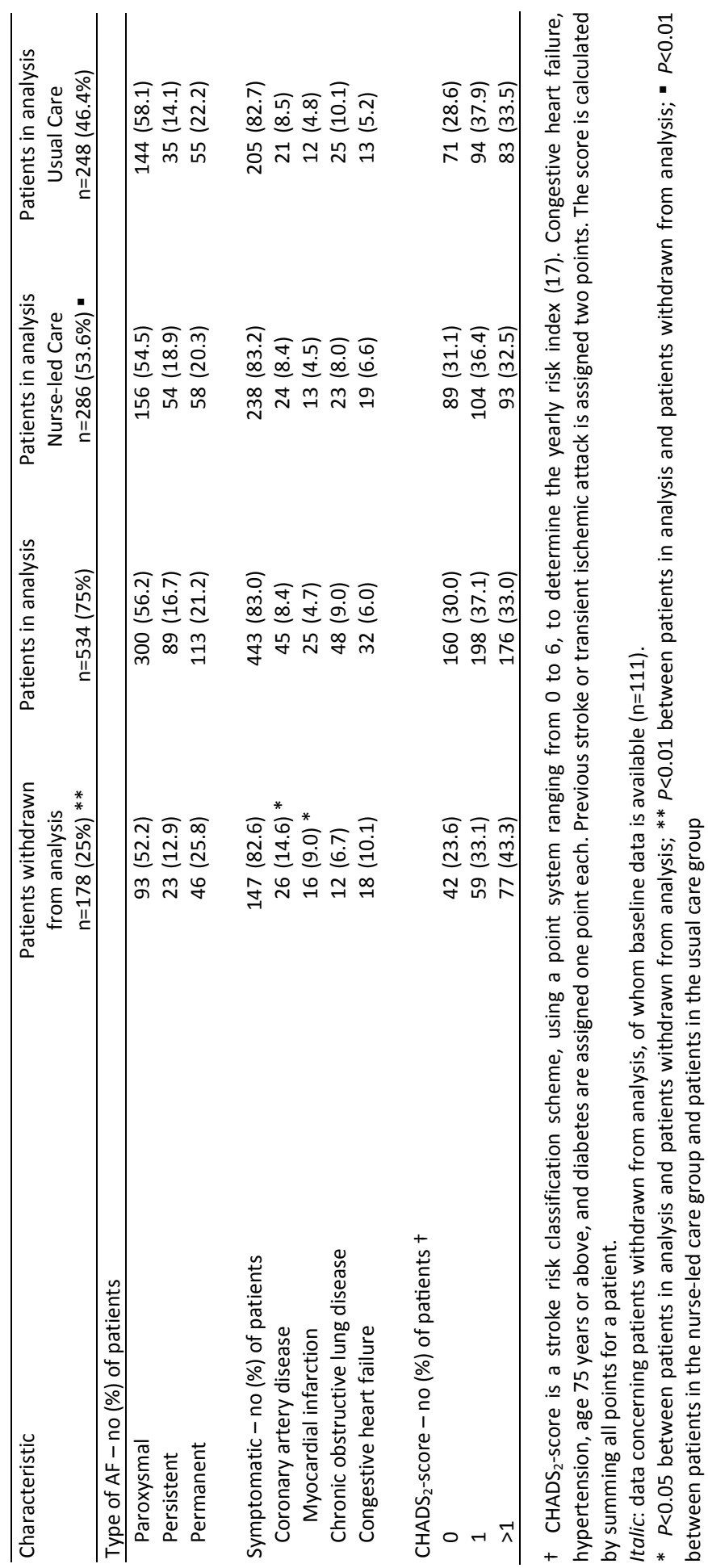




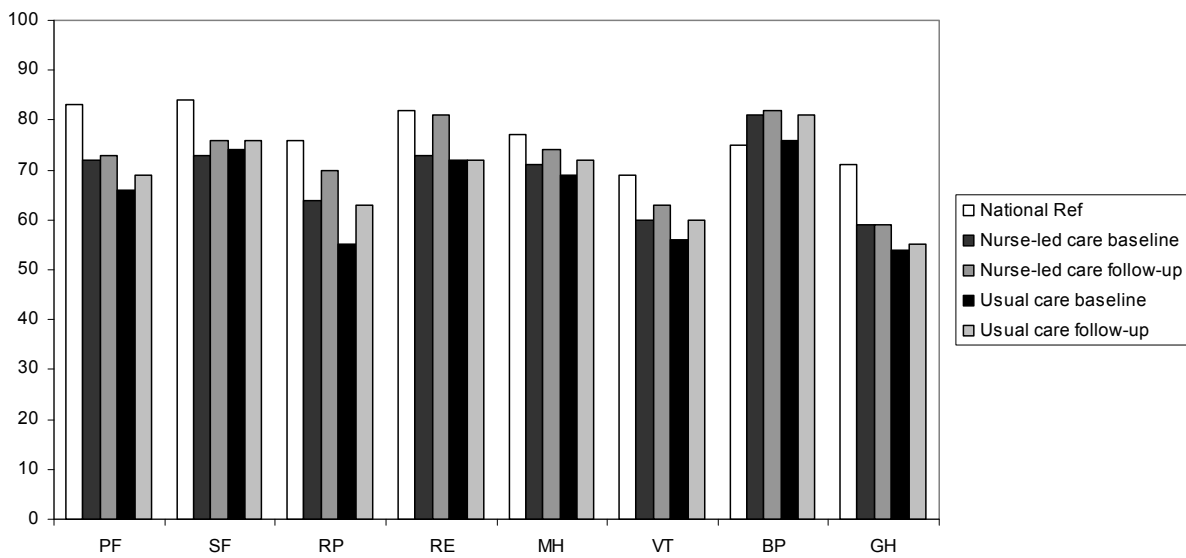

Figure 6.1 Short-Form 36 quality of life scores (expressed in means) of patients in the nurse-led care group and usual care group on baseline and at one year follow-up, compared to the Netherlands healthy reference population ${ }^{21,22}$.

PF: physical functioning; SF: social functioning; RP: role limitations due to physical health problems; RE: role limitations due to emotional problems; $\mathrm{MH}$ : mental health; VT: vitality; BP: bodily pain; $\mathrm{GH}$ : general health perceptions.

Table 6.2 Baseline Short-Form 36 quality of life scores of patients withdrawn from analysis. The right column moreover, provides information regarding the difference in baseline data between patients withdrawn from analysis and patients in whom analysis was performed.

\begin{tabular}{|c|c|c|c|c|}
\hline SF-36 Subscale & Research group & $\begin{array}{c}\text { Baseline } \\
\text { median (IQR) }\end{array}$ & $\begin{array}{l}\text { Difference between } \\
\text { groups at baseline } \\
\text { ( } p \text {-value) }\end{array}$ & $\begin{array}{l}\text { Difference between } \\
\text { groups withdrawn } \\
\text { and within analysis } \\
\text { at baseline ( } P \text {-value) }\end{array}$ \\
\hline \multirow{4}{*}{$\begin{array}{l}\text { Physical } \\
\text { functioning } \\
\text { Social functioning }\end{array}$} & Nurse-led care & $60(35-95)$ & 0.112 & $0.038 *$ \\
\hline & Usual care & $45(20-75)$ & & $0.000 * *$ \\
\hline & Nurse-led care & $75(25-100)$ & 0.567 & 0.270 \\
\hline & Usual care & $63(38-88)$ & & $0.006^{* *}$ \\
\hline \multirow[t]{2}{*}{ Role physical } & Nurse-led care & $0(0-100)$ & 0.994 & $0.001 * *$ \\
\hline & Usual care & $0(0-100)$ & & $0.002 * *$ \\
\hline \multirow[t]{2}{*}{ Role emotional } & Nurse-led care & $100(25-100)$ & 0.191 & 0.815 \\
\hline & Usual care & $100(0-100)$ & & 0.099 \\
\hline \multirow[t]{2}{*}{ Mental health } & Nurse-led care & $72(56-88)$ & 0.273 & 0.906 \\
\hline & Usual care & $64(48-84)$ & & 0.151 \\
\hline \multirow[t]{2}{*}{ Vitality } & Nurse-led care & $45(28-68)$ & 0.995 & $0.005^{* *}$ \\
\hline & Usual care & $45(30-68)$ & & $0.008 * *$ \\
\hline \multirow[t]{2}{*}{ Bodily pain } & Nurse-led care & $78(45-100)$ & 0.626 & $0.007 * *$ \\
\hline & Usual care & $78(55-100)$ & & 0.221 \\
\hline \multirow[t]{2}{*}{ General health } & Nurse-led care & $55(45-65)$ & 0.086 & 0.315 \\
\hline & Usual care & $45(30-63)$ & & 0.019* \\
\hline
\end{tabular}

* $P<0.05 ; * * P<0.01$ 


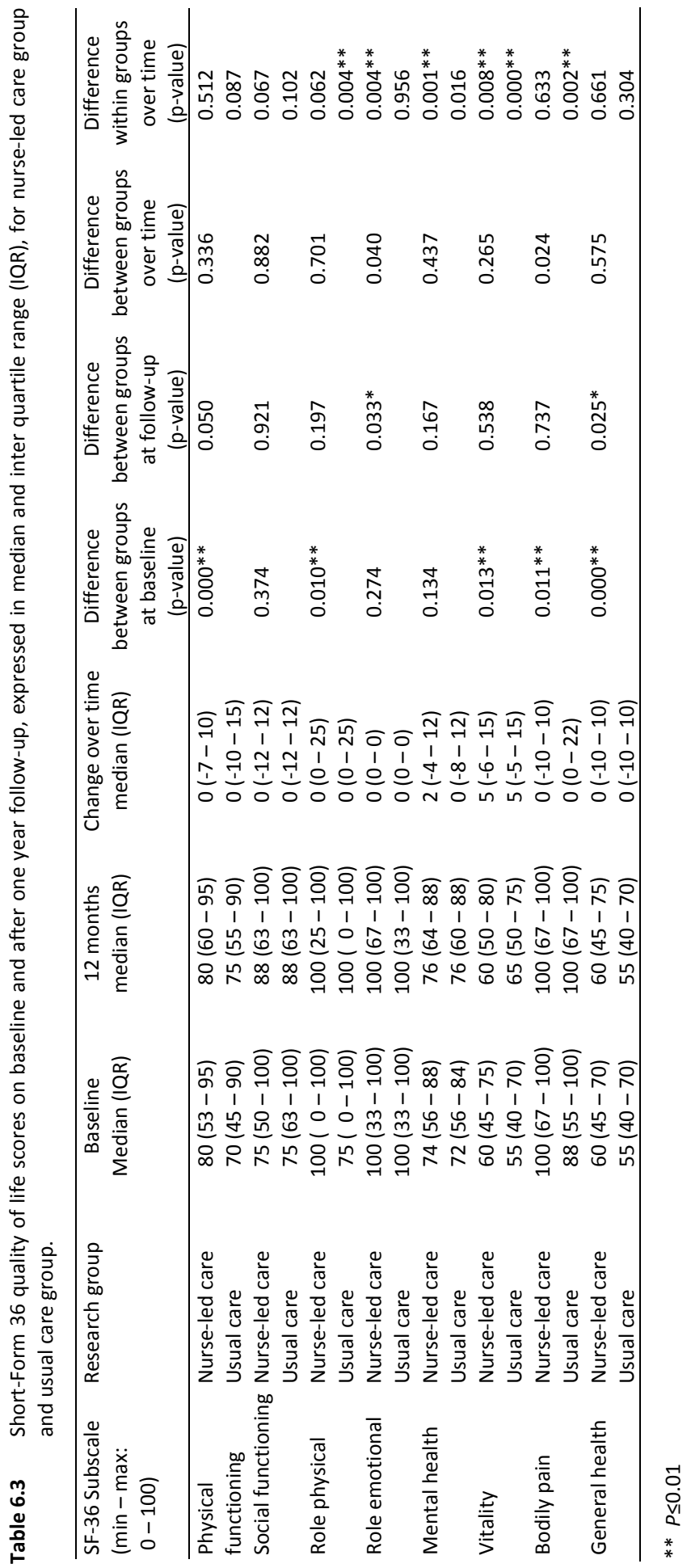




\section{Anxiety and Depression}

At baseline, median scores on anxiety and depression were relatively low and comparable between the two groups. After one year, scores on anxiety decreased significantly $(P \leq 0.001)$ in both groups, while scores on depression remained nearly unchanged. No statistically significant differences for anxiety or depression were demonstrated between both groups over time (Table 6.4).

\section{AF Knowledge}

At baseline, knowledge was comparable between the two groups (Table 6.5). After one year follow-up, knowledge levels significantly improved in both groups.

\section{Correlates of QoL}

All SF-36 subscales positively correlate with each other. Assessment of correlates between patient characteristics and QoL on baseline showed that age was negatively associated with some, but not all QoL domains. Age was associated with anxiety and depression. Women had significantly poorer QoL in all domains, as well as more anxiety and depression. AF-related knowledge on baseline positively correlated with all QoL domains, being statistically significant in the majority of the domains. AFrelated knowledge was negatively associated with anxiety and depression (Table 6.6). 


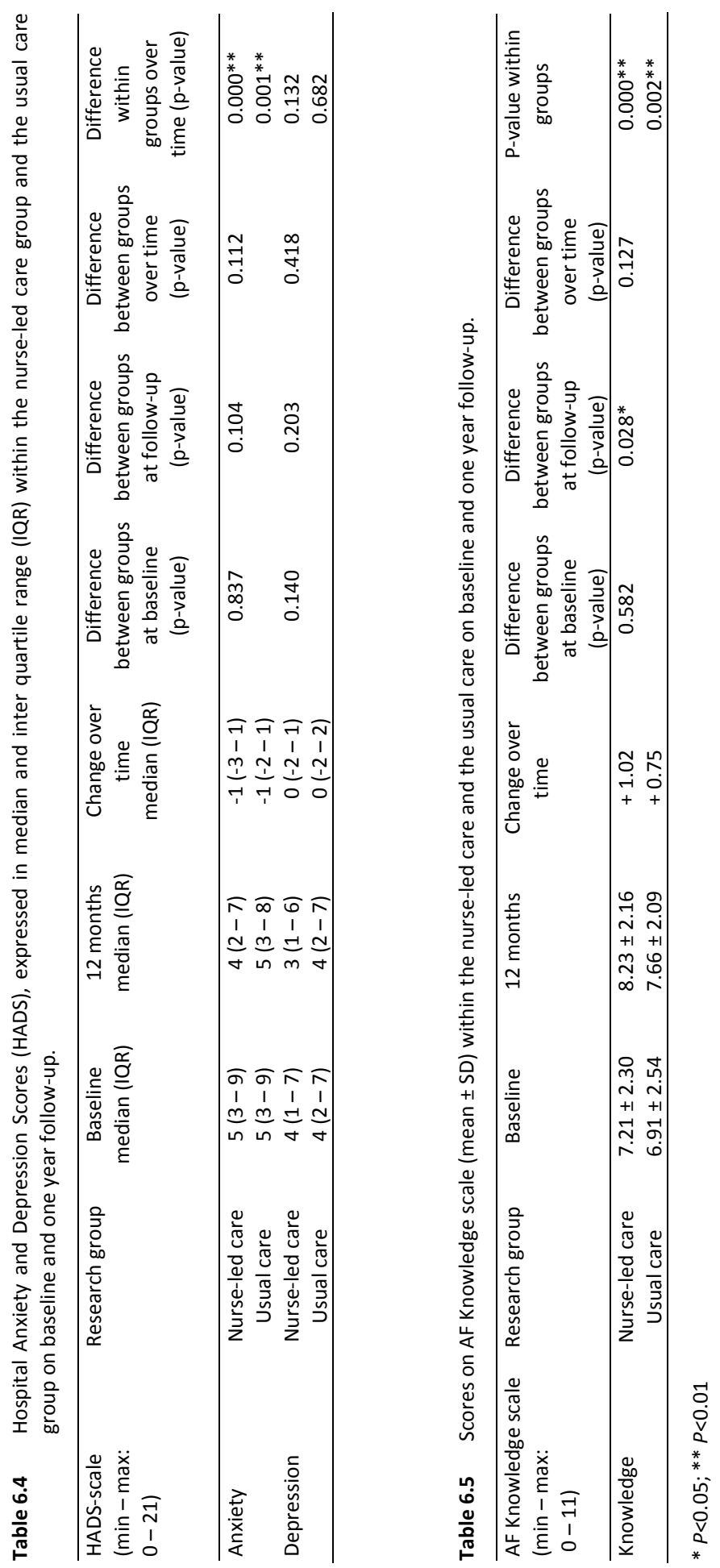




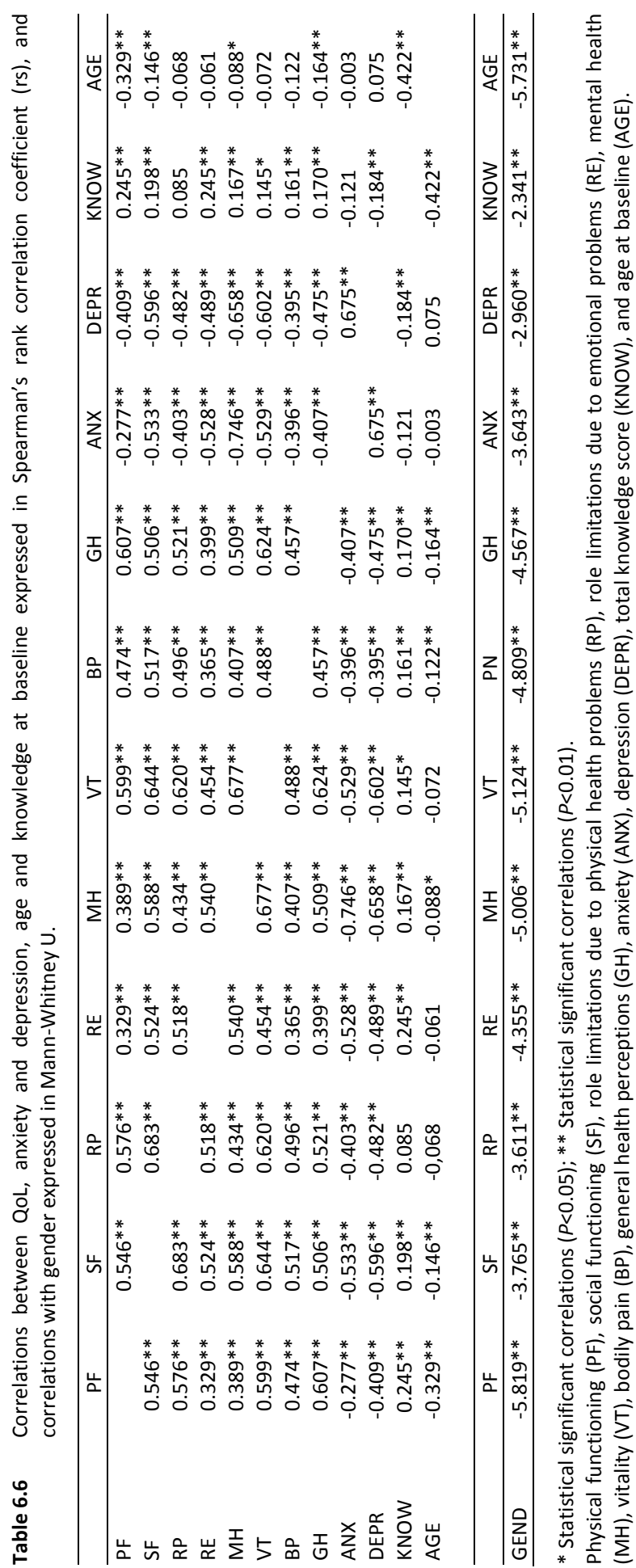




\section{DISCUSSION}

Quality of life was surprisingly good in this population of unselected patients with AF despite the fact that the majority was symptomatic. In fact, it was only slightly worse at baseline than in the general population. QoL significantly improved over time in both groups to levels that were comparable to those seen in the general population in many of the measured domains. This improvement was not influenced by nurse-led care, whereas AF-related knowledge at follow-up was significantly better in this latter group as compared to the usual care group.

Baseline QoL significantly differed in five subscales between both groups, in favour of the nurse-led care. As this is a randomized study, these differences are most likely a matter of chance and might be due some dysbalance in baseline characteristics. Nearly all scales showing differences were related to physical health and patients in the usual care group seem to have experienced worse physical health than those in nurse-led care. Though not statistically significantly different, baseline characteristics in the usual care group demonstrated a somewhat higher proportion of disabling diseases such as stroke/TIA and COPD, also resulting in slightly higher $\mathrm{CHADS}_{2}$-scores. Moreover, more women tended to be present in this group who had significantly worse QoL than men. This is in line with prior research, where women experienced more symptoms of psychological distress to related cardiovascular disease compared to men, resulting in poorer QoL ${ }^{26-28}$. In ICD research, an explanation for this might be found in the fact that women are more concerned about body image, shifts in role responsibilities, and changes in physical functioning ${ }^{29}$, but may also have more attention to weak or diffuse bodily attention ${ }^{30}$. Obviously, this may affect physical health in patients, and is possibly the case in this study.

Over time, scores on the physical health related subscales improved. This is not surprising, since AF treatment reduces symptoms and increases physical capacity in patients ${ }^{3}$. Improvement tended to be more in the usual care group, but baseline scores on these subscales were already high in the nurse-led care group. Thus, to some extent, this may be seen as regression to the mean, but may be also related to the fact that QoL could hardly further improve in the nurse-led group. With respect to anxiety and depression scores, a significant reduction in anxiety over time could be demonstrated in both groups. Moreover, depression scores only decreased significantly in the nurse-led care group while scores in the usual care group remained unchanged. Still, the change over time did not differ significantly between the groups. Moreover, knowledge was better in the former group. Thus a nurse-led integrated approach, focussing on patient education, might improve knowledge in patients while reducing depression. The role of the nurse specialist is considered to be vital in terms of counselling and reassuring by focussing on patient education and selfmanagement ${ }^{24}$. Prior to the analyses, we had hypothesized the nurse-led integrated care approach as a positive contribution to patients' QoL, in comparison with the usual care setting where dedicated time and competencies are often lacking to 
perform these activities. Patients in this study represent a more 'general' AF population who are not pre-selected with respect to interventional, surgical or pharmaceutical therapy. This in contrast to AF populations in whom QoL has been studied before ${ }^{9,31-33}$. Moreover, our population is considered a relatively 'healthy' population, with relatively low $\mathrm{CHADS}_{2}$-scores ${ }^{17}$, a moderate history of associated diseases and co-morbidities, and consequently fairly high baseline QoL scores. However, comparing mean QoL data of both groups to the Netherlands reference population $^{21,22}$ it is obvious that QoL levels were certainly decreased in our AF population.

AF-related knowledge is considered important in the management of $\mathrm{AF}^{34,35}$. Patients might have wrong ideas and perceptions regarding the arrhythmia and prior research demonstrated that patients consider AF life-threatening, resulting in worse QoL and higher anxiety and depression levels. Moreover, it has been demonstrated that the current understanding of AF in patients is poor and that approximately $51 \%$ of patients is in great need for more and improved information ${ }^{35}$. Patient education in terms of knowledge improvement in patients has been regularly demonstrated a positive contribution to QoL ${ }^{31-33,35-37}$. One could argue that too much information might have the opposite effect with respect to QoL, including anxiety and depression. However, we did not find any indications that this might be true. Thus, it is advisable to give information to patients.

\section{Study limitations}

Patients who withdrew from study were significantly older patients and had more often coronary artery disease, and QoL was significantly lower compared to the patients within analysis. It is very likely that QoL decreases in patients at an older age, being 'sicker' and experiencing symptoms of associated heart diseases and its related limitations. The current analysis might, therefore, represent an overestimation of QoL scores and the intervention might have been different in patients with worse QoL. In particular, the effects of the intervention in this group is not known. Our findings should consequently be interpreted with caution. Moreover, despite randomization the groups were mismatched to some extent with respect to baseline QoL scores.

\section{CONCLUSION}

In this study, QoL scores of AF patients were relatively high at baseline and improved over time in all SF-36 subscales, regardless of treatment group. Nevertheless, a nurseled integrated chronic care approach may contribute to the patients' QoL, by focussing on QoL influencing factors, rather than on QoL alone. 


\section{REFERENCES}

1. Go AS, Hylek EM, Phillips KA, Chang Y, Henault LE, Selby JV, Singer DE. Prevalence of diagnosed atrial fibrillation in adults: national implications for rhythm management and stroke prevention: the AnTicoagulation and Risk Factors in Atrial Fibrillation (ATRIA) Study. JAMA 2001;285:2370-5.

2. Camm AJ, Kirchhof P, Lip GY, Schotten U, Savelieva I, Ernst S Van Gelder I, Al-Attar N, Hindricks $G$, Prendergast $B$, Heidbuchel $H$, Alfieri $O$, Angelini A, Atar D, Colonna P, De Caterina R, De Sutter J, Goette A, Gorenek B, Heldal M, Hohnloser SH, Kolh P, Le Heuzey JY, Ponikowski P, Rutten FH. Guidelines for the management of atrial fibrillation: the Task Force for the Management of Atrial Fibrillation of the European Society of Cardiology (ESC). Eur Heart J 2010;31:2369-429.

3. Camm AJ. Quality of live in patients with atrial fibrillation. Rev Esp Cardiol 2010; 63:13935.

4. Fuster V, Rydén LE, Cannom DS, Crijns HJ, Curtis AB, Ellenbogen KA, Halperin JL, Le Heuzey JY, Kay GN, Lowe JE, Olsson SB, Prystowsky EN, Tamargo JL, Wann S, Task Force on Practice Guidelines, American College of Cardiology/American Heart Association; Committee for Practice Guidelines, European Society of Cardiology; European Heart Rhythm Association; Heart Rhythm Society. ACC/AHA/ESC 2006 guidelines for the management of patients with atrial fibrillation - executive summary: a report of the American College of Cardiology/American Heart Association Task Force on Practice Guidelines and the European Society of Cardiology Committee for Practice Guidelines (Writing Committee to Revise the 2001 Guidelines for the Management of Patients with Atrial Fibrillation). Eur Heart J 2006;27:1979-2030.

5. Thrall G, Lip GY, Carroll D, Lane D. Depression, anxiety, and quality of life in patients with atrial fibrillation. Chest 2007;132:1259-64.

6. Lane DA, Langman CM, Lip GY, Nouwen A. Illness perceptions, affective response, and health-related quality of life in patients with atrial fibrillation. I Psychosom Res 2009;66:203-10.

7. Zigmond AS, Snaith RP. The hospital anxiety and depression scale. Acta Psychiatr Scand 1983;67:361-70.

8. Brenes GA. Anxiety, depression, and quality of life in primary care patients. Prim Care Companion J Clin Psychiatry 2007;9:437-43.

9. Thrall G, Lane D, Caroll D, Lip GY. Quality of life in patients with AF: a systematic review. Am J Med 2006;119:448.e1-19.

10. Nieuwlaat R, Capucci A, Camm AJ, Olsson SB, Andresen D, Davies DW, Cobbe S, Breithardt G, Le Heuzey JY, Prins MH, Lévy S, Crijns HJ, European Heart Survey Investigators. Atrial fibrillation management: a prospective survey in ESC member countries: the Euro Heart Survey on Atrial Fibrillation. Eur Heart J 2005;27:3018-26.

11. Nieuwlaat $R$, Prins MH, Le Heuzey JY, Vardas PE, Aliot E, Santini M, Cobbe SM, Widdershoven JW, Baur LH, Lévy S, Crijns HJ. Prognosis, disease progression, and treatment of atrial fibrillation patients during 1 year: follow-up of the Euro Heart Survey on atrial fibrillation. Eur Heart $J$ 2008;29:1181-9.

12. Steg PG, Alam S, Chiang CE, Gamra H, Goethals M, Inoue H, Krapf L, Lewalter T, Merioua I, Murin J, Naditch-Brûlé L, Ponikowski P, Rosenqvist M, Silva-Cardoso J, Zharinov O, Brette $\mathrm{S}$, Neill JO, on behalf of the RealiseAF investigators. Symptoms, functional status and quality of life in patients with controlled and uncontrolled atrial fibrillation: data from the RealiseAF cross-sectional international registry. Heart 2012;98:195-201.

13. Benjamin EJ, Wolf PA, D'Agostino RB, Silbershatz H, Kannel WB, Levy D. Impact of atrial fibrillation on the risk of death: the Framingham Heart Study. Circulation 1998; 98:946-52. 
14. Hendriks JM, de Wit R, Vrijhoef HJ, Tieleman RG, Crijns HJ. An integrated chronic care program for patients with atrial fibrillation: study protocol and methodology for an ongoing prospective randomised controlled trial. Int J Nurs Stud 2010;47:1310-6.

15. Wagner EH, Austin BT, Davis C, Hindmarsh M, Schaefer J, Bonomi A. Improving chronic illness care: translating evidence into action. Health Aff (Millwood) 2001; 20:64-78.

16. Hendriks JM, de Wit R, Crijns HJ, Vrijhoef HJ, Prins MH, Pisters R, Pison LA, Blaauw $Y$, Tieleman RG. Nurse-led care versus usual care for patients with atrial fibrillation: results of a randomized trial of integrated chronic care versus routine clinical care in ambulatory patients with atrial fibrillation. Eur Heart J 2012;33:2692-9.

17. Gage BF, Waterman AD, Shannon W, Boechler M, Rich MW, Radford MJ. Validation of clinical classification schemes for predicting stroke: results from the National Registry of Atrial Fibrillation JAMA 2001;285:2864-70.

18. Brazier JE, Harper R, Jones NM, O'Cathain A, Thomas KJ, Usherwood T, Westlake L. Validating the SF-36 health survey questionnaire: new outcome measure for primary care. BMJ 1992;305:160-4.

19. Ware JE, Snow KK, Kosinski M, Gandek B. SF-36 Health Survey Manual and Interpretation Guide. Boston: MA: New England Medical Center, The Health Institute; 1993.

20. Ware JE, Sherbourne CD. The RAND-36 Short-form Health Status Survey: I. Conceptual framework and item selection. Med Care 1992;30:473-81.

21. Aaronson NK, Muller M, Cohen DP, Essink-Bot ML, Fekkes M, Sanderman R, Sprangers MA, te Velde $A$, Verrips E. Translation, validation, and norming of the Dutch language version of the SF-36 Health Survey in community and chronic disease populations. J Clin Epidemiol 1998;51:1055-68.

22. Rijksinstituut voor Volksgezondheid en Milieu, Ministerie van Volksgezondheid Welzijn en Sport. National Guide on Health: Quality of life in people in The Netherlands (in Dutch: Nationaal Kompas Volksgezondheid: Wat is de kwaliteit van leven van mensen in Nederland?). Available at: http://www.nationaalkompas.nl/gezondheid -en- ziekte/functioneren-en-kwaliteit-van-leven/kwaliteit-van-leven/wat-is-de-kwaliteit-van-leven-vanmensen-in-nederland/. Accessed June 28, 2012.

23. Macabasco-O'Connell A, DeWalt DA, Broucksou KA, Hawk V, Baker DW, Schillinger D, Ruo B, Bibbins-Domingo K, Holmes GM, Erman B, Weinberger M, Pignone M. Relationship between literacy, knowledge, self-care behaviors, and heart failure-related quality of life among patients with heart failure. J Gen Intern Med 2011; 26:979-86.

24. Hendriks JM, Crijns HJ, Tieleman RG, Vrijhoef HJ. The Atrial Fibrillation Knowledge Scale: development, validation and results. Int J Cardiol 2013; doi:10.1016/j.ijcard.2012.12.047.

25. Linkert RA. A technique for the measurement of attitudes. In: Archives of Psychology. New York 1932;140:5.

26. Pilote L, Dasgupta K, Guru V, Humphries KH, McGrath J, Norris C, Rabi D, Tremblay J, Alamian A, Barnett T, Cox J, Ghali WA, Grace S, Hamet P, Ho T, Kirkland S, Lambert M, Libersan D, O'Loughlin J, Paradis G, Petrovich M, Tagalakis V. A comprehensive view of sexspecific issues related to cardiovascular disease. CMAJ 2007;176:S1-44.

27. Parashar S, Rumsfeld JS, Reid KJ, Buchanan D, Dawood N, Khizer S, Lichtman J, Vaccarino $\mathrm{V}$, PREMIER Registry Investigators. Impact of depression on sex differences in outcome after myocardial infarction. Circ Cardiovasc Qual Outcomes 2009;2:33-40.

28. Brouwers C, van den Broek KC, Denollet J, Pedersen SS. Gender disparities in psychological distress and quality of life among patients with an implantable cardioverter defibrillator. Pacing Clin Electrophysiol 2011;34:798-803.

29. Vazquez LD, Conti JB, Sears SF. Female-specific education, management, and lifestyle enhancement for implantable cardioverter defibrillator patients: The female-ICD study. Pacing Clin Electrophysiol 2010;33:1131-40. 
30. Versteeg H, Baumert J, Kolb C, Pedersen SS, Denollet J, Ronel J, Ladwig H. Somatosensory amplification mediates sex differences in psychological distress among cardioverterdefibrillator patients. Health Psychol 2010;29:477-83.

31. Jenkins LS, Bubien RS. Quality of life in patients with atrial fibrillation. Cardiol Clin 1996;14:597-606.

32. Dorian P, Jung W, Newman D, Paquette M, Wood K, Ayers GM, Camm J, Akhatar M, Luderitz B. The impairment of health-related quality of life in patients with intermittent atrial fibrillation: implications for the assessment of investigational therapy. J Am Coll Cardiol 2000;36:1303-9.

33. van den Berg MP, Hassink RJ, Tuinenburg AE, van Sonderen EF, Lefrandt JD, de Kam PJ, van Gelder IC, Smit AJ, Sanderman R, Crijns HJ. Quality of life in patients with paroxysmal atrial fibrillation and its predictors: importance of the autonomic nervous system. Eur Heart $J$ 2001;22:247-53.

34. Lane DA, Ponsford J, Shelley A, Sirpal A, Lip GY. Patient knowledge and perceptions of atrial fibrillation and anticoagulant therapy: effects of an educational intervention programme. The West Birmingham Atrial Fibrillation Project. Int J Cardiol 2006; 110:354-8.

35. Aliot E, Breithardt G, Brugada J, Camm J, Lip GY, Vardas PE, Wagner M, Atrial Fibrillation AWareness And Risk Education group, Atrial Fibrillation Association, European Heart Rhythm Association, Stroke Alliance for Europe, World Heart Federation. An international survey of physician and patient understanding, perception, and attitudes to atrial fibrillation and its contribution to cardiovascular disease morbidity and mortality. Europace 2010;12:626-33.

36. Lycholip E, Celutkiene J, Rudys A, Steponenieni R, Laucevicius A. Patient education significantly improves quality of life, exercise capacity and BNP level in stable heart failure patients. Acta Cardiol 2010;65:549-56.

37. Baker DW, Dewalt DA, Schillinger D, Hawk V, Ruo B, Bibbins-Domingo K, Weinberger $M$, Macabasco-O'Connell A, Grady KL, Holmes GM, Erman B, Broucksou KA, Pignone M. The effect of progressive, reinforcing telephone education and counseling versus brief educational intervention on knowledge, self-care behaviors and heart failure symptoms. $J$ Card Fai 2011;17:789-96. 


\section{CHAPTER}

\section{Cost-effectiveness of a specialized atrial fibrillation clinic versus usual care in patients with atrial fibrillation}

Jeroen ML Hendriks, Florian Tomini, Thea DI van Asselt, Harry JGM Crijns, Hubertus JM Vrijhoef

Submitted 


\section{ABSTRACT}

Aims. A recent randomized controlled trial demonstrated significant reductions in cardiovascular hospitalizations and deaths with a nurse-led integrated chronic care approach in patients with atrial fibrillation (AF) compared to usual care. The aim of the present study is to assess cost-effectiveness of this nurse-led care program versus usual care.

Methods and results. A cost-effectiveness analysis was undertaken alongside the randomized controlled trial in which 712 patients were included at the Maastricht University Medical Centre, The Netherlands, and allocated to nurse-led care or usual care. Nurse-led care implied guideline-adherent management, steered by dedicated software, supervised by cardiologists. Usual care was regular outpatient care performed by cardiologists. A cost per life year and a cost per Quality Adjusted Life Year (QALY) analysis was performed, both from a hospital perspective.

The nurse-led care program was associated with slightly more life years and QALYs at a lower cost. Specifically, the nurse-led program contributed to 0.009 QALY gains with a reduced cost of $€ 1109$ per patient and a gain of 0.02 life years with a reduced cost of $€ 735$ per patient. Therefore, the nurse-led program would be considered dominant. In fact, for all the possible values of willingness to pay for a QALY the nurseled program is considered to be more likely cost effective than the care as usual.

Conclusion. The cost-effectiveness analysis in the present study demonstrated that a nurse-led integrated care approach will save costs and improve survival and quality of life, and is therefore a cost-effective management strategy for patients with AF. 


\section{INTRODUCTION}

Atrial fibrillation (AF) is the most common cardiac arrhythmia, occurring in 1-2\% of the general population. This denotes that over 6 million Europeans suffer from this arrhythmia. The prevalence increases with age from $<0.5 \%$ in persons aged $40-50$ years to $5-15 \%$ in persons at 80 years ${ }^{1}$. The overall prevalence is $5.5 \%$ in patients older than 55 years $^{2}$. AF is strongly associated with increased morbidity and mortality rates. Death rates are doubled compared to individuals without $A F^{3,4}$. In addition, $A F$ leads to a five fold increased risk of stroke, and one in five of all strokes is attributed to the arrhythmia ${ }^{1}$. AF-related hospitalizations account for one-third of all hospital admissions for cardiac arrhythmias ${ }^{1}$ and consequently, costs of treatment increase significantly.

AF is therefore considered an extremely expensive disease with an important economic burden ${ }^{5,6}$. Due to the aging population and limited public resources, there is a growing awareness of the financial costs of $\mathrm{AF}^{7}$. The mean healthcare costs per patient acquired on an annual basis are estimated at $€ 2328$ in the Netherlands, as calculated by Ringborg et al. in $2006^{8}$. The mean annual costs of AF-related admissions (inpatient setting) were estimated at $€ 6445$ and for the outpatient setting at $€ 114$ in the Netherlands, accordingly. Based on this amount, the total costs of AF for Dutch society are estimated to be $€ 583.093 .264$ per year ${ }^{2,8}$, which approximately accounts for $1.3 \%$ of the Netherlands healthcare expenditure in $2008^{9}$. Hospitalization is considered to be the main cost driver due to utilization of expensive resources like interventional procedures and hospitalization days, as these entail the highest costs. Outpatient care costs are driven by use of medication, diagnostics and consultations ${ }^{8}$. Prior research (e.g. Euro Heart Survey on AF) demonstrated that poor adherence to the guidelines (in terms of diagnostic and therapeutic management) was associated with an increased morbidity and mortality ${ }^{10,11}$ leading to increased costs ${ }^{8}$. In response to these findings, we developed an integrated chronic care program consisting of a nurse-driven, guideline-based, software supported AF-Clinic ${ }^{12}$, based on the Chronic Care Model $^{13,14}$. A randomized controlled effectiveness trial was performed at Maastricht University Medical Centre, The Netherlands. This trial has demonstrated superiority in terms of cardiovascular hospitalization and death in favour of the nurseled AF-Clinic compared to usual care ${ }^{15}$. In line with these findings, we hypothesized that the integrated approach also has a positive effect on costs. Moreover, costeffectiveness assessment of a nurse-led integrated care approach in AF has not been performed before. Currently, institutions in the Netherlands and even in Europe consider the development of a nurse-led AF-Clinic or already implemented the approach in daily care. These developments require a shift in financial investments, but more importantly reallocation in costs and funding (e.g. bundled payment) ${ }^{16}$. Consequently, the assessment of related effects and costs through economic evaluation of competing treatment strategies is essential in providing insights on the impact with respect to hospital management, society, and decision makers. 
The main objective of this study therefore, was to assess cost-effectiveness of the nurse-led integrated chronic care approach versus usual care in patients with atrial fibrillation.

\section{METHODS}

\section{Patients and design}

In the trial, comparing the effectiveness of the nurse-led care with usual care, eligible patients were randomly assigned to one of the two treatment groups. Inclusion criteria were: age $\geq 18$ years and AF documented on ECG. Patients were excluded for the study in case of any co-morbidity which was unsatisfactorily treated. Follow-up was at least one year. The primary endpoint was a composite of death from cardiovascular causes and cardiovascular hospitalization. Details regarding in- and exclusion criteria as well as the design of the study have been previously described in more detail ${ }^{12}$. The study is in accordance with the Declaration of Helsinki and ethical approval was obtained from the Institutional Review Board of the Maastricht University Medical Centre (MUMC), where the trial took place. The trial was registered at Clincaltrials.gov (identifier: NCT00753259).

\section{Procedures}

All patients referred to the AF-Clinic underwent protocolized diagnostic procedures, before visiting the outpatient clinic. Thereafter patients were seen by a nurse specialist at the outpatient clinic, who took the patient's history and informed the patient about the arrhythmia, the results of the diagnostic tests and the treatment options. A software system, based on the current guidelines, was used as an assisting tool in the care process (i.e. the system serves as an electronic checklist, and is able to generate individual patient risk profiles to suggest the most appropriate treatment). The nurse specialist was supervised by a cardiologist. The latter met the patient together with the nurse specialist at the end of the first visit, to confirm the medical diagnosis and start the treatment. All visits to the nurse specialist were scheduled to last 30 minutes and follow-up visits were planned at 3, 6 and 12 months. Patients in the usual care received care from the cardiologist in the outpatient setting. This cardiologist did not collaborate with the nurse specialist nor used the dedicated software. Visits to the cardiologist in the usual care setting were scheduled to last 20 minutes for a first visit and 10 minutes for follow-up, and were not pre planned. 


\section{OUTCOMES IN THE ECONOMIC EVALUATION}

\section{Survival}

Survival was expressed as life years, calculated as days alive during the follow-up year divided by 365 .

\section{Quality Adjusted Life Years}

Health status was assessed with the Short Form 36 questionnaire (SF-36) ${ }^{17}$, which was administered at baseline and at one year follow-up converted to a single utility score by means of the Short Form 6D (SF-6D). The SF-6D contains 6 items covering 6 domains (e.g. physical functioning, role limitations, social functioning, pain, mental health, vitality) and describes all 18,000 health states valuations, defined by the SF- $6 D^{18}$. A sample of 249 of these health states were valued by a representative sample of the UK population using the standard gamble validation method ${ }^{18}$, enabling the development of a scoring algorithm to convert SF-6D item scores into utilities. The SF-6D utilities range from 0.29 to 1.00 with higher scores indicating better quality of life. The SF-6D utilities are then used to calculate Quality Adjusted Life Years (QALYs) by multiplying the utility score with the time that the patient was experiencing that utility $^{19}$. In this respect a year of life with a utility score of 0.7 would represent 0.7 QALYs being produced. For the purpose of the economic evaluation the follow-up period was limited to one year.

\section{COSTS}

The analysis on costs is performed from a hospital perspective. This entails all relevant costs related to inpatient and outpatient care, during a one year follow up period. The costs are classified into six modules: diagnostic procedures, outpatient care, medication therapy, interventional procedures, inpatient care, and software. Resource utilization was retrieved from the hospital administration databases as well as from the dedicated software system, used in the trial.

Unit prices regarding hospital procedures were obtained from the financial department of the MUMC. Prices for medication were derived from the Dutch Pharmacotherapeutic Compass ${ }^{20}$. All costs are expressed in Euros at the price level of year 2011.

\section{COST-EFFECTIVENESS}

Cost-effectiveness is expressed as an incremental cost-effectiveness ratio (ICER), which is the difference in average costs between nurse-led care and usual care divided 
by the difference in effect between both groups. An ICER can be helpful in answering the question: what are the additional benefits to be gained from the intervention, and at how much greater costs. As there are two effect measures, there are also two ICERs in this study: the cost per life year and the cost per QALY.

\section{STATISTICAL ANALYSIS}

Data were analyzed according to the intention to treat principle. Multiple imputation was performed with PASW Statistics 18 (SPSS Inc.), based on predictive mean matching and with SF-36 values, age and sex as predictive variables. However, patients who did not fill out a SF-36 questionnaire at baseline nor at one year followup were excluded from the QALY analysis.

Since cost data generally have a highly skewed distribution, we performed nonparametric bootstrap simulations with 1000 replications to estimate uncertainty intervals around the ICERs ${ }^{21}$. The uncertainty interval is determined by the $2.5^{\text {th }}$ and 97. $5^{\text {th }}$ percentiles. We performed this procedure in Microsoft Excel. The results of this analysis are presented in cost-effectiveness planes. These planes show differences in effect (horizontal axis) and costs (vertical axis). The bootstrapped cost-effectiveness pairs that are located in the upper-left quadrant indicate nurse-led care inferior to usual care (less effective against more costs). Cost-effectiveness pairs that are located in the lower-right quadrant demonstrate nurse-led care to be dominant over usual care (more effective against lower costs). Cost-effectiveness acceptability curves are produced to illustrate the probability that the intervention is cost-effective in comparison with the standard treatment for a range of ceiling ratios. The ceiling ratio (or threshold) is defined as the amount society is willing to pay in order to gain one unit of effect ${ }^{22}$, i.e. a QALY or survival year.

\section{RESULTS}

\section{Patients}

In total 712 patients were enrolled in the study, 356 patients allocated to the nurseled care group and 356 patients to the usual care group. There were no significant differences in baseline characteristics ${ }^{15}$. In 125 patients (18\%), baseline quality of life scores needed to compile the SF-6D utility were missing. For another 218 patients (31\%), these data were missing after one year follow-up. Multiple imputations were performed on those patients that had filled in at least the baseline or follow-up SF-36 questionnaire. The final sample resulted in 466 patients (65\% of the initial sample); 244 patients of the nurse-led care group and 222 patients of the usual care group. The analysis on life years were based on the entire initial sample of 712 patients. 


\section{Survival}

Life years, as shown in Table 7.1, were higher for the nurse-led care group $(0.983 \pm 0.013)$, compared to the usual care group $(0.963 \pm 0.009)$ however the difference $(0.020)$ was not statistically significant with a bootstrapped $2.5^{\text {th }}$ percentile of -0.010 and $97.5^{\text {th }}$ percentile of 0.045 .

Table 7.1 Mean (SD) SF-6D utility scores at baseline (T0) and after one year follow-up (T1).

\begin{tabular}{llll}
\hline & Nurse-led care & Usual care & Difference $(P$-value Mann-Whitney) \\
\hline Mean (SD) utility score at T0 & $0.627(0.063)$ & $0.628(0.066)$ & $-0.001(0.5499)$ \\
Mean (SD) utility score at T1 & $0.636(0.059)$ & $0.635(0.059)$ & $0.001(0.8319)$ \\
\hline & & & Difference (bootstrapped $\left.2.5^{\text {th }}-97.5^{\text {th }} \mathrm{Cl}\right)$ \\
\hline Total mean (SD) QALY & $0.603(0.007)$ & $0.594(0.003)$ & $0.009(-0.007-0.024)$ \\
Total mean (SD) Life years & $0.983(0.013)$ & $0.963(0.009)$ & $0.020(-0.010-0.045)$ \\
\hline
\end{tabular}

Also, total mean QALYs and life years is presented and related differences, including the bootstrapped $2.5^{\text {th }}$ $-97.5^{\text {th }}$ Confidence Interval $(\mathrm{Cl})$.

\section{Quality of life}

Mean SF-6D utility scores are reported in Table 7.1. At baseline, as well as after one year follow-up the utility scores were not statistically significantly different between groups. Accordingly, this also holds for the mean QALYs, being 0.603 versus 0.594 in the nurse-led care and usual care respectively. The difference between the groups is very small $(0.009)$ with a bootstrapped $2.5^{\text {th }}$ percentile of -0.007 and a $97.5^{\text {th }}$ percentile of 0.024 which indicates a gain in quality of life, however not statistically significant (zero is included in the uncertainty interval).

\section{Costs}

The mean total health care cost per patient (hospitalization included), is lower in the nurse-led care ( $€ 2.302 \pm 5.506$ ) compared to the usual care ( $€ 3.037 \pm 5.987$ ), however the difference is statistically not significant. From a health economic perspective, inpatient days, including in-hospital interventional procedures, are considered to be important as these entail high costs. The mean outpatient care cost per patient is slightly lower in the nurse-led care compared to the usual care. The difference in outpatient costs is mainly attributable to lower costs for outpatient consultation (including telephone and emergency consultation) and costs for medication, in the nurse-led care compared to usual care. At the same time costs for interventional procedures are higher in the nurse-led care group. All volumes and costs are shown in Table 7.2. 


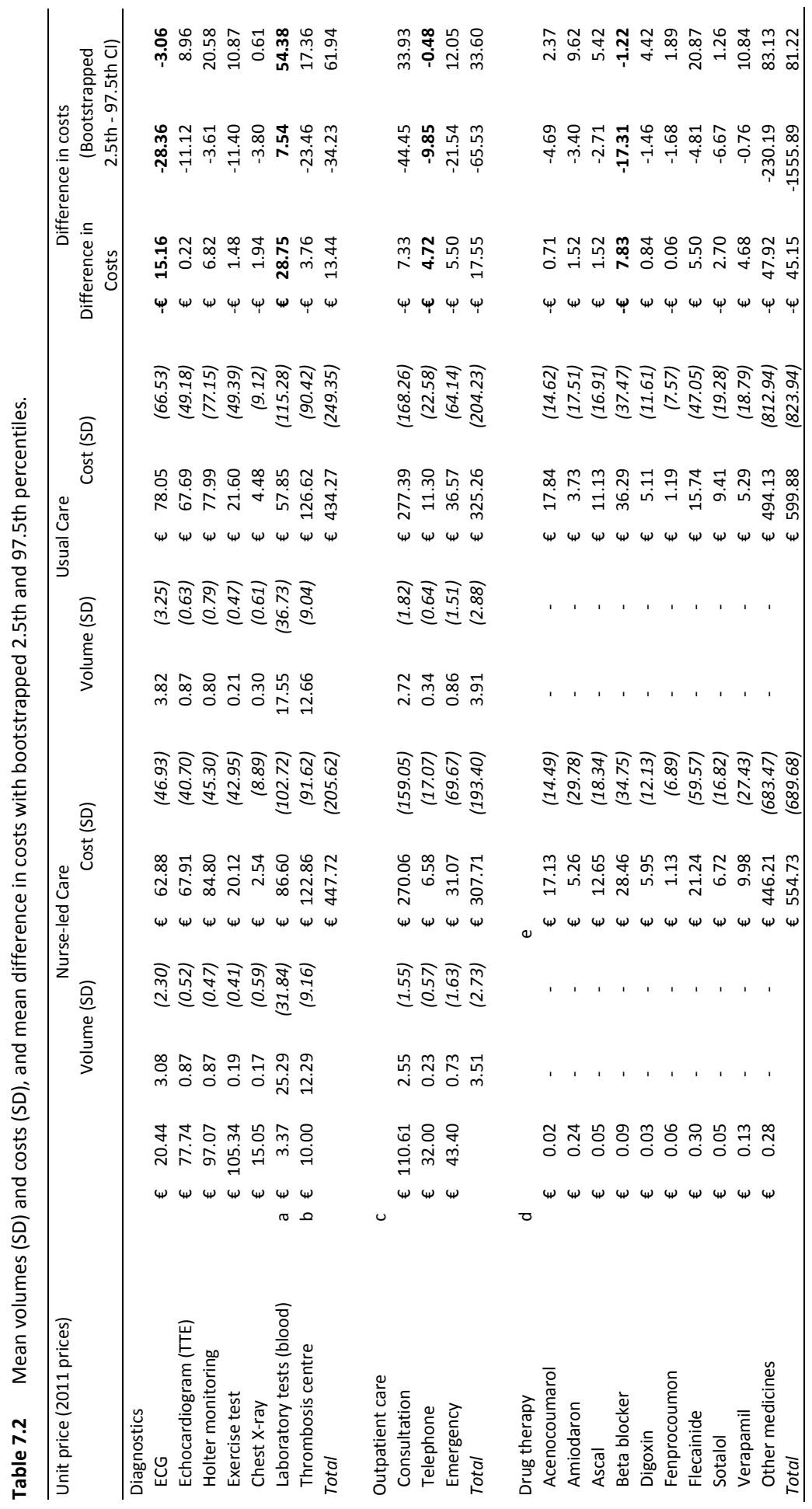




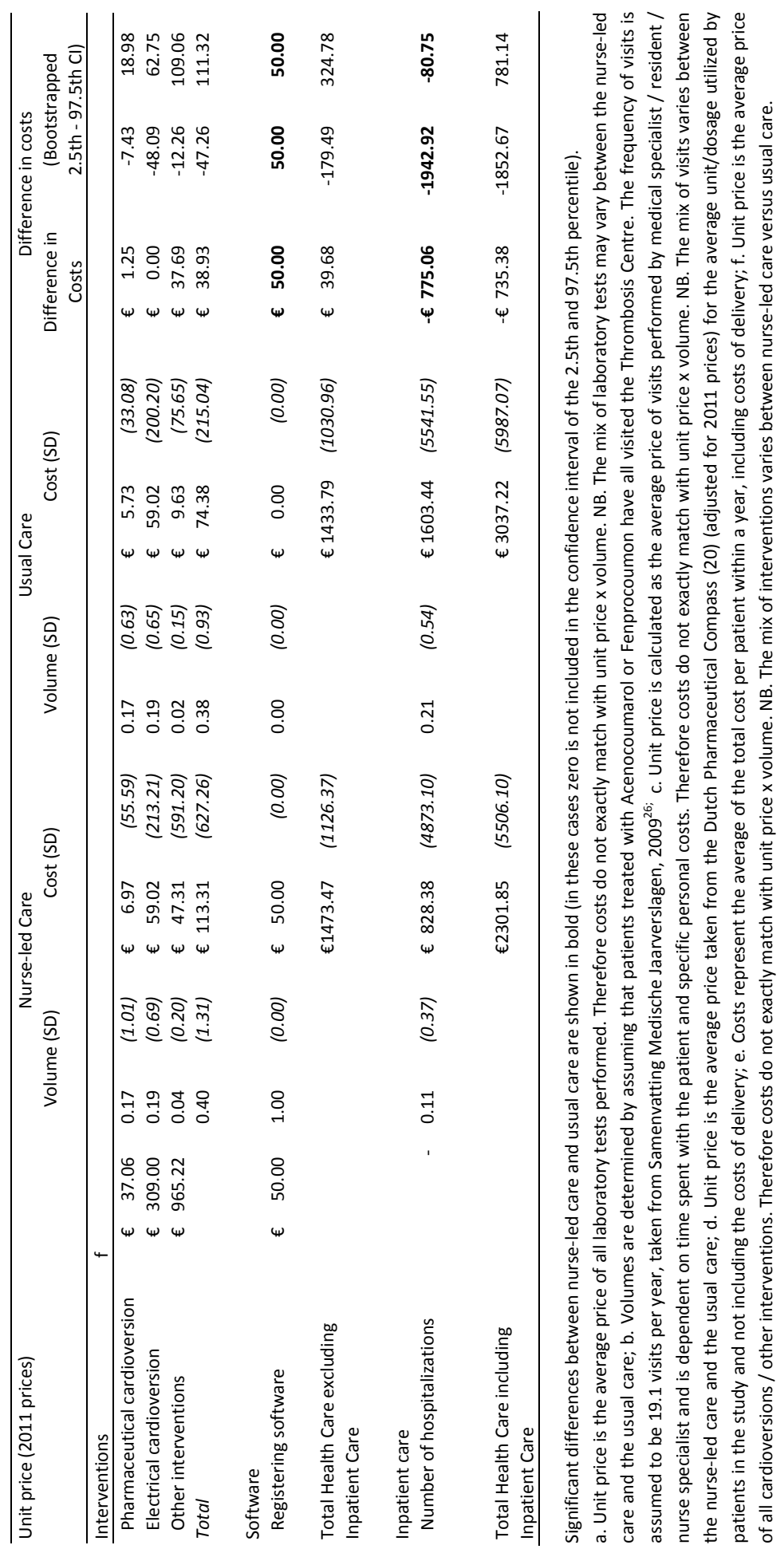




\section{Cost-effectiveness}

The point estimates for costs and effects suggest nurse-led care to be dominant over usual care, since costs for nurse-led care are lower whereas effects are better. This is confirmed by the incremental cost-effectiveness plane for total cost per life year, showing that nurse-led care is more effective compared to usual care (Figure 7.1). The majority of bootstrap replications are located in the lower-right quadrant, where the nurse-led care is more effective against lower costs compared to the usual care. However, some replications are located in other quadrants, indicating some uncertainty about cost and effectiveness.

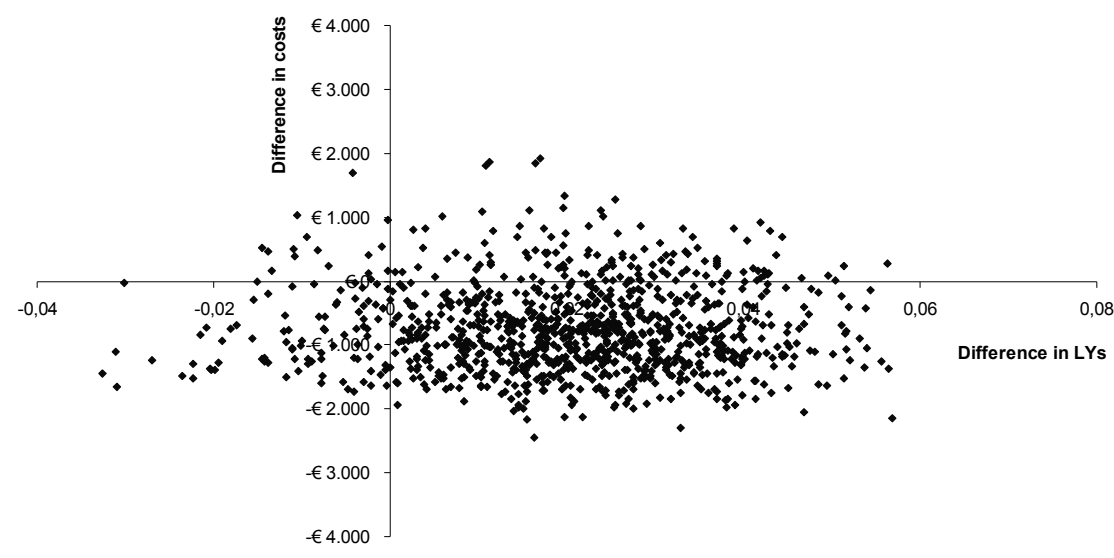

Figure 7.1 Incremental cost-effectiveness plane for total costs per life year in EURO (€).

For cost per QALY, nurse-led care was again dominant over usual care, i.e. nurse-led care was less costly and more effective. The incremental cost-effectiveness plane shown in figure 2, again demonstrates a comparable distribution, with the majority of the cost-effectiveness pairs located in the lower-right quadrant. However, the cloud is more dense. Also, a minority of pairs are located in the lower-left quadrant, indicating that there is some uncertainty regarding effectiveness of the nurse-led care in terms of QALYs. Due to the fact that this concerns only $12 \%$, the uncertainty is considered very small (Figure 7.2).

Given that with considerable certainty, nurse-led care is more effective at a better price compared to usual care, the probability of the cost-effectiveness of nurse-led care is very high, regardless of what society is willing to pay to gain a QALY or an extra life year. The cost-effectiveness acceptability curve for cost per QALY demonstrates that if the willingness to pay is set at $€ 20,000$, the probability of the nurse-led care being cost-effective is $99 \%$ compared to usual care. For cost per life year a probability of $92.5 \%$ is reached at a willingness to pay at $€ 20,000$ (Figure 7.3 ). 


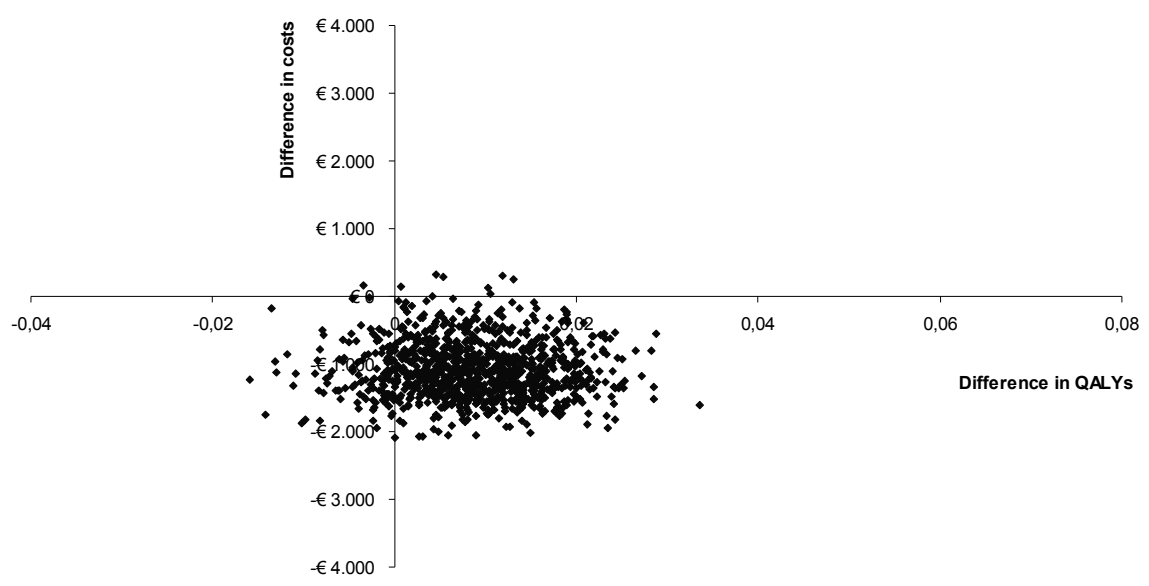

Figure 7.2 Incremental cost-effectiveness plane for total costs per QALY in EURO (€).

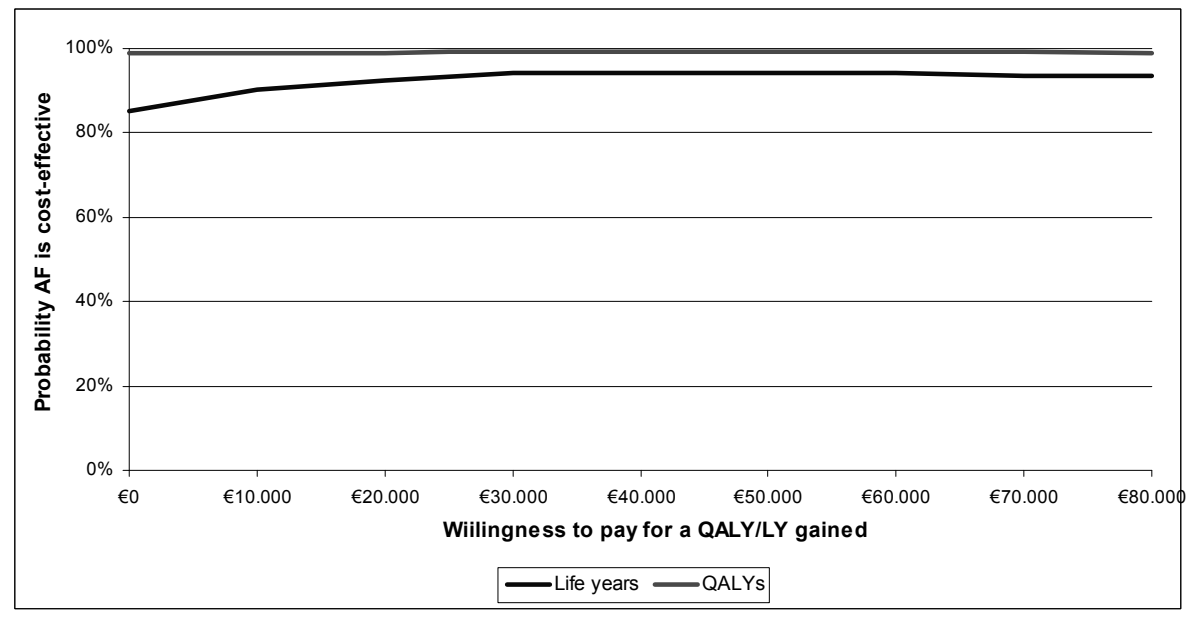

Figure 7.3 Cost-effectiveness acceptability curve for cost per QALY and cost per life year. 


\section{DISCUSSION}

A nurse-led integrated chronic care program for patients with AF was more effective with respect to cardiovascular hospitalization and death and overall less costly than usual care, for QALYs as well as for life years.

In general, outpatient care costs are driven by diagnostic procedures, consultations and medication. In this study, the costs of the majority of diagnostic procedures are lower in the nurse-led care compared to usual care (Table 7.2). Mean laboratory costs per patient however are significantly higher in the nurse-led care ( $€ 86.60 \pm 102.72$ ) than in the usual care ( $€ 57.85 \pm 115.28$ ). The latter related to improved guideline adherent laboratory assessment in nurse-led care patients which should be seen as an investment in the short run, but cost saving in the longer term. In the randomized trial we demonstrated guideline adherent thyroid stimulating hormone level assessment in $91 \%$ versus $54 \%$ patients in the nurse-led care group and the usual care group respectively ${ }^{15}$. Mean total costs spent on diagnostic procedures were $€ 448 \pm 206$ in the nurse-led care group versus $€ 434 \pm 249$ in the usual care group. This amount is much higher as that found by Ringborg et al. They calculated that annually $€ 160$ (7\% of total costs) was spent on diagnostic procedures, such as echocardiography, chest Xrays, Holter monitoring, thyroid function tests and exercise tests (8). The difference in costs between these studies relates to a time-dependent increase in unit prices and higher volumes ${ }^{15}$.

The mean number of outpatient consultations (including visits to the emergency department and telephone consultations) was $3.51 \pm 2.73$ in the nurse-led care versus $3.91 \pm 2.88$ in the usual care. Although the volumes differed, the distribution by type of consultations (first visit, follow-up visit, emergency visit, or telephone consultation) was comparable in both groups.

An integrated care program may trigger costs, especially during the initial phase of management (e.g. costs for dedicated software, higher volume of diagnostics due to guideline adherent management). On the other hand, this can be considered an investment for the future. Due to protocolized performance of diagnostic procedures in all patients and the increased time spent with these patients during consultations, hospitalizations can be prevented. It is reasonable to assume that this indeed caused fewer hospitalizations in the present study but unfortunately a link between both is difficult to establish.

During the 12 month follow-up in this study, hospitalization occurred 38 times $(11.0 \%)$ for patients of the nurse-led care and 73 times (21\%) for patients of the usual care, accounting for an average of 111 hospitalizations in both groups ${ }^{15}$. About $2.95 \%$ of the patients in both groups were hospitalized two or three times.

Previous studies already demonstrated that hospitalizations represent the major cost driver in $\mathrm{AF}^{7-9}$, accounting for $50-70 \%$ of total costs ${ }^{7}$. According to Ringborg et al. patients with AF annually account for an average cost of $€ 834$ (36\%) for inpatient care $^{8}$. Furthermore, it should be noted that the total costs are probably an 
underestimation of the true costs of $A F$ in the Netherlands, with respect to associated underlying cardiovascular diseases ${ }^{9}$, which increases the costs of care in these patients, and these costs have not been taken into account in this study. Furthermore, costs and hospitalizations related to $\mathrm{AF}$ have increased enormously over the last decades $^{7}$ and due to aging of the population and the associated expected increase in the prevalence of $A F$, costs will increase further. With respect to these important facts it should be considered that integrated care programs may trigger costs in the short run, to become cost-saving in the future, which is in line with recently presented early results of bundled payment of integrated care for diabetes type 2 patients in the Netherlands ${ }^{23}$. In this respect, an extended follow-up period for future research, with significant attention to the (elements of) integrated approach and its preconditions, is therefore highly recommended.

To our knowledge this is the first cost-effectiveness analysis in a nurse-led integrated care approach in the treatment of patients with AF. Boodhoo et al. studied a nurse-led cardioversion service and demonstrated its cost-effectiveness in terms of success rates $^{24}$. No other studies were found that studied a similar integrated approach in AF and reported on cost-effectiveness. On the other hand, nurse-led programs in other chronic diseases, like heart failure are available, although only one study with allcause mortality, event-free survival and recurrent hospital stay as the endpoints. Inglis et al. demonstrated in this study that a nurse-led, multidisciplinary, home-based intervention in a cohort of elderly heart failure patients after hospitalization is a remarkably cost- and time-effective strategy over the longer term, in terms of reducing the frequency of recurrent hospitalizations ${ }^{25}$.

A limitation of the study is that the analysis on costs was performed based on a hospital perspective. Therefore indirect costs (e.g. costs due to work loss, means of transportation, visits to healthcare providers outside the hospital - such as a General Practitioner) were not included in the analysis. If the analysis was performed on a societal perspective, this would have affected the economic burden of AF as estimated. However, it should be taken into account that the majority of patients in this study were above the retirement age ( $60 \%$ of patients were $>64$ years) and had stopped working which limits the impact of indirect costs.

\section{CONCLUSION}

The economic evaluation in the present study demonstrates that a nurse-led integrated care approach is cost-effective in patients with atrial fibrillation. 


\section{REFERENCES}

1. Camm AJ, Kirchhof P, Lip GY, Schotten U, Savelieva I, Ernst S, Van Gelder I, Al-Attar N, Hindricks $G$, Prendergast $B$, Heidbuchel $H$, Alfieri $O$, Angelini A, Atar D, Colonna P, De Caterina R, De Sutter J, Goette A, Gorenek B, Heldal M, Hohnloser SH, Kolh P, Le Heuzey JY, Ponikowski P, Rutten FH. Guidelines for the management of atrial fibrillation: the Task Force for the Management of Atrial Fibrillation of the European Society of Cardiology (ESC). Eur Heart J 2010;31:2369-2429.

2. Heeringa J, van der Kuip DA, Hofman A, Kors JA, van Herpen G, Stricker BH, Stijnen T, Lip GY, Witteman JC. Prevalence, incidence and lifetime risk of atrial fibrillation: the Rotterdam study. Eur Heart J 2006;27:949-53.

3. Benjamin EJ, Wolf PA, D'Agostino RB, Silbershatz H, Kannel WB, Levy D. Impact of atrial fibrillation on the risk of death: The Framingham Heart Study. Circulation 1998;98:946-52.

4. Kirchhof P, Auricchio A, Bax J, Crijns H, Camm J, Diener HC, Goette A, Hindricks G, Hohnloser S, Kappenberger L, Kuck KH, Lip GY, Olsson B, Meinertz T, Priori S, Ravens U, Steinbeck G, Svernhage E, Tijssen J, Vincent A, Breithardt G. Outcome parameters for trials in atrial fibrillation: Recommendations from a consensus conference organized by the German Atrial Fibrillation Competence NETwork and the European Heart Rhythm Association. Europace 2007;9:1006-23.

5. Stewart S, Murphy NF, Walker A, McGuire A, McMurray JJ. Cost of an emerging epidemic: an economic analysis of atrial fibrillation in the UK. Heart 2004;90:286-92.

6. Le Heuzey JY, Paziaud O, Piot O, Said MA, Copie X, Lavergne T, Guize L. Cost of care distribution in atrial fibrillation patients: the COCAF study. Am Heart J 2004;147:121-6.

7. Wolowacz SE, Samuel M, Brennan VK, Jasso-Mosqueda JG, van Gelder IC. The cost of atrial fibrillation: a systematic review of the recent literature. Europace 2011;13:1375-85.

8. Ringborg A, Nieuwlaat R, Lindgren P, Jönsson B, Fidan D, Maggioni AP, Lopez-Sendon J, Stepinska J, Cokkinos DV, Crijns HJGM. Costs of atrial fibrillation in five European countries: results from the Euro Heart Survey on atrial fibrillation. Europace 2008;10: 403-11.

9. Heemstra HE, Nieuwlaat R, Meijboom M, Crijns HJ. The burden of atrial fibrillation in the Netherlands. Neth Heart J 2011;19:373-8.

10. Nieuwlaat R, Prins MH, Le Heuzey JY, Vardas PE, Aliot E, Santini M, Cobbe SM, Widdershoven JW, Baur LH, Lévy S, Crijns HJ. Prognosis, disease progression, quality of life and treatment of atrial fibrillation patients during 1 year: follow-up of the Euro Heart Survey on atrial fibrillation. Eur Heart J 2008;29:1181-9.

11. Nieuwlaat R, Eurlings LW, Cleland JG, Cobbe SM, Vardas PE, Capucci A, López-Sendòn JL, Meeder JG, Pinto YM, Crijns HJ. Atrial fibrillation and heart failure in cardiology practice: reciprocal impact and combined management from the perspective of atrial fibrillation: results of the Euro Heart Survey on atrial fibrillation. J Am Coll Cardiol 2009;53:1690-8.

12. Hendriks JM, de Wit R, Vrijhoef HJ, Tieleman RG, Crijns HJ. An integrated chronic care program for patients with atrial fibrillation: study protocol and methodology for an ongoing prospective randomised controlled trial. Int J Nurs Stud 2010;47:1310-6.

13. Wagner EH, Austin BT, Davis C, Hindmarsh M, Schaefer J, Bonomi A. Improving chronic illness care: translating evidence into action. Health Aff (Millwood) 2001;20:64-78.

14. Epping-Jordan JE, Pruitt SD, Bengoa R, Wagner EH. Improving the quality of health care for chronic conditions. Qual Saf Health Care 2004;13:299-305.

15. Hendriks JM, de Wit R, Crijns HJ, Vrijhoef HJ, Prins MH, Pisters R, Pison LA, Blaauw Y, Tieleman RG. Nurse-led care versus usual care for patients with atrial fibrillation: results of a randomized trial of integrated chronic care versus routine clinical care in ambulatory patients with atrial fibrillation. Eur Heart J 2012;33:2692-9 . 
16. de Bakker DH, Struijs JN, Baan CB, Raams J, de Wildt JE, Vrijhoef HJ, Schut FT. Early results from adoption of bundled payment for diabetes care in the Netherlands show improvement in care coordination. Health Aff (Millwood) 2012;31:426-33.

17. Ware JE Jr, Sherbourne CD. The MOS 36-item short-form health survey (SF-36). I.Conceptual framework and item selection. Med Care 1992;30:473-83.

18. Brazier J, Roberts J, Deverill M. The estimation of a preference based measure of health from the SF-36. J Health Econ 2002;21:271-92.

19. Drummond MF, O'Brien BJ, Stoddart GL, Torrance GW. Methods for the economic evaluation of health care programmes. 2nd ed. Oxford, NY: Oxford University Press; 1997.

20. Pharmacotherapeutic Compass. Available from http://www.fk.cvz.nl. Accessed March 20, 2012.

21. Briggs $A H$, Wonderling DE, Mooney CZ. Pulling cost-effectiveness analysis up by its bootstraps: a non-parametric approach to confidence interval estimation. Health Econ 1997;6:327-40.

22. Fenwick E, O'Brien BJ, Briggs A. Cost-effectiveness acceptability curves - facts, fallacies and frequently asked questions. Health Econ 2004;13:405-15.

23. Rijksoverheid, Evaluatiecommissie Integrale Bekostiging. Integrale bekostiging van zorg: Werk in uitvoering (eindrapport). Available at: http://www.rijksoverheid.nl/documentenen-publicaties/rapporten/2012/06/26/eindrapport-van-de-evaluatiecommissie-integralebekostiging-integrale-bekostiging-van-zorg-werk-in-uitvoering.html. Accessed July 24, 2012.

24. Boodhoo L, Bordoli G, Mitchell AR, Lloyd G, Sulke N, Patel N. The safety and effectiveness of a nurse led cardioversion service under sedation. Heart 2004;90:1443-6.

25. Inglis SC, Pearson S, Treen S, Gallasch T, Horowitz JD, Stewart S. Extending the horizon in chronic heart failure: effects of a multidisciplinary, home-based intervention relative to usual care. Circulation 2006;114:2466-73.

26. Federatie van Nederlandse Trombosediensten. Samenvatting Medische Jaarverslagen. Available at: http://www.fnt.nl/media/docs/jaarverslagen/JV_FNT_Medisch_2009.pdf. Accessed March 20, 2012. 



\section{SECTION IV}

Epilogue 



\section{CHAPTER 8}

General discussion 
Chapter 8 


\section{INTEGRATED CHRONIC CARE FOR PATIENTS WITH ATRIAL FIBRILLATION}

Atrial fibrillation (AF) is a highly prevalent heart rhythm disturbance, often associated with underlying heart disease ${ }^{1}$, and with a variety of clinical presentations and complaints. Underlying heart disease is often present, implying specific treatment and making the management of AF a complex task. Frequently, physicians overly focus on the arrhythmia itself, while neglecting appropriate treatment of the underlying disease and instalment of proper oral anticoagulation ${ }^{2,3}$. Even more, an integrated treatment with a central role for the patient in terms of self-management and shared decision making should be pursued. Since recurrences are most likely in AF it is considered a chronic condition, implying the need for long-lasting treatment. At the same time the prevalence of $A F$ is age-related ${ }^{4}$ and since the population is ageing it is expected that the number of AF patients will rise dramatically in the near future ${ }^{1,5,6}$. Consequently, we face future capacity problems and growing waiting lists. As a first response to these issues, an Integrated Chronic Care Program in terms of a nurse-led, guidelines based, software supported outpatient clinic for patients with AF was developed at the Maastricht University Medical Centre.

This thesis focuses on the effects of this novel approach. The present chapter provides a concise discussion of the most important findings of the randomized clinical trial which dealt with Integrated Chronic Care for AF. New insights and recommendations for future research, and for future management of AF patients are provided.

\section{THE FOUR PILLARS OF THE INTEGRATED ATRIAL FIBRILLATION CLINIC}

Integrated chronic care in the AF-Clinic is defined by four essential pillars, which together form the comprehensive, integrated approach ${ }^{7,8}$, translated into the Taxonomy of Integrated Chronic Atrial Fibrillation Management (Figure 8.1). It has been demonstrated before for diseases other than AF that the fusion of all individual pillars is the strength of this approach ${ }^{9}$. The results of the randomized study in this thesis seems to confirm the efficacy of integrated chronic care in AF. 


\begin{tabular}{|c|c|c|c|}
\hline & \multicolumn{2}{|c|}{ Integrated Chronic Atrial Fibrillation Management } & \\
\hline Task Substitution & $\begin{array}{l}\text { Evidence Based } \\
\text { Guidelines }\end{array}$ & Dedicated Software & Supervision \\
\hline $\begin{array}{l}\text { - Collaborative } \\
\text { practice model } \\
\text { - Multidisciplinary } \\
\text { team approach } \\
\text { - Communication } \\
\text { processes } \\
\text { - Skill mix } \\
\text {-Accessibilityof } \\
\text { care } \\
\text { - Redesigning } \\
\text { health care } \\
\text { - Nursing education }\end{array}$ & $\begin{array}{l}\text {-Availability and } \\
\text { accessibility } \\
\text { - Recommendations } \\
\text { on diagnostics and } \\
\text { therapeutics } \\
\text { - Risk assessment } \\
\text { schemes } \\
\text { - Prevention of } \\
\text { guideline deviant } \\
\text { procedures }\end{array}$ & $\begin{array}{l}\text { - Clinical decision } \\
\text { support } \\
\text { - Incorporation of } \\
\text { evidence based } \\
\text { guidelines } \\
\text { - Electronic checklist } \\
\text { - Individual risk } \\
\text { profile } \\
\text { - Focus on AF and } \\
\text { underlying disease } \\
\text { - Input required from } \\
\text { both caregiver and } \\
\text { patient }\end{array}$ & $\begin{array}{l}\text { - Indispensablework } \\
\text { relationship } \\
\text { - Reciprocal reliance } \\
\text { - Case manager and } \\
\text { ultimate medical } \\
\text { responsible } \\
\text { - Feedback loops } \\
\text { - Staff meetings } \\
\text { - Pre-condition: } \\
\text { availability of } \\
\text { supervising } \\
\text { cardiologist }\end{array}$ \\
\hline
\end{tabular}

Figure 8.1 Taxonomy on Integrated Chronic Atrial Fibrillation Management.

\section{Task substitution}

The increasing number of chronically ill patients, the changing consumer expectations and the limited capacity of resources and related costs of health care are the main drivers for task substitution from physicians to allied professionals ${ }^{10,11}$. Tasks that used to be reserved for medical doctors are now performed by nurse specialists, based on an efficient skill mix - identified care needs of AF population matched to the staff available in the AF-Clinic - and a multidisciplinary team approach ${ }^{12}$. In the literature the effectiveness of this principle was demonstrated in a variety of studies. The findings demonstrate a larger but more judicious use of resources in nursing care (e.g. requesting more diagnostic tests) and the duration of visits to the nurse are significantly longer - but qualitatively different - compared to physicians ${ }^{10}$. Nurses are more likely to provide effective patient education than physicians working alone, are easily accessible, and patients are more satisfied regarding the care provided compared to physicians ${ }^{11,13}$. Even more striking is the fact that clinical outcomes of nurse-led care for specific patient groups are better compared to standard care ${ }^{11,14-17}$. In line with prior findings, the results of the randomized study in this thesis suggest that nurse-led integrated care is associated with improved outcomes in patients with AF (chapter 5). 
Task substitution is an important pillar of the integrated chronic care approach. The fact that several disciplines work together in a collaborative practice model can be interpreted in terms of redesigning health care. The nurse specialist is a true specialist in the field of managing AF, who is highly trained and educated, operating largely independently and consulting the supervising cardiologist in case tasks go beyond the traditional borders of the nursing profession. This requires significant communication processes between both disciplines. As a consequence of task substitution, professional roles are changing and allied professional roles have been extended to the medical domain. Recently, the Netherlands Law regarding Professions in the Individual Health Care (Wet BIG) ${ }^{18}$ has been changed (by adding article 36a) to create a legal basis for assigning an independent competence for physician assistants and nurse specialists to perform restricted medical actions like prescribing medication or performing elective electrical cardioversions ${ }^{19,20}$. These new regulations are in effect, but content and practicability are as yet not sufficiently clear ${ }^{21}$. Obviously, dissemination needs time ${ }^{20}$.

\section{Evidence based guidelines}

The importance of guideline adherence might be obvious, but the Euro Heart Survey (EHS) demonstrated significant gaps between the evidence-based guidelines on the management of $\mathrm{AF}$ and daily practice ${ }^{2,3,22}$. AF awareness in patients is increasing ${ }^{23}$. Considering the enormous attention given to the guidelines by stakeholders, on websites, in research and publications, and also taking into account the improved accessibility, the availability of pocket versions, and the regular revisions of guidelines in the last decade, one may expect an excellent adherence to guideline recommendations among health care providers these days. Nevertheless, the results in this thesis still demonstrate significant guideline deviant AF management including non-adherence to diagnostic and therapeutic guideline recommendations in the usual care setting (chapter 4 and 5). In addition, the use of risk assessment schemes is recommended in the guidelines. A remarkable example is the appropriate use of oral anticoagulation conform the individual stroke risk analysis based on the $\mathrm{CHADS}_{2}$ score $^{24}$. Only $83 \%$ of patients in the usual care received appropriate oral anticoagulation treatment compared to $99 \%$ of patients is the nurse-led care group. As a consequence, a significant number of patients was not adequately protected against thromboembolic complications. Another guideline recommendation is the fact that thyroid stimulating hormone levels should be measured at least once ${ }^{25}$. Notably, this diagnostic procedure was performed in only half of the patients in the usual care (54\%) versus $91 \%$ in the nurse-led care (chapter 5 ).

The EHS on AF already demonstrated poor guideline adherence a few years before the AF-clinic was developed ${ }^{2,3}$. In a preliminary comparison of patients treated in the AF-Clinic with a historical control group (patients from our institution who participated in the EHS), we were able to demonstrate improved guideline adherent management in favour of the AF-Clinic. Patients in the historical control group had a 
longer treatment history which, we believe, should have resulted in increased guideline adherent management rather than the reverse. We reasoned that integrated chronic care prevents patients from receiving incomplete diagnostic and therapeutic management procedures (chapter 4). Moreover, these initial results gave us an indication that the intervention could work and encouraged us to move forward with the execution of the study, as we were convinced that there was room for further improvement in the treatment of patients with AF.

\section{Dedicated software}

The use of clinical decision support technology in patient care, incorporating evidence based guidelines, and primarily used by care providers, has grown tremendously in recent decades ${ }^{26-28}$. In heart failure, telemonitoring is a well known example, in which the patient is the primary user, resulting in a reduction of heart failure related hospitalizations and death ${ }^{29}$. In $\mathrm{AF}$, systems are marginally available to determine whether or not to prescribe guideline adherent oral anticoagulation in AF patients (30). No alternatives are available that focus on the management of AF and the underlying diseases, in terms of guideline adherent diagnostics and therapeutics, and in which input is required from both patient and care provider. Therefore, the development of the dedicated knowledge software system within the AF-Clinic is regarded innovative. The decision support software, based on the current guidelines ${ }^{25}$, is developed as an assisting tool in the care process for both the care provider (e.g. guideline-adherent checklist in terms of diagnostics and therapeutics) and the patient (e.g. in order to provide tailor-made care, active patient input is required). The system provides an individual patient risk profile and acts as an electronic checklist to ensure adherence to all diagnostic and therapeutic guideline recommendations. This not only results in guideline adherence, but also contributes to downsizing the complexity of AF management. Moreover, it ensures a more complete approach by focussing on underlying cardiovascular diseases rather than treating the arrhythmia alone. An additional effect of using the software is that it stimulates and facilitates communication processes in the multidisciplinary team (e.g. discussing guideline deviant decisions) which also has a teaching effect (chapter 2). However, in our opinion, one should bear in mind to use the software as an assisting tool rather than blindly trust it. Clinical thinking is still an essential task of the professional in collaboration with the patient.

\section{Supervision}

The multidisciplinary approach is built on the indispensable work relationship between cardiologists and nurse specialists, as these disciplines work closely together within the AF-Clinic. Both disciplines are in charge of care delivery to patients with AF, each in a specified role: the nurse specialist being the case manager and care provider, and the cardiologist being the supervising, and ultimately medically responsible health professional. The question always is, which discipline is most suited to provide the 
care the individual patient needs and at what time? Task substitution contributes to improved accessibility and quality of care, yet depends on additional expertise of medical specialists. Its expression may also be steered by down-to-earth financial incentives $^{31}$. However that may be, the relationship between involved disciplines is based on reciprocal reliance, which is vital in revealing clinically relevant findings on which therapeutic decisions can be made. According to this, staff meetings and feedback loops are of vital importance and contribute to multidisciplinary communication processes. I am convinced that the educational level and expertise of the nurse specialist as well as the duration and intensity of the relationship between stakeholders are critical success factors in nurse-led care (chapter 2). Both parties should feel safe to give and receive feedback, as this is an essential cornerstone in the integrated approach. Like in the aviation industry, pilot and co-pilot should cooperate and rely on each other to warrant a safe flight ${ }^{32}$. The same holds for the cardiologist and nurse specialist to secure guideline-based decisions and justify reciprocally guideline-deviant behaviour in order to provide the best available treatment strategy. In this respect, availability of the supervising cardiologist in this redesigned practice model is of utmost importance.

\section{DISCUSSION OF THE MAIN FINDINGS}

\section{Cardiovascular hospitalization and cardiovascular death}

The primary outcome parameter in the randomized trial was the composite of cardiovascular hospitalization and cardiovascular death. Since AF is associated with underlying heart disease, hospitalization and death, we reasoned that the choice for a composite outcome parameter is most appropriate. Moreover, in relevant related studies a similar combined endpoint has been used ${ }^{33-37}$.

In this study, the occurrence of the primary endpoint was significantly lower with nurse-led integrated care compared to usual care. More specific, the relative risk of cardiovascular hospitalization or death decreased by $35 \%$ in favour of the nurse-led integrated care. We considered this finding a consequence of using the integrated approach. Although the influences of the separate components were not investigated, the improved adherence to guidelines is considered to be a crucial element. Most striking was the benefit of integrated care in elderly patients with multi-morbidity in whom the management of both $\mathrm{AF}$ and underlying cardiovascular disease is very complex. Effects were however less evident in female and diabetic patients. It is well known that gender differences exist in patients with cardiac arrhythmias ${ }^{38-40}$. Notwithstanding the fact that women with AF frequently have more co-morbidities and consequently are sicker than men, therapeutic management in women is applied less attentively compared to men ${ }^{39}$. Therefore, integrated chronic care should have benefited especially women in the randomized study. However, that did not seem to be the case for which we do not have an explanation. Equally puzzling and not 
offering an explanation for the above was the finding that women in the study had similar characteristics at baseline and received similar guideline adherent therapy compared to men both in nurse-led care but unexpectedly also in the usual care group. Nevertheless, differences concerning impact of integrated care may have occurred since women - compared to men - may opt out on complex treatments like cardioversion and ablation especially if they are asymptomatic ${ }^{39,40}$. Not only in women, but also in patients with diabetes mellitus the effect of integrated care was less convincing. This may relate to the well-established integrated chronic care for diabetes patients in the Maastricht area ${ }^{41,42}$.

\section{Patient knowledge}

The nurse-led integrated care approach focuses on the promotion of healthy behaviour in patients, with a central role for the patient himself. The traditional physician - patient relationship, based on the belief that the 'doctor knows what's best for the patient', is for many patients not suitable anymore. Productive interaction is assumed to facilitate the care process and improve patient outcomes and is more likely in informed patients who are activated in their self-care role. Ideally, the patient becomes the principal caregiver ${ }^{43,44}$ and is increasingly recognized as a true member of the treatment team. The management of AF can be adequately taught to patients, with specific elements under direct control of the patient (e.g. use of medication, controlling INR, but also healthy life style activities). In this respect, providing knowledge on specific AF related subjects (e.g. the disease itself, potential AF related morbidities, treatment options, prognosis) is vital in helping patients understand the importance and fulfilment of self-management. The Atrial Fibrillation Knowledge Scale (AF knowledge scale) was developed in this study as a tool to gain insight in patients' AF related knowledge. During consultations with the patient, knowledge can be checked for correctness in order to tune the actual education to the patient's needs (chapter 3). Above all, during consultation the nurse specialist can check whether the patient is inclined to learn about his or her AF disease at all. After all this is the seeding soil patient self-care and empowerment has to grow on.

Patient education is provided by nurse specialists who - in contrast to physicians - can spend more dedicated time to the patient and are also properly trained for this activity. Together, this yields a dynamic process of 'collaborative care' in which communication, trust and reciprocal respect are vital elements that enable shared decision making ${ }^{45,46}$ leading to beneficial effects in the process and outcomes of medical care.

\section{Quality of life}

Quality of Life (QoL) is a broad concept and consists of objective and subjective indicators, covering a broad range of life domains and individual values ${ }^{47}$. Consequently, QoL is very divers and determined individually. Prior research demonstrated that $\mathrm{QoL}$ in patients with $\mathrm{AF}$ is often impaired ${ }^{48}$. This relates to 
symptoms of AF, the fact that recurrences in AF are very likely and consequently visits to the hospital or (re)admissions are often necessary. In this study we assessed the impact of the nurse-led approach on patients' QoL by means of the Medical Outcomes Study 36-Item Short Form Survey Instrument (SF-36), a standardized, generic questionnaire $^{49}$. The analysis on QoL demonstrated relatively favourable baseline scores in both groups, only somewhat worse compared to the general Netherlands population ${ }^{50,51}$. This may relate to the fact that we included patients with 'new' AF, which may have yielded a relatively 'healthy' patient study population with a short disease history. Despite the relatively high scores at baseline we demonstrated improvements in all QoL scales over time (chapter 6). Strikingly, this holds for both treatment arms. Since we hypothesized that the nurse-led integrated chronic care approach - with special attention for counselling and patient education - would have increasingly contributed to the patients' QoL compared to the usual care. Obviously, QoL was not influenced by the integrated care approach. On the other hand, these results are not that surprising since the management of $A F$ in general, aims to reduce symptoms and improve physical capacity ${ }^{52}$. Notwithstanding the above, we were able to show that knowledge is positively associated with QoL while anxiety and depression levels decrease. Therefore, it is recommendable to not only focus on QoL scores alone, but above that focus on factors that determine QoL.

\section{Patient satisfaction}

To determine patients' experiences of the treatment in both treatment arms, three questions regarding the satisfaction of patients were included in the follow-up questionnaire (not presented in the above). These questions evaluated the likeliness that patients would choose the same care in the future and the extent to which patients would recommend the received care to others. Finally, patients were asked to rate the care with a score from 0 to 10, in which higher scores indicate a better satisfaction. Overall, patients in both treatment arms were very satisfied, with very small differences between groups indicating an average likeliness of using the same care in the future again (94.3\% in the nurse-led care vs. $93.4 \%$ in the usual care), and recommendation to others with $96.7 \%$ vs. $94.1 \%$, respectively. Significant differences were however present with respect to the $0-10$ score. As shown in Figure 8.1, the nurse-led care is valued with higher scores, compared to usual care, resulting in a mean score $( \pm \mathrm{SD})$ of $8.1 \pm 1.5$ versus $7.7 \pm 1.4$ respectively $(P=0.003)$.

Patient satisfaction is related to many components, e.g. length, type and intensity of treatment, environment, goals, and outcomes ${ }^{53}$. Satisfaction in our study is comparable with other studies overall demonstrating higher levels of patient satisfaction in nurse-led cardiovascular care ${ }^{54-57}$ and in particular also in nurse-led cardioversion $^{58,59}$. 


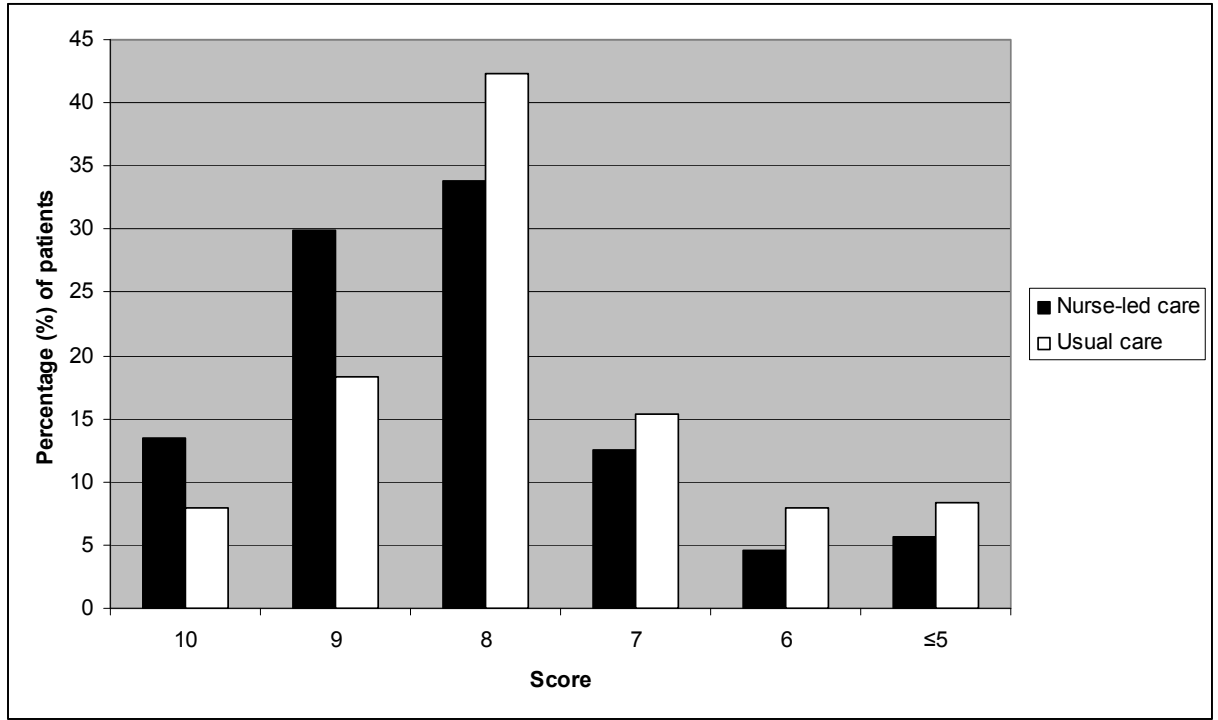

Figure 8.2 Patient satisfaction regarding the care received in the nurse-led care versus usual care, expressed on a point scale from $0-10$, with higher scores indication better patient satisfaction.

\section{Cost-effectiveness}

Evidence regarding the practicability and effectiveness of Chronic Care Model interventions demonstrates improved patient outcomes regarding knowledge, selfmanagement, quality of life, utilization of care, and clinical outcomes. Although studies predict lower health care costs for the future ${ }^{60-62}$, cost-effectiveness of integrated chronic care strategies however, remains rather unclear ${ }^{63}$. An explanation for this might be that it is too early for analysing empirical cost data as being cost saving. This relates to the fact that redesign interventions - like in the nurse-led approach of this thesis - is an investment for the future with higher costs in the short run and a return of investment only later in time ${ }^{64}$. Notwithstanding the above, the cost-benefit evaluation during a one year follow-up period, based on a hospital perspective (only incorporating hospital-related costs), showed that the nurse-led approach was effective in terms of clinical and patient-related outcome, towards lower costs compared to the usual care. However, as also recommended just recently ${ }^{65}$, further research on this topic is needed (chapter 7). 


\section{CONCEPTUAL AND METHODOLOGICAL CONSIDERATIONS}

\section{Integrated care}

In the introduction of this thesis the Chronic Care Model has been described as a synthesis of quality and disease management improvement. Quality improvement relates to theories focussing on quality improvement with respect to the impact of the intervention (e.g. how to realise the desired change) and the process of change (e.g. the method on how to create the change). However, it is recommended to integrate both theories ${ }^{66}$. Disease management aims to identify patients with common diseases, in order to provide them with education to stimulate self-management activities $^{67}$. The Chronic Care Model however goes beyond the borders of the current care system due to a 'systems approach'68, with attention for the individual components, as well as connections between them ${ }^{9}$. Inspired by the principles on quality improvement - being a combination of six elements - in the Chronic Care Model $^{7,8}$, we translated these elements and applied it to the nurse-led integrated approach. By doing so, we realized 1) collaboration between various care providers, particularly within the hospital, 2) providing patient education with the main aim to support patients and their families in managing their chronic disease in life, 3) a structural change in the process of care delivery (e.g. redesigning health care in terms of development of multidisciplinary teams within a collaborative practice model, using a planned approach), 4) a structured use of (and adherence to) evidence based guidelines, and 5) the application of clinical decision support systems to warrant evidence based care, and providing a tool to reflect on professionals' own actions. Although this is an achievement completely in line with an integrated chronic care management approach, room for improvement remains since the nurse-led integrated approach focussed on horizontal integration rather than on vertical integration. Collaboration and communication with care providers outside the hospital (e.g. general practitioners, thrombosis services and other societal services) is relatively poor in AF management. By involving the combination of these different parties, vertical integration can be stimulated. Also, prioritization of chronic care in terms of goals, structure and cultural changes could be strengthened, to further improve quality, collaboration between care providers, and management in patients with AF. Moreover, the endpoints as described in this study can be studied in a broader, multi-centre perspective. A structured approach to patient education and self-care management for patients (and their families) deserves a central role in the approach, using the AF knowledge scale. Also concentration on prevention of cardiovascular risks, the use of tailored patient technology and investigating possibilities to save health related costs are of significant importance.

Since AF is associated with multi co-morbidity, straightforward disease management of AF only would not have been appropriate (enough), since it mainly focuses on patients with that specific disease. Therefore we defined the nurse-led approach in 
this study, based on the principles of the Chronic Care Model, as an integrated chronic care approach, rather than a disease management program.

\section{Patient population}

The longer AF exists, the higher the odds it will remain (AF begets AF), developing from paroxysmal into persistent or even permanent AF. Likewise, AF-related complications increase steadily over time ${ }^{69}$. In the present study, patients with newly diagnosed AF were included. The majority of cases had a short AF-history with many showing paroxysmal AF, although persistent and permanent AF were seen also (e.g. in new detected asymptomatic patients). In case of early detection of the arrhythmia, AF-related complications can be prevented by an integrated approach. The AF population I studied is generally considered relatively 'healthy'. Nevertheless, associated diseases - even concealed ${ }^{70,71}$ and also cardiovascular events can be frequent, especially in first detected $\mathrm{AF}^{3}$.

\section{Primary endpoint}

The choice for cardiovascular hospitalizations in the primary endpoint is based on the fact that a relevant proportion of hospitalizations can be attributed to major adverse cardiac and cerebral events (MACCE) directly or indirectly associated with $\mathrm{AF}^{72}$. Hospitalization was considered to be at least one overnight stay, including two consecutive days. One could argue the appropriateness of the chosen endpoint regarding the difference between acute or unplanned cardiovascular hospitalizations versus planned hospitalizations (e.g. in terms of interventional or surgical procedures). To prevent uncertainty in future studies of the kind I did, it is recommended to specify this in the definition of the type of hospitalization. The same holds for the definition of the duration of hospitalization. In this study, visits to the emergency department as well as planned visits for cardioversion were not considered a cardiovascular hospitalization, for the reason that these were one-day-admissions without patients staying overnight. For completeness it can be mentioned that cardiovascular death

was assessed on the basis of criteria originally developed by Hinkle and Thaler ${ }^{73}$, classifying death into cardiac arrhythmic, cardiac non-arrhythmic, vascular non cardiac deaths, and non cardiovascular. All events were adjudicated by an independent Endpoint Event Committee.

\section{The existence of the AF-Clinic influencing the control group}

Possible contamination of control group patients is worth attention. To prevent contamination through an effect on patient behaviour, randomization was done such that control patients did not learn about the execution of the study nor the existence of the AF-Clinic. The cardiologists managing AF patients routinely in our clinic, might have been affected by the procedures followed in the AF-Clinic. Even though they did not know which patients were taking part in the study, patients themselves might 
have indicated this (e.g. by handing in their completed questionnaires to their physician). Consequently, physicians may have been triggered to improve their performance, from which control patients might have benefited. From a methodological point of view this is not desirable, while from a practical point of view this improvement of care is very much applauded.

\section{IMPLICATIONS FOR PRACTICE AND FUTURE RESEARCH}

\section{Implications for practice and policy}

Guideline deviant patient care is a long-standing, wide spread problem in health care for which providing evidence-based guidelines alone is not the solution. Moreover, physicians apparently cannot handle this problem alone. Therefore, we advocate integrated chronic care management as an important contribution in closing the gap between guidelines and current practice. Notably, the current guidelines in the management of $\mathrm{AF}^{69,74}$ do not advocate (nurse-led) integrated chronic care management yet, while one would have expected that current opinion leaders are convinced of the necessity of this approach by now. Indeed, one randomized single centre study is not enough for a class I, level of evidence A recommendation. Nevertheless, I strongly advocate nurse-led integrated chronic care management preferably according to the Taxonomy of Chronic Atrial Fibrillation Management, as presented in this thesis - to be adopted in the next AF guidelines albeit as an option based level of evidence $C$ recommendation.

In daily AF management, attention for patient education and self-management is lacking, while self-care is considered essential in the management of chronic illness ${ }^{75}$. Not surprisingly, patient education is not structured and therefore insufficiently provided in current AF practices and in worst case scenarios even not provided. Consequently, patients are not activated in their self-management role. I am convinced that the results presented in this thesis might be a trigger to improve activities regarding this theme, not only for those colleagues who consider developing future AF-clinics, but all others involved in the management of patients with AF. This also includes the importance of assessing patient capabilities for self-management resulting in an individualized tailored approach matching the patients' level and capacities $^{76}$. Moreover, I advocate for development of structured patient educational and self-management programs in the near future and feel encouraged in this since related research has been largely conducted in the field of heart failure, with favourable outcome ${ }^{75,77}$. These important examples can act as a guide in the development of structured patient educational and self-management programs in AF. With respect to the redesigning process and the organisational aspects of nurse-led integrated chronic care management within an AF-Clinic, significant attention should be paid to the principles of the Chronic Care Model as the basis of integrated care development. Further, one should bear in mind that redesigning processes require a 
new vision concerning the need for role changes of all parties involved (i.e. patient, nurse specialist, cardiologist, general practitioner, hospital management, hospital board, health insurer, Ministry of Health). Regarding the practicability of the intervention, supervision is considered one of the most essential preconditions. Agreements on presence of the supervising cardiologist during nurse-led consulting hours and the interpretation and scope of the supervision should be installed. Also, agreements on reimbursement of integrated care delivery with health insurers must be considered ${ }^{78,79}$. In conclusion, many new avenues need to be taken before the integrated approach can come into operation. It is highly recommended to spend significant attention to the preparation and implementation of a redesigning process like that undertaken in this study, which will be of major future benefit ${ }^{80}$.

\section{Implications for future research}

The current study has been performed in the Maastricht University Medical Centre. The hospital serves as a regional hospital for the Maastricht area but also provides highly specialized academic clinical care. The department of cardiology is nationally and internationally respected for the highly specialized treatment of arrhythmias, in particular AF. A new building block for integrated AF management being the hybrid approach, has become available and is the most recent innovation from the centre ${ }^{81}$. Knowing the focussed attention on AF in the Maastricht university hospital, the results of the randomized study are even more noteworthy. Therefore, I recommend to further study the generalizability of the findings in our study to other cardiologic outpatient settings by doing new multi-centre studies (e.g. in university as well as non-university institutions, as well as national and international comparative studies).

With respect to the prior recommendation it is likely that more AF-clinics will be developed using the integrated care approach. Investigation of the implementation process, including objectifying the barriers and facilitators, the necessary conditions for such an approach as well as its cost-effectiveness is recommended to be subject of future studies.

Patient education and self-management in the field of AF are important topics that have been insufficiently researched. Moreover, structural patient educational programs are not available and provision of information and instruction in daily care is dependent of practical, organizational, personal and time-related factors. This relates to a professional as well as a patient perspective. However, relevant factors as well as facilitators and barriers in the process of patient education and self-management in AF have not been mapped well. This would also need to be researched in the future. 


\section{CONCLUSION}

In this thesis, the effectiveness of an integrated chronic care program for patients with AF has been studied, in comparison with usual care. The integrated nurse-led, guideline-based, software supported approach turned out to be superior in terms of cardiovascular hospitalization and death. Moreover, guideline-adherent management was significantly better and knowledge levels were higher in the nurse-led approach. Although innovations are associated with high costs, the nurse-led approach is costeffective, in particular by preventing patients from being hospitalized. In conclusion, integrated chronic care management for patients with AF is (cost)-effective. However, before widespread implementation of the approach, further (multi-centre) research is necessary to determine the generalizability of the data. 


\section{REFERENCES}

1. Go AS, Hylek EM, Phillips KA, Chang Y, Henault LE, Selby JV, Singer DE. Prevalence of diagnosed atrial fibrillation in adults: national implications for rhythm management and stroke prevention: the AnTicoagulation and Risk Factors in Atrial Fibrillation (ATRIA) Study. JAMA 2001;285:2370-5.

2. Nieuwlaat R, Capucci A, Camm AJ, Olsson SB, Andresen D, Davies DW, Cobbe S, Breithardt G, Le Heuzey JY, Prins MH, Levy S, Crijns HJ. Atrial fibrillation management: a prospective survey in ESC member countries: the Euro Heart Survey on Atrial Fibrillation. Eur Heart $J$ 2005;26:2422-34.

3. Nieuwlaat R, Prins MH, Le Heuzey JY, Vardas PE, Aliot E, Santini M, Cobbe SM, Widdershoven JW, Baur LH, Lévy S, Crijns HJ. Prognosis, disease progression, and treatment of atrial fibrillation patients during 1 year: follow-up of the Euro Heart Survey on atrial fibrillation. Eur Heart $J$ 2008;29:1181-9.

4. Heeringa J, van der Kuip DA, Hofman A, Kors JA, van Herpen G, Stricker BH, Stijnen T, Lip GY, Witteman JC. Prevalence, incidence and lifetime risk of atrial fibrillation: the Rotterdam study. Eur Heart J 2006;27:949-53.

5. Stewart S, Hart CL, Hole DJ, McMurray JJ. Population prevalence, incidence, and predictors of atrial fibrillation in the Renfrew/Paisley study. Heart 2001;86:516-21.

6. Miyasaka Y, Barnes ME, Gersh BJ, Cha SS, Bailey KR, Abhayaratna WP, Seward JB, Tsang TS. Secular trends in incidence of atrial fibrillation in Olmsted County, Minnesota, 1980 to 2000, and implications on the projections for future prevalence. Circulation 2006;114: 119-25.

7. Wagner EH, Austin BT, Von Korff M. Improving outcomes in chronic illness Manag Care $Q$ 1996(a);4:12-25.

8. Wagner EH, Austin BT, Von Korff M. Organizing care for patients with chronic illness. Milbank Q 1996(b);74:511-44.

9. Coleman K, Mattke S, Perrault PJ, Wagner EH. Untangling practice redesign from disease management: how do we best care for the chronically ill? Annu Rev Public Health 2009;30:385-408.

10. Laurant $M$, Harmsen $M$, Wollersheim $H$, Grol R, Faber M, Sibbald B. The impact of nonphysician clinicians: do they improve the quality and cost-effectiveness of health care services? Med Care Res Rev 2009;66:36S-89S.

11. Laurant M, Harmsen M, Faber M, Wollersheim H, Sibbald B, Grol R. Revision of professional roles and quality improvement: a review of the evidence. London: The Health Foundation; 2010.

12. Buchman J, Dal Poz MR. Skill mix in the health care workforce: reviewing the evidence. Bull Wold Health Organ 2002;80:575-80.

13. Laurant M, Reeves D, Hermens R, Braspenning J, Grol R, Sibbald B. Substitution of doctors by nurses in primary care. Cochrane Database Syst Rev 2004;CD001271.

14. Vrijhoef HJ, Diederiks JP, Spreeuwenberg C, Wolffenbuttel BH. Substitution model with central role for nurse specialist is justified in the care for stable type 2 diabetic outpatients. J Adv Nurs 2001;36:546-55.

15. Meulepas MA, Jacobs JE, Smeenk FW, Smeele I, Lucas AE, Bottema BJ, Grol RP. Effect of an integrated primary care model on the management of middle-aged and old patients with obstructive lung diseases. Scand J Prim Health Care 2007;25:186-92.

16. Houweling ST, Kleefstra N, van Hateren KL, Kooy A, Groenier KH, Ten Vergert E, Meyboomde Jong B, Bilo HJ, Langerhans Medical Research Group. Diabetes specialist nurse as main care provider for patients with type 2 diabetes. Neth J Med 2009;67:279-84. 
17. Houweling ST, Kleefstra N, van Hateren KL, Groenier KH, Meyboom-de Jong B, Bilo HJ. Can diabetes management be safely transferred to practice nurses in a primary care setting? A randomised controlled trial. J Clin Nurs 2011;20:1264-72.

18. Inspectie voor de Gezondheidszorg, Ministerie van Volksgezondheid Welzijn en Sport. Wet op de beroepen in de individuele gezondheidszorg (Wet BIG). Available at: http://www.igz.nl/onderwerpen/handhavingsinstrumenten/wetten/wet_big/ Accessed July 10, 2012.

19. Eerste Kamer der Staten Generaal. Wijziging van de Wet op de beroepen in de individuele gezondheidszorg onder andere in verband met de opneming van de mogelijkheid tot taakherschikking. Available at: http://www.eerstekamer.nl/wetsvoorstel/32261_ wijziging_van_de_wet_op_de. Accessed July 18, 2012.

20. De Bruijn-Geraets D, van Eijk-Hustings $Y$, Vrijhoef B. Nulmeting Evaluatieonderzoek Art. 36a Wet BIG met betrekking tot de inzet van de Physician Assistant en de Verpleegkundig Specialist: een samenvatting. Available at: http://venvnvs.nl/wp-content/uploads/ 2012/06/Samenvatting-Nulmeting-Evaluatieonderzoek-Art-36a-Wet-BIG.pdf. Accessed July 18, 2012.

21. Dierick-van Daele AT, Spreeuwenberg C, Derckx EW, van Leeuwen Y, Toemen T, Legius M, Janssen JJ, Metsemakers JF, Vrijhoef HJ. The value of nurse practitioners in Dutch general practices. Qual Prim Care 2010;18:231-41.

22. Nieuwlaat R, Capucci A, Lip GY, Olsson SB, Prins MH, Nieman FH, López-Sendón J, Vardaz $\mathrm{PE}$, Aliot $\mathrm{E}$, Santini $\mathrm{M}$, Crijns HJ. Antithrombotic treatment in real-life atrial fibrillation patients. Eur Heart J 2006;27:3018-26.

23. StopAfib.org. Available at: http://www.stopafib.org/newsitem.cfm/NEWSID/277/ atrial\%20fibrillation\%20patient\%20information/educate\%20afib\%20caregivers/ Accessed July 18, 2012.

24. Gage BF, Waterman AD, Shannon W, Boechler M, Rich MW, Radford MJ. Validation of clinical classification schemes for predicting stroke: results from the National Registry of Atrial Fibrillation. JAMA 2001;285:2864-70.

25. Fuster V, Rydén LE, Cannom DS, Crijns HJ, Curtis AB, Ellenbogen KA, Halperin JL, Le Heuzey JY, Kay GN, Lowe JE, Olsson SB, Prystowsky EN, Tamargo JL, Wann S, Task Force on Practice Guidelines, American College of Cardiology/American Heart Association; Committee for Practice Guidelines, European Society of Cardiology, European Heart Rhythm Association, Heart Rhythm Society. ACC/AHA/ESC 2006 guidelines for the management of patients with atrial fibrillation - executive summary: a report of the American College of Cardiology/American Heart Association Task Force on Practice Guidelines and the European Society of Cardiology Committee for Practice Guidelines (Writing Committee to revise the 2001 guidelines for the management of patients with atrial fibrillation). Eur Heart $J$ 2006;27:1979-2030.

26. Lobach DF, Hammond WE. Computerized decision support based on a clinical practice guideline improves compliance with care standards. Am J Med 1997;102:89-98.

27. Persson M, Mjörndal T, Carlberg B, Bohlin J, Lindholm LH. Evaluation of a computer-based decision support system for treatment of hypertension with drugs: retrospective, nonintervention testing of cost and guideline adherence. J Intern Med 2000;247:87-93.

28. Milani RV, Lavie CJ, Dornelles AC. The impact of achieving perfect care in acute coronary syndrome: The role of computer assisted decision support. Am Heart J 2012;164:29-34.

29. Inglis SC, Clark RA, McAlister FA, Ball J, Lewinter C, Cullington D, Stewart S, Cleland JG. Structured telephone support or telemonitoring programmes for patients with chronic heart failure. Cochrane database Syst Rev 2010;CD007228. 
30. Wess ML, Schauer DP, Johnston JA, Moomaw CJ, Brewer DE, Cook EF, Eckman MH. Application of a decision support tool for anticoagulation in patients with non-valvular atrial fibrillation. J Gen Intern Med 2008;23:411-7.

31. Raad voor de Volksgezondheid en Zorg. Taakherschikking in de gezondheidszorg. Available at: http://rvz.net/publicaties/bekijk/taakherschikking-in-de-gezondheidszorg. Accessed July 18, 2012.

32. Buljac-Samardzic $M$, Dekker-van Doorn CM, van Wijngaarden JD, van Wijk KP. Interventions to improve team effectiveness: a systematic review. Health Policy 2010; 94:183-95.

33. Van Gelder IC, Hagens VE, Bosker HA, Kingma JH, Kamp O, Kingma T, Said SA, Darmanata JI, Timmermans AJ, Tijssen JG, Crijns HJ, Rate Control versus Electrical Cardioversion for Persistent Atrial Fibrillation Study Group. A comparison of rate control and rhythm control in patients with recurrent persistent atrial fibrillation. N Engl J Med 2002;347:1834-40.

34. Carlsson J, Miketic S, Windeler J, Cuneo A, Haun S, Micus S, Walter S, Tebbe U, STAF Investigators. Randomized trial of rate-control versus rhythm-control in persistent atrial fibrillation: the Strategies of Treatment of Atrial Fibrillation (STAF) study. J Am Coll Cardiol 2003;41:1690-6.

35. Opolski G, Torbicki A, Kosior DA, Szulc M, Wozakowska-Kaplon B, Kolodziej P, Achremczyk $P$. Rate control vs. rhythm control in patients with nonvalvular persistent atrial fibrillation: the results of the Polish How to Treat Chronic Atrial Fibrillation (HOT CAFE) Study. Chest 2004;126:476-86.

36. Connolly S, Pogue J, Hart R, Pfeffer M, Hohnloser S, Chrolavicius S, Yusuf S. Clopidogrel plus aspirin versus oral anticoagulation for atrial fibrillation in the Atrial fibrillation Clopidogrel Trial with Irbesartan for prevention of Vascular Events (ACTIVE W): a randomised controlled trial. Lancet 2006;367:1903-12.

37. Van Gelder IC, Van Veldhuisen DJ, Crijns HJ, Tuininga YS, Tijssen JG, Alings AM, Bosker HA, Cornel JH, Kamp O, Veeger NJ, Volbeda M, Rienstra M, Ranchor AV, TenVergert EM, Van den Berg MP. RAte Control Efficacy in permanent atrial fibrillation: a comparison between lenient versus strict rate control in patients with and without heart failure. Background, aims, and design of RACE II. Am Heart J 2006; 152:420-6.

38. Rienstra M, Van Veldhuisen DJ, Hagens VE, Ranchor AV, Veeger NJ, Crijns HJ, Van Gelder IC, RACE Investigators. Gender-related differences in rhythm control treatment in persistent atrial fibrillation: data of the Rate Control Versus Electrical Cardioversion (RACE) study. J Am Coll Cardiol 2005;46:1298-306.

39. Dagres N, Nieuwlaat R, Vardas PE, Andresen D, Lévy S, Cobbe S, Kremastinos DT, Breithardt G, Cokkinos DV, Crijns HJ. Gender-related differences in presentation, treatment, and outcome of patients with atrial fibrillation in Europe: a report from the Euro Heart Survey on Atrial Fibrillation. J Am Coll Cardiol 2007;49:572-7.

40. Ghani A, Maas AH, Delnoy PP, Ramdat Misier AR, Ottervanger JP, Elvan A. Sex-Based Differences in Cardiac Arrhythmias, ICD Utilisation and Cardiac Resynchronisation Therapy. Neth Heart J 2011;19:35-40.

41. Steuten LM, Vrijhoef HJ, Landewé-Cleuren S, Schaper N, Van Merode GG, Spreeuwenberg C. A disease management programme for patients with diabetes mellitus is associated with improved quality of care within existing budgets. Diabet Med 2007;24:1112-20.

42. Elissen A, Duimel I, Spreeuwenberg C, Vrijhoef B. Towards tailored disease management for type 2 diabetes. Am J Man Care 2012 (in press).

43. Lorig K. Self-management of chronic illness: a model for the future. Generations 1993;17:11-4.

44. Bodenheimer T, Wagner EH, Grumbach K. Improving primary care for patients with chronic illness. JAMA 2002;288:1775-9. 
45. van der Weijden $T$, van Veenendaal $H$, Drenthen $T$, Versluijs $M$, Stalmeier $P$, Koelewijn-van Loon M, Stiggelbout A, Timmermans D. Shared decision making in the Netherlands, is the time ripe for nationwide, structural implementation? Z Evid Fortbild Qual Gesundhwes 2011;105:283-8.

46. Stiggelbout AM, Van der Weijden T, De Wit MP, Frosch D, Légaré F, Montori VM, Trevena L, Elwyn G. Shared decision making: really putting patients at the centre of healthcare. BMJ 2012;344:e256. doi: 210.1136/bmj.e1256.

47. Felce D, Perry J. Quality of life: its definition and measurement. Res Dev Disabil 1995;16:51-74.

48. Thrall G, Lane D, Caroll D, Lip GY. Quality of life in patients with AF: a systematic review. Am J Med 2006;119:448.e1-19.

49. Brazier JE, Harper R, Jones NM, O'Cathain A, Thomas KJ, Usherwood T, Westlake L. Validating the SF-36 health survey questionnaire: new outcome measure for primary care. BMJ 1992;305:160-4.

50. Aaronson NK, Muller M, Cohen DP, Essink-Bot ML, Fekkes M, Sanderman R, Sprangers MA, te Velde A, Verrips E. Translation, validation, and norming of the Dutch language version of the SF-36 Health Survey in community and chronic disease populations. J Clin Epidemiol 1998;51:1055-68.

51. Rijksinstituut voor Volksgezondheid en Milieu, Ministerie van Volksgezondheid Welzijn en Sport. National Guide on Health: Quality of life in people in The Netherlands (in Dutch: Nationaal Kompas Volksgezondheid: Wat is de kwaliteit van leven van mensen in Nederland?). Available at: http://www.nationaalkompas.nl/gezondheid-en-ziekte/ functioneren-en-kwaliteit-van-leven/kwaliteit-van-leven/wat-is-de-kwaliteit-van-levenvan-mensen-in-nederland/ Accessed June 28, 2012.

52. Camm AJ. Quality of life in patients with atrial fibrillation. Rev Esp Cardiol 2010; 63:1393-5.

53. Hoekstra T, Lesman-Leegte I, van der Wal M, Luttik ML, Jaarsma T. Nurse-led interventions in heart failure care: patient and nurse perspectives. Eur J Cardiovasc Nurs 2010;9:226-32.

54. Broers CJ, Smulders J, van der Ploeg TJ, Arnold AE, Umans VA. [Nurse practitioner equally as good as a resident in the treatment of stable patients after recent myocardial infarction, but with more patient satisfaction]. Ned Tijdschr Geneeskd 2006;150:2544-8.

55. Voogdt-Pruis HR, Gorgels AP, van Ree JW, van Hoef EF, Beusmans GH. Patient perceptions of nurse-delivered cardiovascular prevention: cross-sectional survey within a randomised trial. Int J Nurs Stud 2010;47:1237-44.

56. Edwall LL, Hellström AL, Ohrn I, Danielson E. The lived experience of the diabetes nurse specialist regular check-ups, as narrated by patients with type 2 diabetes. J Clin Nurs 2008;17:772-81.

57. Ovaisi S, Ibison J, Leontowitsch M, Cloud G, Oakeshott P, Kerry S. Stroke patients' perceptions of home blood pressure monitoring: a qualitative study. $\mathrm{Br} J$ Gen Pract 2011;61:e604-10.

58. Valente $M$, Zwaan E, Wit M, Kimman GP, Umans V. Effects of a digital clinical pathway for elective electrocardioversion for atrial fibrillation on quality of care. Crit Pathw Cardiol 2010;9:207-11.

59. Boodhoo L, Bordoli G, Mitchell AR, Lloyd G, Sulke N, Patel N. The safety and effectiveness of a nurse led cardioversion service under sedation. Heart 2004; 90:1443-6.

60. Wagner EH, Sandhu N, Newton KM, McCulloch DK, Ramsey SD, Grothaus LC. Effect of improved glycemic control on health care costs and utilization. JAMA 2001; 285:182-9.

61. Steuten L, Palmer S, Vrijhoef B, van Merode F, Spreeuwenberg C, Severens H. Cost-utility of a disease management program for patients with asthma. Int J Technol Assess Health Care 2007;23:184-91. 
62. Drewes HW, Steuten LM, Lemmens LC, Baan CA, Boshuizen HC, Elissen AM, Lemmens KM, Meeuwissen JA, Vrijhoef HJ. The Effectiveness of Chronic Care Management for Heart Failure: Meta-Regression Analyses to Explain the Heterogeneity in Outcomes. Health Serv Res 2012; doi: 10.1111/j.1475-6773.2012.01396.x.

63. Coleman K, Austin BT, Brach C, Wagner EH. Evidence on the Chronic Care Model in the new millennium. Health Aff (Millwood) 2009;28:75-85.

64. Huang ES, Brown SE, Zhang JX, Kirchhoff AC, Schaefer CT, Casalino LP, Chin MH. The cost consequences of improving diabetes care: the community health center experience. $J t$ Comm J Qual Patient Saf 2008; 34:138-146.

65. Vrijhoef HJ. Chronically ill are the future (in Dutch: Chronisch zieken hebben de toekomst), Inaugural Speech. Tilburg, The Netherlands: Tilburg University; 2010.

66. Grol RP, Bosch MC, Hulscher ME, Eccles MP, Wensing M. Planning and studying improvement of care: the use of theoretical perspectives. Milbank Q 2007;85:93-138.

67. Casalino LP. Disease management and the organization of physician practice. JAMA 2005;293:485-8.

68. Todd WE, Nash D. Disease Management: a systems approach to improving patient outcomes. San Francisco: Jossey-Bass;1997.

69. Camm AJ, Kirchhof P, Lip GY, Schotten U, Savelieva I, Ernst S, Van Gelder IC, Al-Attar N, Hindricks $G$, Prendergast $B$, Heidbuchel $H$, Alfieri $O$, Angelini $A$, Atar D, Colonna $P$, De Catarina R, De Sutter J, Goette A, Gorenek B, Heldal M, Hohloser SH, Kolh P, Le Heuzey JY, Ponikowski P, Rutten FH, European Heart Rhythm Association, European Association for Cardio-Thoracic Surgery. Guidelines for the management of atrial fibrillation of the European Society of Cardiology (ESC). Eur Heart J 2010;31:2369-429.

70. Weijs B, de Vos CB, Tieleman RG, Peeters FE, Limantoro I, Kroon AA, Cheriex EC, Pisters R, Crijns HJ. The occurrence of cardiovascular disease during 5-year follow-up in patients with idiopathic atrial fibrillation. Europace 2012; doi:10.1093/europace/eus203.

71. Weijs B, Pisters R, Haest RJ, Kragten JA, Joosten IA, Versteylen M, Timmermans CC, Pison L, Blaauw Y, Hofstra L, Nieuwlaat R, Wildberger J, Crijns HJ. Patients originally diagnosed with idiopathic atrial fibrillation more often suffer from insidious coronary artery disease compared to healthy sinus rhythm controls. Heart Rhythm 2012; doi.org/10.1016/j.hrthm.2012.08.013.

72. Kirchhof P, Auricchio A, Bax J, Crijns H, Camm J, Diener HC, Goette A, Hindricks G, Hohnloser S, Kappenberger L, Kuck KH, Lip GY, Olsson B, Meinertz T, Priori S, Ravens U, Steinbeck G, Svernhage E, Tijssen J, Vincent A, Breithardt G. Outcome parameters for trials in atrial fibrillation: executive summary. Eur Heart J 2007; 28:2803-17.

73. Hinkle LE Jr, Thaler HT. Clinical classification of cardiac deaths. Circulation 1982; 65:45764.

74. Authors/Task Force Members, Camm AJ, Lip GY, De Caterina R, Savelieva I, Atar D, Hohnloser SH, Hindricks G, Kirchhof P, ESC Committee for Practice Guidelines (CPG), Bax JJ, Baumgartner H, Ceconi C, Dean V, Deaton C, Fagard R, Funck-Brentano C, Hasdai D, Hoes A, Kirchhof $P$, Knuuti J, Kolh P, McDonagh T, Moulin C, Popescu BA, Reiner Z, Sechtem $U$, Sirnes PA, Tendera $M$, Torbicki A, Vahanian A, Windecker $S$, Document Reviewers, Vardas P, Al-Attar N, Alfieri O AA, Blömstrom-Lundqvist C, Colonna P, De Sutter J, Ernst S, Goette A, Gorenek B, Hatala R, Heidbüchel H, Heldal M, Kristensen SD, Kolh P, Le Heuzey JY, Mavrakis H, Mont L, Filardi PP, Ponikowski P, Prendergast B, Rutten FH, Schotten U, Van Gelder IC, Verheugt FW. 2012 focussed update of the ESC Guidelines for the management of atrial fibrillation: An update of the 2010 ESC Guidelines for the management of atrial fibrillation * Developed with the special contribution of the European Heart Rhythm Association. Eur Heart J 2012;33:2719-47. 
75. Riegel B, Jaarsma T, Strömberg A. A middle-range theory of self-care of chronic illness. Adv Nurs Sci 2012; doi:10.1097/ANS.0b013e318261b1ba.

76. Hibbard JH, Greene J, Tusler M. Improving the outcomes of disease management by tailoring care to the patient's level of activation. Am J Manag Care 2009;15:353-60.

77. Stromberg A, Martensson J, Fridlund B, Levin LA, Karlsson JE, Dahlstrom U. Nurse-led heart failure clinics improve survival and self-care behaviour in patients with heart failure: results from a prospective, randomised trial. Eur Heart J 2003;24:1014-23.

78. de Bakker DH, Struijs JN, Baan CB, Raams J, de Wildt JE, Vrijhoef HJ, Schut FT. Early results from adoption of bundled payment for diabetes care in the Netherlands show improvement in care coordination. Health Aff (Millwood) 2012;31:426-33.

79. Rijksoverheid. Eindrapport van de Evaluatiecommissie Integrale Bekostiging - Integrale bekostiging van zorg: Werk in uitvoering. Available at: http://www.rijksoverheid.nl/ ministeries/vws/documenten-en-publicaties/rapporten/2012/06/26/eindrapport-van-deevaluatiecommissie-integrale-bekostiging-integrale-bekostiging-van-zorg-werk-inuitvoering.html. Accessed July 18, 2012.

80. Voogdt-Pruis HR, Vrijhoef HJ, Beusmans GH, Gorgels AP. Quality improvement of nurse-led aftercare to outpatients with coronary heart disease: report of a case study. Int J Qual Health Care 2012;24:286-92.

81. Pison L, La Meir M, van Opstal J, Blaauw Y, Maessen J, Crijns HJ. Hybrid thoracoscopic surgical and transvenous catheter ablation of atrial fibrillation. J Am Coll Cardiol 2012;60:54-61. 



\section{SUMMARY}

This thesis consists of eight chapters that are arranged into four interrelated sections. In this summary, the key points from the various chapters are succinctly presented.

The general introduction of this thesis (chapter 1) describes the cardiac arrhythmia atrial fibrillation (AF) and the background of this thesis in terms of the Euro Heart Survey on AF, evidence based guidelines, disease management and integrated chronic care. Moreover, the aims and outline of the thesis are presented in this chapter.

AF is the most common cardiac arrhythmia in the Western world. It is associated with underlying heart diseases (e.g. hypertension, heart failure, valvular heart disease) and an increased risk of tromboembolic complications like Transient Ischaemic Attack (TIA) or stroke. The prevalence of AF is 1-2 \% in general population and increasing with age. Due to aging of the population this number is expected to rise dramatically in the near future. The economic burden of AF is high and consequently AF is considered a relative expensive disease.

Between 2003 and 2005, the Euro Heart Survey on AF was performed in 35 European Society of Cardiology (ESC) member countries, including 5333 AF patients. The survey gave important insights in the management of AF throughout Europe and demonstrated generally poor guideline adherence. Moreover, the suboptimal management was associated with increased morbidity and mortality. The nonadherence contrasts to the fact that evidence based guidelines for the management of $\mathrm{AF}$ are available, being yearly reviewed and revised if needed.

The number of patients with chronic diseases has evolved enormously over the last decade. Chronic diseases increasingly manifest at younger ages. Early detection allows early intervention and consequently patients live longer with a chronic disease. The latter especially holds for the burden of cardiovascular diseases. Furthermore, chronic care is associated with undesirable fragmentation, which results in reactive behaviour of care providers, with the emphasis of care on medical-technical performance, a limited scope for patient input in determining the treatment plan and its implementation, and limited cooperation between the various care providers involved. Since the understanding that the fragmented nature of care for chronically ill patients is undesirable, disease management has been recognized as a way to reorganize medical care for chronically ill patients. Disease management aims to reorganize care, focussing on an integrated, patient-centred approach to care, however without changing the system of care delivery. As a consequent response to disease management, the Chronic Care Model was developed. This model aims to change the routine delivery of care by fusion of significant interrelated elements, in order to deliver patient-centred, evidence-based care. To describe the theoretical framework of the integrated chronic care approach on AF presented in this thesis, the elements of the Chronic Care Model were ordered in the domains of the Taxonomy of Disease Management (American Heart Association). 
Section I of this thesis focuses on the methodology used in this study, the development of the AF Knowledge Scale, and the first results of the nurse-led, guideline-based, software supported outpatient clinic for patients with AF.

Chapter 2 outlines the study protocol and the methodology of the randomized controlled trial comparing the nurse-led integrated chronic care approach with the usual care setting. It was hypothesized that the integrated approach contributes towards closing the gap between guideline recommendations and current practice in $A F$, and that it has potential to optimise AF management and improve efficiency and coordination of patient care. The primary outcome measures were defined as cardiovascular hospitalization and death. Secondary outcome measures include guideline adherence, patient AF-related knowledge, quality of life, patient satisfaction and cost-effectiveness. It was determined that 698 participants were needed (349 in each group) to demonstrate the expected impact on the primary outcome after a follow-up period of at least one year.

Chapter $\mathbf{3}$ describes the development and validation of the AF Knowledge Scale. It is of utmost importance that patients understand the nature and complications as well as the therapy of AF, in order to contribute to the treatment in terms of selfmanagement. To achieve this, structural patient education is required, which is often lacking in current daily practice. To measure knowledge in patients, the AF Knowledge Scale was developed. This is the first and currently the only instrument with a combined focus on AF in general, symptom recognition and therapy. The scale consists of 11 items, with a score range between $0-11$.

Content and face validity was determined by judgements of patients, specialized nurses and physicians. Factor analysis was performed to assess construct validity. Sensitivity analysis demonstrated significantly improved knowledge scores in patients in the nurse-led integrated chronic care compared to the usual care, after one year follow-up. The reliability is considered borderline due to a relatively low Cronbach's $\alpha$ (0.58). Nevertheless, the instrument is considered to be sufficiently valid and able to distinguish knowledge levels in patients with AF. However, further development is recommended to enhance its performance.

In chapter 4 the evaluation of the clinical feasibility of the nurse-led integrated chronic care approach is illustrated in terms of guideline adherence. To achieve this, 111 ambulant AF patients were enrolled in the integrated approach. They underwent protocolized clinical testing, were then managed by a nurse specialist, using dedicated software and supervized by a cardiologist. A recent historical control group of 102 patients who participated in the Maastricht part of the Euro Heart Survey on AF was used for comparison. The comparison between both groups demonstrated improved guideline adherence, in terms of diagnostic and therapeutic management, suggesting that a nurse-led integrated chronic care approach is justifiable. 
Section II describes the effectiveness of the Prospective, Open label, Blinded Endpoint (PROBE) randomized comparison of patients in the nurse-led integrated chronic care approach versus patients in the usual care setting. The primary endpoint was defined as cardiovascular hospitalization and death, as well as the extent to which the management was in accordance with the evidence based guidelines.

In total, 712 patients with AF were randomly assigned to the nurse-led integrated chronic care and the usual care group (chapter 5 ). Patients in the nurse-led integrated chronic care received care as described in chapter 4 of this thesis. Visits to the nurse specialist were scheduled to last 30 minutes and took place at set times (i.e. 3, 6, and 12 months). Patients in the usual care setting were treated by a cardiologist in the outpatient setting. These visits were not pre-planned and scheduled to last 20 minutes for the first visit and 10 minutes for follow-up visits. After a mean follow-up of 22 months the primary endpoint occurred in 14.3\% of patients in the nurse-led integrated chronic care group compared to $20.8 \%$ of patients in the usual care group, demonstrating a significant difference in favour of the nurse-led integrated chronic care. Moreover, significant differences were demonstrated for both the occurrence of cardiovascular hospitalization as well as cardiovascular death independently. These findings were confirmed by multivariate analyses for male patients, in patients with heart failure, hypertension, prior stroke / TIA, and patients aged 75 years or older. The trend in favour of nurse-led integrated chronic care was not found in female patients and was not very strong in patients with diabetes mellitus, compared to the other medical conditions in analysis. However, we concluded that nurse-led integrated chronic care is superior in terms of cardiovascular hospitalization and death, compared to usual care. Finally, it is worth mentioning that adherence to guideline recommendations was significantly better in the nurse-led integrated chronic care approach.

Section III focuses on the impact of the nurse-led integrated care approach in terms of quality of life (QoL), including anxiety and depression as well as knowledge in patients with AF. In addition, the impact from an economical perspective in terms of costeffectiveness was determined.

QoL is often impaired in patients with AF. In chapter 6, the impact of the nurse-led integrated chronic care approach is assessed in terms of QoL, by means of the Medical Outcomes Study 36-Item Short Form Survey Instrument (SF-36). Moreover, anxiety and depression was assessed by means of the Hospital Anxiety and Depression Scale (HADS), and finally the AF Knowledge Scale was used to gain insights in patients' AFrelated knowledge levels. The analysis on QoL demonstrated relatively high baseline scores in both groups. Despite this, QoL significantly improved over time in both groups, without significant differences between the two groups. Also, AF-related knowledge improved over time and was significantly higher at follow-up in the nurseled care group. 
AF is considered a relatively expensive disease with an important economic burden. Hospitalization is considered to be the main cost driver, while outpatient care costs are determined by diagnostic procedures, consultations and pharmacological therapy. The development of an integrated chronic care approach in AF requires a shift in financial investments. To determine the nurse-led approach as a profitable investment, an economic evaluation was performed to assess cost-effectiveness of the nurse-led integrated chronic care approach versus usual care (chapter 7 ). The analysis on costs was performed, based on a hospital perspective. The nurse-led integrated chronic care approach was associated with slightly more life years and QALYs at a lower cost. In particular, the nurse-led chronic care approach contributed to 0.009 QALY gains with a reduced cost of $€ 1109$ per patient and a gain of 0.02 life years with a reduced cost of $€ 735$ per patient. Consequently, the nurse-led integrated chronic care approach is considered dominant in terms of efficiency. In fact, for all the possible values of willingness to pay for a QALY, the nurse-led integrated chronic care approach is considered to be more likely cost-effective than the care as usual. Therefore, the nurse-led integrated chronic care approach is a cost-effective management strategy for patients with AF.

Section IV consists of the epilogue wherein the general discussion is presented (chapter 8). The general conclusion of this study is that the nurse-led integrated chronic care approach is superior in terms of cardiovascular hospitalization and death, compared to usual care. In addition, guideline adherent management is significantly better in the nurse-led integrated chronic care approach, as well as AF-related knowledge in these patients. Finally, cost-effectiveness of the nurse-led integrated chronic care approach has been demonstrated in terms of QALYs and life years.

An integrated chronic care approach in terms of a nurse-led, guideline-based, software supported AF-Clinic is an efficient and effective redesign approach for AF management in contemporary practice of the Maastricht University Medical Centre. However, to determine generalizability of the findings, further research is recommended before proceeding to a more comprehensive implementation of this approach. 


\section{SAMENVATTING}

Dit proefschrift bestaat uit acht hoofdstukken die zijn gerangschikt in vier met elkaar samenhangende onderdelen. In deze samenvatting zijn de kernpunten uit de diverse hoofdstukken kort en bondig weergegeven.

De algemene introductie van dit proefschrift (hoofdstuk 1) beschrijft de hartritmestoornis atriumfibrilleren ( $\mathrm{AF}$ ) en de achtergrond van het proefschrift in termen van de Euro Heart Survey naar AF, evidence based richtlijnen, disease management en geïntegreerde chronische zorg. Tevens worden de doelstellingen en de opzet van het proefschrift weergegeven in dit hoofdstuk.

AF is de meest voorkomende hartritmestoornis in de Westerse wereld, die vaak gepaard gaat met onderliggend hartlijden (zoals hypertensie, hartfalen, en aandoeningen van de hartkleppen) en een verhoogd risico op tromboembolische complicaties, zoals een Transient Ischaemic Attack (TIA) of beroerte. De prevalentie van AF bedraagt $1-2 \%$ in de algemene bevolking en neemt toe naarmate de leeftijd stijgt. Met het oog op de vergrijzing van de bevolking is de verwachting dat dit cijfer sterk zal toenemen in de nabije toekomst. Gezien de hoge economische belasting wordt AF beschouwd als een relatief dure aandoening.

Tussen 2003 en 2005 werd de Euro Heart Survey naar AF uitgevoerd in 35 bij de European Society of Cardiology (ESC) aangesloten landen. In dit onderzoek werden 5333 patiënten geïncludeerd. Het onderzoek heeft belangrijke inzichten opgeleverd in het management van AF in Europa. Het heeft aangetoond dat het opvolgen van de richtlijnen marginaal is en dat dit suboptimale management leidt tot een toename van morbiditeit en mortaliteit. Het niet opvolgen van de richtlijnen staat in schril contrast met de beschikbaarheid van evidence based richtlijnen voor het management van AF. Deze richtlijnen worden jaarlijks beoordeeld, en herzien indien nodig.

Het aantal patiënten met chronische ziekten is in de laatste decennia flink toegenomen. Chronische ziekten manifesteren zich in toenemende mate op jongere leeftijd. Vroegtijdige ontdekking maakt vroegtijdig ingrijpen mogelijk, waardoor patiënten langer met een chronische ziekte leven. Dit geldt met name voor cardiovasculaire aandoeningen. Chronische zorg gaat gepaard met onwenselijke fragmentatie, hetgeen zich uit in reactief handelen van zorgverleners, waarbij de nadruk van zorg ligt op het medisch-technisch handelen, er een beperkte ruimte is voor inbreng van de patiënt bij het bepalen van het behandelplan en de uitvoering ervan, en een beperkte samenwerking bestaat tussen de diverse zorgverleners. Omdat gefragmenteerde zorg voor chronisch zieken onwenselijk is, wordt disease management herkend als een manier om de zorg voor chronisch zieken te reorganiseren, gericht op een geïntegreerde, patiëntgerichte benadering van zorg, echter zonder het systeem van zorgverlening te veranderen. Als reactie op disease management, is het Chronic Care Model ontwikkeld. Dit model heeft ten doel om de routinematige verstrekking van zorg te veranderen door het samenvoegen van belangrijke samenhangende elementen, om op die manier patiëntgerichte, evidence 
based zorg te verlenen. Om het theoretische raamwerk van de geïntegreerde benadering voor AF zorg uit dit proefschrift te beschrijven, zijn de elementen van het Chronic Care Model geordend aan de hand van de domeinen van de Taxonomy van Disease Management (American Heart Association).

Deel I van dit proefschrift focust op de gehanteerde methoden in dit onderzoek, de ontwikkeling van de AF Kennis Schaal, en de eerste resultaten van een door verpleegkundigen geleide, op de richtlijnen gebaseerde, en door software ondersteunde polikliniek voor patiënten met AF.

Hoofdstuk 2 schetst het studieprotocol en de methoden van het gerandomiseerde onderzoek waarin de geïntegreerde benadering van zorg voor patiënten met AF wordt vergeleken met de reguliere zorg. De hypothese hierbij was dat de geïntegreerde benadering bijdraagt aan het sluiten van de hiaten tussen het opvolgen van op richtlijnen gebaseerde aanbevelingen en de huidige AF zorg. Daarnaast werd gesteld dat de benadering potentie heeft om het management van AF te optimaliseren, en tevens efficiëntie en coördinatie van patiëntenzorg kan verbeteren. De primaire uitkomstmaat werd gedefinieerd als cardiovasculaire ziekenhuisopnames en sterfte. De secundaire uitkomsten bestaan uit de mate waarin de richtlijnen nageleefd worden, AF-gerelateerde kennis bij patiënten, kwaliteit van leven, patiënttevredenheid en kosteneffectiviteit. Bepaald werd dat 698 patiënten nodig waren (349 in beide groepen) om de verwachte impact op de primaire uitkomstmaat aan te kunnen tonen na een follow-up duur van ten minste één jaar.

Hoofdstuk 3 beschrijft de ontwikkeling en de validatie van de AF Kennis Schaal. Het is uiterst belangrijk dat patiënten de aard en complicaties alsook de behandeling van AF begrijpen, om een bijdrage te kunnen leveren aan de behandeling in termen van zelfmanagement. Om dat te bereiken, is structurele patiënteneducatie noodzakelijk, welke vaak ontbreekt in de dagelijkse praktijk. De AF Kennis Schaal werd ontwikkeld om AF-gerelateerde kennis bij patiënten te meten. Dit is het eerste en vooralsnog enige instrument met een gecombineerde focus op AF in het algemeen, symptoomherkenning en therapie. De schaal bestaat uit 11 items, met een score reeks tussen 0 en 11 . Inhoud- en indrukvaliditeit (content and face validity) werden bepaald aan de hand van het oordeel van patiënten, gespecialiseerd verpleegkundigen en artsen. Een factoranalyse werd uitgevoerd om construct validiteit vast te stellen. Sensitiviteitsanalyse toonde een significante verbetering van kennis scores na één jaar bij patiënten die de geïntegreerde benadering van zorg ontvingen, in vergelijking met patiënten uit de reguliere zorg groep. Als gevolg van een relatief lage Cronbach's $\alpha(0.58)$ is er sprake van een matige betrouwbaarheid. Desondanks wordt het instrument als voldoende valide beschouwd, en is het in staat om kennisniveaus in patiënten te onderscheiden. Verdere ontwikkeling van de schaal is aanbevolen om de prestaties ervan te verbeteren.

In hoofdstuk 4 wordt de klinische uitvoerbaarheid van de geïntegreerde benadering geïllustreerd aan de hand van het naleven van de richtlijnen. Hiervoor werden 111 
ambulante AF-patiënten geïncludeerd in de geïntegreerde benadering. Deze patiënten ondergingen klinische onderzoeken volgens protocol, werden vervolgens gezien door een gespecialiseerd verpleegkundige welke gebruik maakt van een toegewijd software systeem met supervisie door een cardioloog. De historische controle groep, die ter vergelijking gebruikt werd, bestond uit 102 patiënten die geparticipeerd hebben in het Maastrichtse gedeelte van de Euro Heart Survey naar AF. De vergelijking tussen de groepen toonde een verbetering in het naleven van de richtlijnen, in termen van diagnostiek en behandeling, wat suggereert dat de geïntegreerde benadering klinisch gerechtvaardigd is.

Deel II beschrijft de effectiviteit van de Prospectieve, Open label, Blinded Endpoint (PROBE) gerandomiseerde vergelijking van patiënten in de geïntegreerde benadering versus patiënten in de reguliere zorg. Het primaire eindpunt werd gedefinieerd als cardiovasculaire ziekenhuisopnames en sterfte, alsook de mate waarin het management van AF volgens de evidence-based richtlijnen werd uitgevoerd.

In totaal werden 712 patiënten gerandomiseerd naar de geïntegreerde benadering versus de reguliere zorg (hoofdstuk 5). Patiënten in de geïntegreerde benadering ontvingen zorg zoals beschreven in hoofdstuk 4 van dit proefschrift. Een bezoek aan de verpleegkundige duurde 30 minuten en deze bezoeken waren op vaste tijden gepland (nl. 3, 6, en 12 maanden). Patiënten in de reguliere zorg werden poliklinisch behandeld door een cardioloog en deze bezoeken werden niet op vaste tijden gepland. Een eerste bezoek duurde 20 minuten en een controle bezoek 10 minuten. $\mathrm{Na}$ een gemiddelde follow-up van 22 maanden openbaarde het primaire eindpunt zich in $14.3 \%$ van de patiënten in de geïntegreerde benadering tegenover $20.8 \%$ bij de patiënten in de reguliere zorg. Hiermee is sprake van een significant verschil ten gunste van de geïntegreerde benadering. Bovendien werden significante verschillen aangetoond in het optreden van cardiovasculaire ziekenhuisopnames en cardiovasculaire sterfte afzonderlijk. Aan de hand van multivariate analyse werden deze bevindingen bevestigd in mannen, in patiënten met hartfalen, hypertensie, en met een TIA of beroerte in de voorgeschiedenis, en in patiënten van 75 jaar of ouder. Deze trend was zwakker in patiënten met diabetes mellitus, en kon niet worden aangetoond in vrouwen. Op basis van deze bevindingen is geconcludeerd dat de geïntegreerde benadering superieur is in termen van cardiovasculaire ziekenhuisopnames en sterfte ten opzichte van de reguliere zorg. Tenslotte is het noemenswaardig, dat het naleven van aanbevelingen uit de richtlijnen significant beter was in de geïntegreerde benadering.

Deel III richt zich op de impact van de geïntegreerde benadering in termen van kwaliteit van leven, inclusief angst en depressie, als ook kennis in patiënten met AF. Daarnaast werd de impact vanuit economisch perspectief bepaald in termen van kosteneffectiviteit.

Kwaliteit van leven is vaak verminderd in patiënten met AF. In hoofdstuk 6 is de impact van de geïntegreerde benadering op kwaliteit van leven bestudeerd, door 
middel van het Medical Outcomes Study 36-item Short Form Survey Instrument (SF36). Bovendien werd angst en depressie bestudeerd aan de hand van de Hospital Anxiety and Depression Scale (HADS). Tenslotte werd de AF Kennis Schaal gebruikt om inzicht te verkrijgen in AF-gerelateerde kennis in patiënten. De baseline kwaliteit van leven scores waren relatief hoog in beide groepen. Gedurende de follow-up namen deze scores significant toe in beide groepen, zonder significant verschil tussen de beide groepen. AF-gerelateerde kennis nam eveneens toe gedurende de follow-up waarbij deze kennis significant hoger was in de geïntegreerde benadering.

AF wordt beschouwd als een relatief dure aandoening met een belangrijke economische belasting. Ziekenhuisopnames vormen hierbij de belangrijkste kostenpost. De kosten van de poliklinische zorg voor mensen met AF bestaan met name uit diagnostische procedures, consulten en medicamenteuze therapie. De ontwikkeling van de geïntegreerde benadering brengt een verschuiving in financiële investeringen met zich mee. Om te bepalen of deze benadering een winstgevende investering is, werd een economische evaluatie uitgevoerd om de kosteneffectiviteit te bepalen (hoofdstuk 7). De kostenanalyse werd uitgevoerd op basis van een ziekenhuis perspectief (ziekenhuis gerelateerde kosten). De geïntegreerde benadering toonde een lichte toename van het aantal overlevingsjaren en QALYs bij lagere kosten en leverde een 0,009 QALY winst bij een reductie van de kosten met $€ 1109$ per patiënt, en een winst van 0,02 overlevingsjaren bij een reductie van de kosten met $€ 735$ per patiënt. Dit betekent dat de geïntegreerde benadering dominant is vanuit het oogpunt van efficiëntie. Voor alle mogelijke waarden waartoe men bereid is te betalen voor een gewonnen QALY, is de geïntegreerde benadering naar verwachting meer kosteneffectief dan de reguliere zorg. Op deze gronden wordt de geïntegreerde benadering beschouwd als een kosteneffectieve wijze van zorgverlening voor patiënten met AF.

Deel IV bevat de epiloog waarin de algemene discussie gepresenteerd wordt (hoofdstuk 8). De algemene conclusie van dit onderzoek luidt dat de geïntegreerde, benadering superieur is in termen van cardio-vasculaire ziekenhuisopnames en sterfte in vergelijking met de reguliere zorg. Het management van AF volgens de richtlijnen is significant beter bij deze benadering, alsook de AF-gerelateerde kennis van deze patiënten. Tenslotte is gebleken dat de geïntegreerde zorgbenadering kosteneffectief is in termen van QALYs en overlevings-jaren.

Een geïntegreerdebenadering van zorg voor patiënten met $A F$, in termen van een door verpleegkundigen geleide, op richtlijnen gebaseerde, en door software ondersteunde AF-polikliniek, is een effectieve en efficiënte benadering voor AF management in de hedendaagse praktijk van het Maastricht Universitair Medisch Centrum. Om de generaliseerbaarheid van de bevindingen te bepalen, wordt vervolgonderzoek aanbevolen, alvorens over te gaan tot een meer uitgebreide implementatie van deze benadering. 


\section{DANKWOORD}

Promoveren is een intensief proces waarbij je in grote mate op jezelf bent aangewezen.

Je kunt het echter niet alleen. Dit proefschrift is tot stand gekomen door inzet en samenwerking van velen. Enkele personen wil ik hierbij in het bijzonder danken.

Prof. dr. Crijns, beste Harry, ontzettend veel dank voor de geweldige begeleiding en samenwerking in de afgelopen jaren. Van $u$ als promotor, heb ik ontzettend veel geleerd op het terrein van de cardiologie en onderzoek in het algemeen. Maar met name heeft u mij geleerd om 'kort en krachtig' te schrijven. En om in termen van dit onderzoek te spreken leverde dat bij mij een paradigma op van 'Learned-and-will-notforget'. Harry, heel veel dank voor alles!

Prof. dr. Vrijhoef, beste Bert. Onze samenwerking is een goed voorbeeld van samenwerking-op-afstand. Of het nu Seattle, Singapore of Tilburg was, maakte voor de voortgang van het onderzoeksproces geen verschil. Heel veel dank voor je begeleiding tijdens mijn onderzoek. Ik heb de wijze van samenwerking en de overlegmomenten (op welke manier dan ook) als zeer prettig ervaren. De manier waarop je jou kennis met me deelde en je advies en steun, met name in de laatste fase van het onderzoek, heb ik enorm gewaardeerd. Bert, heel erg bedankt!

Prof. dr. de Wit, beste Rianne. Graag wil ik jou heel hartelijk bedanken voor de begeleiding gedurende de eerste helft van mijn onderzoek. Jouw open kijk op de wetenschap, als ook je enthousiasme hebben mij gestimuleerd in het onderzoeksproces. Het zonder enige moeite opsommen van mogelijkheden of oplossingen, ten aanzien van zaken waar ik (nog) geen uitkomsten zag, heeft me vaak positief doen verbazen. Het is erg jammer dat onze samenwerking vroeger ten einde liep dan we beiden gehoopt hadden. Maar jouw Limburgse woorden zijn me tijdens het verdere verloop van het onderzoek bijgebleven: 'het kump good'.

Dr. Tieleman, beste Robert. Jij bent de directe aanleiding voor mijn promotieonderzoek! In 2006 werden de eerste ideeën geboren en bestond de AF-poli uit jou, mij en een laptop! Je leerde me de 'ins \& outs' van AF en hoe een spreekuur te draaien. En daar waar ik twijfelde aan het geheel, was jij ervan overtuigd dat deze innovatie me geen windeieren zou leggen. Je kreeg absoluut gelijk! Bedankt voor je geweldige ideeën en de samenwerking in Maastricht. Onze duo presentatie tijdens de late-breaking session in New Orleans zal ik niet snel vergeten... het bezoek aan de Cat's Meow Bar en het nuttigen van een Hurricane trouwens ook niet! 
De leden van de beoordelingscommissie, prof. dr. van Achterberg, prof. dr. Gorgels, prof. dr. Jaarsma en prof. dr. van Schayck, onder voorzitterschap van prof. dr. Ruwaard, wil ik hartelijk bedanken voor het kritisch lezen van mijn proefschrift.

Graag wil ik de leden van de Entpoint Event Committee, prof. dr. ten Cate, dr. van Ommen, en dr. Rennenberg, onder voorzitterschap van dr. Franke, hartelijk danken voor de samenwerking en de tijdsinvestering om als onafhankelijke commissie de geregistreerde endpoint events in het onderzoek als zodanig te beoordelen.

Het invoeren van de grote hoeveelheid data in de database was zo'n gigantische klus die ik nooit in mijn eentje had kunnen klaren. Ivo, Suzanne, Tijs, Danny, Astrid, Eleana, Caroline, Marjan, Dagmar, Anniek, Karin, Merel en Juul: heel hartelijk bedankt voor jullie hulp. Zelfs tijdens de 'invoer-dagen' op zaterdag kon ik op jullie rekenen. Jullie waren een geweldige steun!

Graag wil ik Joyce Janssen bedanken voor de ondersteuning bij het gebruik van diverse software programma's. Het gemak waarmee jij de technologie beheerst en bestuurt is voor mij nog steeds iets om jaloers op te zijn! Tevens weet ik nu hoeveel verschillende soorten thee bestaan! Heel veel dank voor je hulp en support. Onze bijeenkomsten in 'Klein Zwitserland' zal ik niet snel vergeten.

Ron Pisters, hartelijk bedankt voor je inzichten en hulp bij de data-analyse, het was een gigantische klus.

Dr. Tomini, dear Florian, many thanks for your help in the analysis of the cost data and the co-writing of the manuscript accordingly. I really enjoyed our collaboration and learned a lot from your 'bootstrapping explanation'.

Dr. van Asselt, beste Thea, hartelijk bedankt voor jouw bijdrage aan dit proces. Met een kritische, open blik op het geheel wist jij het de juiste draai te geven.

Prof. Brunner-La Rocca, beste Hans-Peter, hartelijk bedankt voor je kritische blik op het schrijfproces bij het kwaliteit van leven artikel. De door jouw gecontroleerde concepten kwamen mijn eigen kwaliteit van leven vaak niet zo zeer ten goede, maar ik doorzag je doel om een zo optimaal mogelijk resultaat af te leveren. Ik heb mijn 'wishful thinking' daarom bijgesteld!

Beste Tiny, ernom bedankt voor je hulp bij de opmaak van het proefschrift!

Miriam, menige keer zat ik bij jou 'in de wacht' op de hoek van het bureau. Bedankt voor je assistentie en raad bij zovele zaken. Nadine, ik hoop van harte dat het écht een keer gaat lukken in de Staatsloterij! Gerda, na het vertrek van Robert werd jij een beetje 'mijn' secretaresse! Bedankt voor het ondersteunen van de administratie van 
de AF-poli en voor alle overige klusjes waarbij je te hulp schoot. Onze leuke gesprekken heb ik altijd als erg prettig ervaren. En die met je compagnon natuurlijk, want een blik in mijn postvak was direct gerelateerd aan een praatje met Lianne! Dank-jullie-wel dames.

Dr. Blaauw en dr. Pison, beste Yuri en Laurent, bedankt voor het superviseren van de AF-poli. Ik heb veel geleerd van de vele patiëntenbesprekingen. De samenwerking in de piloot / co-piloot constructie heb ik als erg prettig ervaren.

Maar wat is een spreekuur zonder administratieve ondersteuning? Daarom wil ik graag alle polikliniek medewerkers van het HVC heel hartelijk bedanken voor de samenwerking en de ondersteuning op welke manier dan ook. Het verzoek om het printen van een adresstikker blijft één van mijn favoriete vragen aan jullie... Het was prettig met jullie samen te werken!

Mijn dank gaat ook uit naar mijn collega's. Christel, Tjerkje, Mariet, Pia, Bianca, Angèle, Suzanne en Huub, graag wil ik jullie bedanken voor jullie interesse in het onderzoek en de vrijheid die ik kreeg om het onderzoek gestalte te geven.

Mijn paranimfen Josiane en Noémi.

Josiane, mijn partner in crime! Vanaf het begin is er een band tussen ons ontstaan, mede door de relatie AF-HF, maar ook omdat we qua onderzoek min of meer in het zelfde schuitje zaten. Daarbij vullen we elkaar goed aan, ter illustratie: daar waar ik een 'kijk-de-kat-uit-de-boom' beleid hanteer ga jij vastberaden ten strijd. Wat hebben wij samen veel beleefd tijdens onze promotietijd: de oprichting van de BB-club (vreemd overigens dat wij de enige leden zijn...), de vele gezamenlijke congresbezoeken, de EANS summer schools, het beklimmen van de besneeuwde Chinese muur in Beijing als cadeautje op pakjesavond 2011 (een ervaring die ik nooit meer vergeet!), de vlucht vanuit Turku - Finland waarbij jij tijdens deze vlucht reeds afscheid nam van je dierbaren, het samen stoom afblazen na de beruchte SOS telefoontjes, en zeker niet te vergeten mijn rol als oproepkracht bij de danslessen van Nicole ter vervanging van Hans-Peter. Heel erg bedankt voor de samenwerking, je steun en de geweldige tijd! Ik ben heel blij dat je nu als paranimf aan mijn zijde staat.

Noémi, ik ben blij dat jij als paranimf aan mijn andere zijde staat! Mijn eerste kennismaking met jou was 'indrukwekkend' te noemen. Ik werd voorgesteld aan de collega's van de uni: handje geven, kort gesprekje en weer weg. Totdat ik bij jou kwam... 45 minuten later stond ik nog steeds bij je aan het bureau (en hoefde alleen maar te luisteren). We werden kamergenoten op UNS 40 en al snel werd donderdag dé dag van de week. Wat hebben we veel gelachen op deze kamer samen met Esther. Met jou even 'plat Mestreechs te mojle' was voor mij echt dé ultieme ontspanning. Jij bent de organizer, de druktemaker (in de goede zin van het woord), de helpende hand 
en de bezige bij. Heel erg bedankt voor de mooie tijd, en met name je steun en gezelligheid in je rol van paranimf. En dat bij een overheerlijke kop échte Hongaarse goulashsoep. Jij maakt de beste! Nagyon köszönöm a támogatást, és a barátság!

Mijn dank gaat ook uit naar de Nederlandse Vereniging voor Hart en Vaat Verpleegkundigen (NVHVV). Geacht bestuur, in 2009 boden jullie mij de mogelijkheid om een werkgroep atriumfibrilleren op te richten. Dit heeft bijgedragen aan de profilering van mijn onderzoek en het stimuleren van verpleegkundigen op dit terrein. Graag wil ik ook de leden van de werkgroep AF en de redactie van Cordiaal bedanken voor de prettige samenwerking, de interessante discussies en de vele inzichten die ik mede door jullie verworven heb. Ik ben trots om als jullie voorzitter de NVHVV te mogen vertegenwoordigen.

Mijn werk is belangrijk voor me, maar komt niet (altijd) op de eerste plaats. Daarom wil ik mijn familie en vrienden bedanken voor de belangstelling in de afgelopen jaren en het samen beleven van de mooie andere zaken die het leven te bieden heeft.

Tante Mien, u weet als geen ander hoe atriumfibrilleren het leven kan beïnvloeden. Dit was een belangrijke drijfveer voor me. Hartelijk bedankt voor uw interesse in alle facetten van mijn onderzoek.

Juul en Kris, jullie aanwezigheid zorgde ervoor dat ik het onderzoek even helemaal kon vergeten en kon genieten van jullie onderzoekende kijk op de wereld.

Lieve pap en mam, niets voelt zo vertrouwd als op vrijdagmiddag in de auto stappen om lekker naar 'huis' te rijden en bij jullie gezellig aan te schuiven en bij te praten. Ik wil jullie heel erg bedanken voor de steun en goede zorgen in alles wat jullie voor me doen. Ik ben dankbaar voor hetgeen jullie me in het leven hebben meegegeven, jullie zijn de basis van dit mooie resultaat. Daarom draag ik dit proefschrift met liefde aan jullie op!

Bert, promoveren heb ik niet alleen gedaan. Jij hebt daar achter de schermen meer dan significant aan bijgedragen. Je steun, rust, nuchterheid, gigantische relativeringsvermogen én je passie voor reizen waren hierbij voor mij van onschatbare waarde. Dank-je-wel! Op naar de volgende trip! 


\section{CURRICULUM VITAE}

Jeroen Hendriks was born on the 2nd of May 1975 in Swalmen, The Netherlands.

After completing secondary school at the Bisschoppelijk College Broekhin (HAVO) in Roermond 1993, he started the education and training program for Registered Nurses at Hogeschool Limburg in Sittard. For preparing his final thesis he went to Norrköping - Sweden, where he worked on the orthopaedics department of the Vrinnevisjukhuset (general hospital) and followed an international scholarship at the Hälsouniversitetet. In 1998 he obtained his bachelor's degree in nursing.

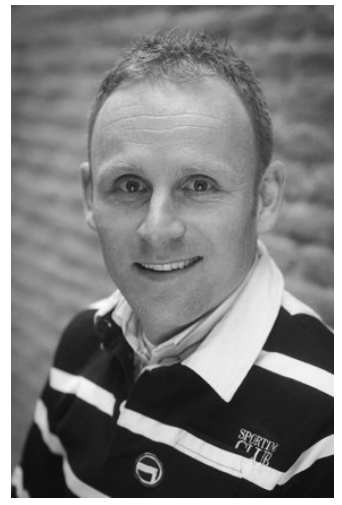

He started his work as a nurse at the department of vascular surgery of the University Hospital Maastricht. At the same time, he studied Health Sciences, at the Faculty of Health, Medicine and Life Sciences at Maastricht University (1999-2003) and graduated as master in Health Sciences in 2003.

Subsequently, Jeroen moved to the cardiology department, where he was involved in the development of the multidisciplinary cardio vascular centre. Here his interest for cardiology was aroused. In 2006 he was involved in the preparations of a specialized AF-Clinic within the cardio vascular centre. This resulted in the start of his PhD research in 2007. In a combined work agreement between the University Hospital Maastricht and the Faculty of Health, Medicine and Life Sciences at Maastricht University (department of Health Care and Nursing Science), Jeroen worked part-time as a specialized nurse in the AF-Clinic and part-time as a researcher at Maastricht University. During his $\mathrm{PhD}$, he presented his work on many national and international congresses. In April 2011 he presented the main results of the study during a latebreaking clinical trial session at the annual conference of the American College of Cardiology in New Orleans, USA.

In 2008 Jeroen completed the three-year Ph.D. summer course of the European Academy of Nursing Science (2006-2008) and is a Scholar since then. During six years (2007-2012), Jeroen has been editor of Cordiaal, the Journal of the Dutch Society of Cardiovascular Nurses (Nederlandse Vereniging voor Hart en Vaat Verpleegkundigen NVHVV). In 2009 he founded the working group on Atrial Fibrillation and served as the chairman until recently. In June 2012 he was installed as the President of the NVHVV. At the same time, he was selected as board member on the post of Communications within the Council on Cardiovascular Nurses and Allied Professions (CCNAP) of the European Society of Cardiology (ESC). 



\section{LIST OF PUBLICATIONS}

\section{Original research}

Hendriks JM, Vrijhoef HJ, Crijns HJ, Tieleman RG. The Atrial Fibrillation Knowledge Scale: Development, Validation and Results. International Journal of Cardiology 2013 doi:10.1016/j.ijcard.2012.12.047.

Hendriks JM, de Wit R, Crijns HJ, Vrijhoef HJ, Prins MH, Pisters R, Pison LA, Blaauw Y, Tieleman RG. Nurse-led care versus usual care for patients with atrial fibrillation Results of a randomized trial of integrated chronic care versus routine clinical care in ambulatory patients with atrial fibrillation. European Heart Journal 2012;33:2692-9.

Domburg van RT, Hendriks JM, Kamp O, Smits P, Melle van M, Bax J, Schenkeveld L, Simoons ML. Three life years gained after reperfusion therapy in acute myocardial infarction: 25-30 years after a randomized controlled trial. European Journal of Cardiovascular Prevention and Rehabilitation 2012;19:1316-23.

Hendriks JM, de Wit R, Vrijhoef HJ, Tieleman RG, Crijns HJ. An integrated chronic care program for patients with atrial fibrillation: study protocol and methodology for an ongoing prospective randomised controlled trial. International Journal of Nursing Studies 2010;47:1310-6.

Hendriks JM, Nieuwlaat R, Vrijhoef HJ, de Wit R, Crijns HJ, Tieleman RG. Improving guideline adherence in the treatment of atrial fibrillation by implementing an integrated chronic care program. Netherlands Heart Journal 2010;18:471-7.

Hendriks JM, Tomini F, van Asselt AD, Vrijhoef HJ, Crijns HJ. Cost-effectiveness of a specialised atrial fibrillation clinic versus usual care in patients with atrial fibrillation. Submitted.

Hendriks JM, Vrijhoef HJ, Crijns HJ, Tieleman RG. Quality of Life in patients with Atrial Fibrillation - The impact of a nurse-led integrated chronic care approach on quality of life in patients with atrial fibrillation. Submitted.

Berti D, Hendriks JM, Brandes A, Deaton C, Crijns HJ, Camm AJ, Hindricks G, Moons P, Heidbuchel $\mathrm{H}$. Interdisciplinary, nurse-coordinated AF-clinics in order to tackle the AF epidemic. Submitted. 


\section{National publications}

Hendriks JM and Crijns HJ. De AF-poli - Een geïntegreerde benadering van atriumfibrilleren. Cardio Actueel 2012; 12.

Hendriks J. Een hart-long transplantatie door de ogen van een patiënt. Cordiaal 2011;4:118-9.

Hendriks J. Richtlijn Atriumfibrilleren. Cordiaal 2008;3:94-5.

\section{Reports}

Brouwers JR, Hendriks JM, van Laarhoven $\mathrm{H}$, van der Ree C, Visser E, van Woerkom $\mathrm{MH}$. Patient relevance and validation procedure: the patient perspective on the treatment with oral anticoagulation in atrial fibrillation. (In Dutch: Patiëntenrelevantie en validatieprocedure: het patiëntenperspectief op de behandeling met orale antistollingsmiddelen bij atriumfibrilleren). München: Europe-Expo 2012. 